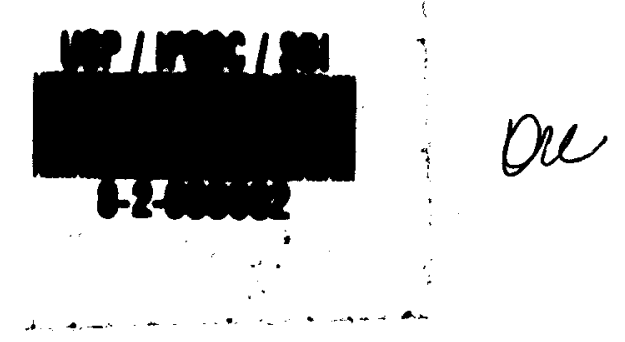

"CONSTRUÇÃO DE UM GERADOR E MISTURADOR DE HARMÔNICOS"

MILSON TADEU CAMARGO SILVA

\begin{abstract}
Dissertação apresentada ao Instituto de Física e Química de são Carlos, para obtencão do título de: Mestre em Física Aplicada.
\end{abstract}

Orientador: Prof. Dr. Maria Cristina Terrile

Departamento de Física e Ciência dos Materiais São Carlos - 1982

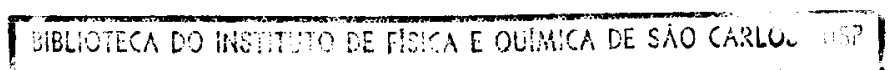
FIS I CA 
MEMBROS DA COMISSAO JULGADORA DA DISSERTACAO DE MESTRADO DE MILSON TADEU CAMARGO SILVA

APRESENTADA AO INSTITUTO DE FISICA E OUIMICA DE SAO CARLOS, DA UNIVERSIDADE DE SAO PAULO, EM_ 18 DE_janeiro DE $198 \underline{2}$.

COMISSATO JULGADORA:
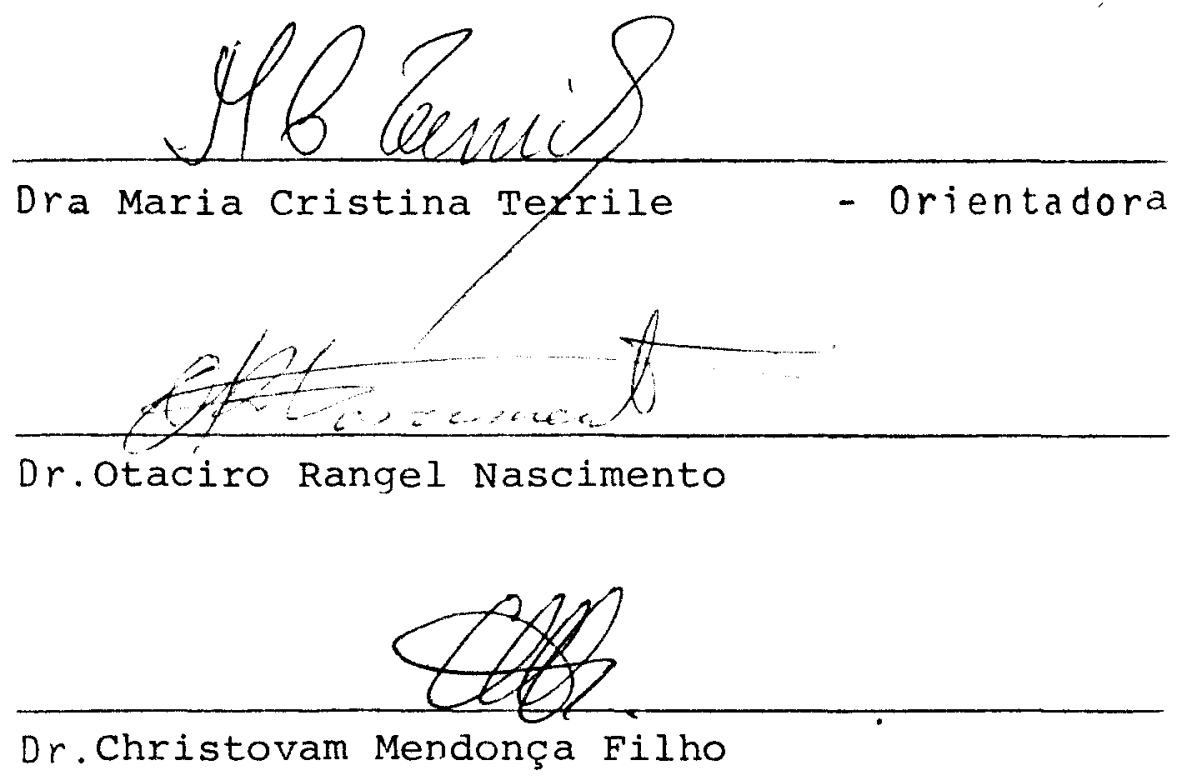
À minha mãe Laércia e a memória de meu pai Antonio.

Aos meus irmãos Mirley, Miltes

e Milton,

que tantos esforcos fizeram

para a minha educação.

À minha esposa Vera e a minha

filha Thaíz,

pelo constante estímulo e

alegria. 
Quero agradecer, em primeiro lugar, ao Prof. Dr. Maria Cristina Terrile, pela sua amizade, confiança e orientação.

Importante também é mostrar o meu agradecimento ao Prof. Dr. Horacio Carlos Panepucci, por sua hospitalidade e pela sugestão do trabalho.

Agradeço ao Prof. Dr. René Ayres Carvalho por sua amizade e contribuição a minha formaço profissional.

Ao Prof. Dr. Otaciro Rangel Nascimento pelo incentivo. A todos os membros do grupo de "ressonância e magnetoótica" pelo apoio recebido.

Ao L. L. Ling pela colaboração e primeiros desenhos. Aos senhores João Carlos dos Santos, Edson Fernandes e José Luiz Menegazzo, pela construqão do dispositivo.

Ao Sr. Odir Adolfo Canevarollo pela assistência técnica.

A minha esposa pela paciência, carinho e incentivo. 
Lista de ilustracões e de tabelas I

Resumo e abstract II

Introdução 1

Capitulo I: CONCEITOS GERAIS 5

1.1 - Introdução 5

1.2 - Propriedades de semicondutores 7

1.3 - o gerador de harmônicos 17

1.4 - O misturador de harmônicos 23

1.5 - Propagação de microondas 31

1.6 - Componentes de microondas 52

Capitulo II: PROJETO DO GERADOR E MISTURADOR DE HARMÔNICOS 64

2.1 - Introducão 64

2.2 - o gerador de harmônicos 64

2.3 - O misturador de harmônicos 65

2.4 - o gerador e misturador de harmônicos 66

2.5 - o prójeto do gerador e misturador de harmônicos

Capítulo III: CARACTERIZAÇÃo E APLICAÇÃo DO GERADOR E MISTURADOR DE HARMÔNICOS 78

3.1 - Introdução 78

3.2 - Medida da perda de conversão do gerador de harmônicos $\quad 78$

3.3 - Medidas de isolação e perda de conversão do misturador de harmônicos

3.4 - Aplicação - Calibração de um frequencímetro de Banda-Q

3.5 - Comentário sobre as medidas realizadas com - terceiro harmônico 
Cápitulo IV: RESUlTAdOS E CONCLUSÕES

4.1 - Introdução

4.2 - Potencia do terceiro e quarto harmônicos e perda de conversão do gerador de harmônicos

4.3 - Perda de conversão e isolacão do misturador do quarto harmônico

4.4 - Calibracào do frequencímetro de Banda-Q 101

4.5 - Comparaçào entre o dispositivo construí do e aqueles citados na literatura

4.6 - Conclusões

4.7 - Sugestões para trabalhos futuros 


\section{IISTA DE ILUSTRACÕES}

Figura 1.1 - Bandas de energia eletrônica de um isolante ou de um semicondutor

Figura 1.2 - Barreira de potencial formada pelo contato semicondutor-metal

Figura 1.3 - Característica V - I de um contato semicondutor-metal

Figura 1.4 - Circuito equivalente do contato semicondutor-metal

Figura 1.5 - Circuito equivalente do contato semicondutor-metal para baixas frequências

Figura 1.6 - Circuito equivalente do contato semicondutor-metal para altas frequências

Figura 1.7 - Esquema simplificado de um gerador de harmônicos

Figura 1.8 - Circuito equivalente proposto por Page para o gerador de harmônicos

Figura 1.9 - Diagrama em blocos do conversor de frequências

Figura 1.10 - Circuito equivalente da linha de transmissão

Figura 1.11 - Sistema de referência da linha de transmissão

Figura 1.12 - 0 modo TEM de propagacão

Figura 1.13 - Sistema de referência e dimensões do guia de onda retangular

Figura 1.14 - Configuração dos campos elétrico e magnético do modo $\mathrm{TE}_{10}$

Figura 1.15 - Modos de transmissão de ordem mais alta 
Figura 1.16 - Relação entre comprimentos de onda em um guia de onda

Figura 1.17 - Distribuição de corrente do modo $\mathrm{TE}_{10}$

Figura 1.18 - Atenuação abaixo do corte em um guia de onda

Figura 1.19 - Esquema geral do acoplador direcional

Figura 1.20 - Tipos de curtos móveis não-contato

Figura 1.21 - Sistema de referência de un guia de onda curto-circuitado

Figura 1.22 - Impedância de entrada de um guia de onda curto-circuitado

Figura 1.23 - Curto móvel tipo quarto de onda nãocontato

Figura 1.24 - Poste indutivo

Figura 1.25 - Susceptância de um poste indutivo em um guia de onda

Figura 2.1 - Esquema, do gerador e misturador de harmônico

Figura 2.2 - Vista de topo do gerador e misturador de harmônicos construido

Figura 2.3 - Vista de topo e lado do curto móvel do guia de onda de Banda-x

Figura 2.4 - Vista de topo e lado do curto móvel do guia de onda de Banda-Ka

Figura 2.5 - Vista em explosão do dispositivo mostrando as dimensões da montagem do diọdo e do terminal de FI

Figura 2.6 - Vista em explosão do gerador e misturador de harmônicos construido

Figura 2.7 - Circuito equivalente do casador de impedâncias 
Figura 3.1 - Diagrama em blocos do arranjo experimental empregado nas medidas da perda de conversão do gerador de harmônicos e na calibracão do frequencimetro

Figura 3.2 - Diagrama em blocos do arranjo experimental para medidas da perda de conversão e isola cão do misturador de harmônicos e calibraçào do frequencímetro

Figura 3.3 - Equipamento de microondas utilizado na caracterizacão do gerador e misturador de harmônicos

Figura 4.1 - Potência do terceiro harmônico em função da potência do sinal fundamental

Figura 4.2 - Perda de conversão do terceiro harmônico em função da potência da fundamental

Figura 4.3 - Potência do quarto harmônico em funcão da potência da fundamental

Figura 4.4 - Perda de conversão do quarto harmônico em funcão da potência do sinal fundamental

Figura 4.5 - Perda de conversão do misturador do quarto harmônico em funfão da potência do oscilador-local, para uma FI de $30 \mathrm{MHz}$

Figura 4.6 - Perda de conversão do misturador do quarto harmônico em funçào da potência do oscilador-local, para uma $\mathrm{FI}$ de $60 \mathrm{MHz}$

Figura 4.7 - Isolacão entre os terminais de OL e FI em função da frequência do osciladorlocal

Figura 4.8 - Linearidade entre os sinais de RF e FI, sendo a frequència da FI $30 \mathrm{MHz}$

Figura 4.9 - Linearidade entre os sinais de RF e FI, para uma frequencia de $\mathrm{FI}$ de $60 \mathrm{MHz}$ 
Figura 4.10 - Espectro da $\mathrm{Fi}$ em $30 \mathrm{MHz}$

Figura 4.11 - Espectro da FI em $60 \mathrm{MHz} \quad 104$

Figura 4.12 - Sinal da FI em $30 \mathrm{MHz} 105$

Figura 4.13 - Sinal da FI em $60 \mathrm{MHz} 105$

Figura 4.14 - Curva de calibracão do Erequencímetro de Banda-Q

Figura 4.15 - Modo do klystron de Banda-X e do modo do quarto harmônico desta banda

Figura 4.16 - Comparacão entre o dispositivo construido e os citados na literatura

Figura 4.17 - Perda de conversão do misturador do terceiro harmônico de Banda-X da indústria Hughes Aircraft Co.

LISTA DE TABELAS

Tabela - I - Amplitude dos harmônicos até a quinta potência da frequência fundamental, com e sem polarização

Tabela - II- Amplitude das várias componentes das frequências na saída do misturador 
RESUMO

Neste trabalho descrevemos o projeto e a construcão de um gerador e misturador de harmônicos que opera na Banda-X $(\varepsilon, 2-12,4 \mathrm{GHz})$. Como gerador de harmônicos, o dispositivo gera - terceiro e quarto harmônicos das frequências da fundamental, enquanto como misturador de harmônicos, ele mistura sinais da Banda-Ka $(26,5-40,0 \mathrm{GHz})$ e Banda-Q $(33,0-50,0 \mathrm{GHz})$, respectivamente com o terceiro e quarto harmônicos do oscilador-local e a frequência-intermediária é 30 ou $60 \mathrm{MHz}$.

Apresentamos também as medidas dos parâmetros que caracterizam seu funcionamento como gerador do terceiro e quarto harmônicos e misturador do quarto harmônico das frequências da banda fundamental.

Finalmente mostramos o resultado da calibracão de um fre quencimetro de Banda-Q, obtida com o dispositivo construído. 


\section{ABSTRACT}

We describe in this paper the planning and construction of a harmonics generator and mixer. The fundamental frequency is $\mathrm{X}$-Band $(8.2-12.4 \mathrm{GHz})$, and it generates the third and fourth harmonics of this band. As a harmonics mixer, it mixes signals of $\mathrm{Ka}-\mathrm{Band}(26.4-40.0 \mathrm{GHz})$ and Q-Band $(33.0-50.0 \mathrm{GHz})$ respectively with the third and fourth harmonics of local-oscilator, and the intermediary-frequency is 30 or $60 \mathrm{MHz}$.

We are presenting measurements of parameters which caracterize its functioning as a harmonics generator and mixer.

The results of calibration of a Q-Band wavemeter realized with this device also are presented. 
INTRODUÇĀO

O interesse em geradores e misturadores de harmônicos de frequências de microondas sempre foi grande, devido as suas várias aplicacoes, desde os primeiros trabalhos, os quais surgiram no ano final da IIa Guerra Mundial. Este interesse foi ainda estimulado com o desenvolvimento de fontes e amplificadores de microondas a estado sólido e de técnicas de construqão de circuitos de microondas, stripline e microstripline. Sendo assim podemos gerar uma ampla gama de frequências utilizando apenas dispositivos de estado sólido, em um circuito que não seria maior que uma caixa de fósforos, isto significa baixos custos, peso reduzido e maior confiabilidade.

o gerador de harmônicos é um dispositivo apropriado para a obtenção de frequências múltiplas de uma frequência fundamental. O mesmo dispositivo pode ser construído de tal maneira que permita ser usado como misturador de harmônicos; neste caso o sinal da frequência de trabalho é misturado com um harmônico da frequência do oscilador-local e a resultante é um sinal cuja frequência é duas ordens de magnitude mais baixa que as frequências anteriormente citadas.

A necessidade de padrões de frequências de microondas levou à construcão dos primeiros geradores de harmônicos por Ginzton e outros (1), assim a primeira aplicacão é em Metrologia. Neste trabalho, um cristal de quartzo é a fonte do sinal fundamental, o qual incide em uma cadeia de geradores de harmônicos e obtem-se como resultado sinais na região de microondas. Para frequencias fundamentais compreendidas entre $50 \mathrm{kHz}$ e $102,4 \mathrm{MHz}$, os elementos geradores de harmônicos são válvulas, enquanto que para frequencias superiores foram usados diodos 
de semicondutor (Si), que foram denominados diodos a cristal.

A construcão de um oscilador de onda continua, sintonizável e estável que fornecesse suficiente potência para ser usado como oscilador-local, era problemática em frequências acima de $30,0 \mathrm{GHz}$ nos anos 45-46. Uma alternativa era usar o sinal harmônico de uma frequência mais baixal este sinal podia ser gerado por um diodo a cristal. Para a obtencão deste sinal, um método era usar dois diodos, um para gerar a potência harmônica e o outro para misturar os sinais. Uma segunda possibilidade era utilizar somente um diodo, o qual teria ambas as funföes, sendo esta mais preferivel que a primeira em termos de projeto e custos do circuito.

Os primeiros experimentos com misturadores de harmônicos foram realizados por Falkoff (2), neste trabalho, utilizando apenas um diodo, foi construido um misturador do segundo harmônico, no qual a frequência do oscilador-local pertencia a Banda-C $(4,0-6,2 \mathrm{GHz})$ e a frequência de trabalho erà de Banda-x $(8,2-12,4 \mathrm{GHz})$. Este era um trabalho exploratório e foi realizado com frequências mais baixás que o desejado e foi terminado antes de ser extendido às frequências de interesse.

Com o advento e desenvolvimento de componentes ativos e passivos de microondas, abriu-se um novo campo para a Física e sabia-se que as transicões atômicas tornavam-se mais fortes e abundantes quando as frequências se aproximavam da região ótica. Nesta época (pós-guerra), havia grande interesse em estudar-se a absorção de microondas por gases; em um destes estudos foi observada uma forte absorção das frequências 18,75 e $25,0 \mathrm{GHz}$ por vapor d'água e isto evitou a aplicação destas frequências em radar.

A principal questão em espectroscopia de gases era a obtenfão de fontes cujas frequências deveriam ser cada vez mais altas (ondas milimétricas), além disto elas deveriam ser estáveis 
e sintonizáveis. Tal fato ievou a construcão de geradores de harmônicos que geralmente operavam com frequência fundamental pertencente a Banda-K $(18,0-26,5 \mathrm{GHz})$ e cujos harmônicos de trabaIho variavam entre 2 e 5 ; isto possibilitava a obtencão de frequências compreendidas entre 36,0 e 132,5 GHz, Gordy (3). Com a fabricacão de magnetrons e klystrons que operavam em frequências acima de $60,0 \mathrm{GHz}$, conseguiu-se com geradores de harmônicos frequências na região de ondas sub-milimétricas (3).

Os geradores de harmônicos construídos por Gordy (3), Nethercot (4), Grifone (5), Johnson (6) e Richardson (7) utilizavam como elemento gerador de harmônicos, diodos a cristal de Si. Para diminuir as perdas de conversão, alguns autores (3), (4) e (7) retiravam os cristais de seus encapsulamentos e os montavam diretamente nos guias de onda. Uma revisão da literatura até 1958 foi realizada por Coleman (8).

Com a descoberta dos diodos de capacitância variável "varactor", as perdas de conversão dos geradores de harmônicos decresceram sensivelmente, isto foi mostrado experimentalmente por chang (9). O trabalho de chl e outros (10) mostrou que as per das de conversão são também diminuías pela utilizacão de cristais de $\mathrm{Si}$ bombardeados com íns de $\mathrm{P}$ e $\mathrm{C}$.

Bauer e outros (11) mostraram que com a utilizacão de dio dos a cristal de GaAs, era possivel construir geradores e misturadores de harmônicos, os quais geravam e misturavam sinais de até $600 \mathrm{GHz}$. Utilizando técnicas de circuitos integrados híbridos e um diodo varactor de GaAs, Schneider e outros (12) construiram um gerador do terceiro harmônico de Banda-X, cuja perda de conversão era de apenas $5,4 \mathrm{~dB}$.

Um gerador de harmônicos cuja frequência fundamental é $100 \mathrm{GHz}$ e as frequências harmônicas: $200,300,400$ e $500 \mathrm{GHz}$ é descrito por schneider (13) que usou como elemento gerador de 
harmônicos um diodo schottky de GaAs. Goy (14) descreve uma série de geradores e misturadores de harmônicos que cobrem frequências compreendidas entre 36,0 e $340 \mathrm{GHz}$ a partir de uma frequência fun damental de $11,5 \mathrm{GHz}$. O diodo usado foi um Schottky de GaAs dopado com Te. O autor utilizou este dispositivo em um novo tipo de espetroscopia de ondas milimétricas e sub-milimétricas, denominada espectroscopia de Rydberg.

os geradores e misturadores de harmônicos são aplicados em campos tão diversoscomo: rádio-astronomia, espectroscopia, metrologia, comunicacões (15), instrumentafão, etc.

No laboratório em que foi desenvolvido este trabalho, um gerador misturador de harmônicos tem diversas aplicações, entre as quais salientamos: calibracão de frequencímetros e outros dispositivos, estabilizacão de klystrons, receptor (detefão superheterodina) de microondas e ondas milimétricas, como fonte de microondas e ondas milimétricas para espectroscopia de Ressonância Paramagnética Eletrônica (RPE) de substâncias em que altas potências não são necessárias e podendo ele próprio ser utili zado como erequencímetro.

A proposta do trabalho é projetar, construir e caracterizar um gerador e misturador do quarto harmônico de Banda-x. Como gerador de harmônicos deverão ser obtidas frequências situadas na Banda-Q e na operação como misturador, 0 sinal da Banda- $Q$ será misturado com o quarto harmônico do oscilador-local (Banda-x) e a frequência intermediária deverá ser 30 ou $60 \mathrm{MHz}$. Além disto tal dispositivo deverá eer aplicado na resolufão de algumas questões existentes no laboratório, tal como a calibração de um frequêncímetro de Banda-Q.

o material disponível para o trabalho são guias de onda de bandas compreendidas entre $\mathrm{X}$ e Ka e o elemento gerador de harmônicos é um diodo a cristal de Si, IN53B. 


\section{CAPÍTULO I}

\section{CONCEITOS GERAIS}

1.1. Introducão

Microondas é a denominacão que recebe a faixa do espectro eletromagnético compreendido entre $300 \mathrm{MHz}$ e $30 \mathrm{GHz}$, enquanto a banda que é limitada pelas frequências $30 \mathrm{GHz}$ e $300 \mathrm{GHz}$ é chamada ondas milimétricas. Frequências entre $300 \mathrm{MHz}$ e 1,0 GHz são geradas por válvulas, mas este meio é proibido para frequências superiores devido as reatâncias parasitas inter-eletrodos. Sinais pertencentes ao intervalo 1,0 - $300 \mathrm{GHz}$ são obtidos através de magnetrons, klystrons, carcinotrons, etc e mais recentemente por diodos de estado sólido tais como: gunn, tunel, impatt, etc.

Os meios empregados para conduzir microondas são linhas coaxiais e guias de onda, enquanto que apenas guias de onda são utilizados para transmitir ondas milimétricas, em virtude das altas perdas apresentadas por linhas coaxiais nestas frequências.

iva operacão de um sistema de microondas e ondas milimétricas, vários tipos de componentes são usados. Com tais dispositivos podemos, por exemplo, controlar a potência do sinal, acoplar parte desta para propósitos de monitoracăo, casar impedâncias, ajustar a fase do sinal e diversos outros.

Uma maneira mais econômica e simples, embora o fator limi tante seja a potência, de se obter microondas, ondas milimétricas e também ondas sub-milimétricas é através dos geradores de harmônicos, neste o sinal fundamental alimenta um elemento nãolinear (por exemplo um diodo a cristal) onde são gerados os harmô nicos e o sinal do harmônico de interesse é retirado através de um circuito apropriado. 
Microondas e sinais de frequências mais altas são detetados através das técnicas denominadas homodina e superheterodina. No sistema homodino, o sinal que contém a informacão, denominado rádio-frequência $(R F)$, é demodulado diretamente, ou seja o sinal é detetado pela retificacão em um elemento não-linear. Tal detetor opera na região quadrática de sua característica não-linear, isto é, a voltagem na saída do detetor é proporcional ao quadrado da voltagem de entrada. A sensibilidade de um sistema heterodino é em torno de - $50 \mathrm{dBm}$ (16).

A recepção superheterodina proporciona a conversão da frequência portadora (RF) em uma frequência mais baixa; isto é conseguido através de um oscilador-local (OL) e um elemento nãolinear. o oscilador-local e o siral são acoplados ao elemento não-linear onde geram, entre outras frequências, aquela que é a diferenca entre as frequências do oscilador-local e do sinal, denominada frequência-intermediária (FI), sendo a amplitude deste sinal proporcional a amplitude do sinal de $R F$, visto que o elemento não-linear opera na região linear de sua característica. Se o sinal é uma onda modulada em amplitude, o sinal na saída do diodo consistirá de uma portadora na frequência-intermediária mais bandas laterais que reproduzem a modulafão original do sinal de RF. O circuito que contém o elemento não-linear e os terminais para o oscilador-local, rádio-frequência e frequenciaintermediária é denominado misturador e o processo chamado mistura ou conversão de frequência. O sinal da FI é então amplificado e o circuito completo é denominado receptor superheterodino e cuja sensibilidade é da ordem de - $100 \mathrm{dBm}$ (16).

Misturadores em que a frequência-intermediária é a diferenca das frequências do oscilador-local e do sinal são denominados misturadores fundamentais, enquanto que a frequência-intermediária resultante da diferença de harmônicos da frequência do 
oscilador-local e da frequência do sinal de RF são chamados mistú radores de harmônicos.

Neste capítulo discutiremos os processos de geração de harmônicos e conversão de frequências que ocorrem em um contato semicondutor-metal (diodo a cristal). Os fatores que caracterizam o dispositivo, a perda de conversão para o gerador de harmônicos e a isolacão e perda de conversão para o misturador de harmônicos são definidas. Além disto, expomos a teoria de propagafão de ondas eletromagnéticas em linhas de transmissão e guias de onda, co mo também as características e aplicações de alguns componentes de microondas.

1.2. Propriedades de semicondutores

A classificacão de materiais cristalinos de acordo com suas propriedades elétricas e óticas e o estudo detalhado das diferentes espécies é facilitado pela Teoria de Bandas (17, 18), a qual desempenha um importante papel na Física do Estado sólido.

Existe uma conexão entre os níveis de energia eletrônica de um átomo individual livre e as bandas de energia eletrônica de um sólido, o qual consiste de uma coleção de átomos formando uma rede cristalina.

Como em um átomo livre, existe na rede, um número de niveis de energia acessiveis ao elétron. Estes estados de energia são agrupados em bandas consistindo de um grande número de níveis de energia ligeiramente espacados, sendo o número de níveis de uma banda da ordem do número $\mathrm{N}$ de átomos da rede.

As bandas permitidas são separadas por intervalos que não contém níveis de energia (exceto aqueles causados por imperfeicōes da rede ou impurezas) e, portanto, não são permitidos para elétrons; esta região é denominada Banda Proibida. 
$\therefore$ banda formada pelos niveis de energia dos elétrons de valência, denominada Banda de Valência, pode estar parcial ou com pletamente preenchida; enquanto que a banda de energias mais altas, chamada Banda de Condução, pode estar ou não completamente vazia.

Com base nesta teoria, é possivel compreender melhor a di ferença na condutividade elétrica entre metais, isolantes e semi condutorès.

a) Metais e isolantes

Um metal tem sua banda de valência parcialmente preenchida; além disto a banda de conducão é superposta a ela ou separada dela por uma estreita banda proibida. Como resultado, uma corrente elétrica pode ser produzida pela aplicafão de um campo elétri$\mathrm{CO}$.

Por outro lado, em um isolante, cuja estrutura de bandas é mostrada na figura 1.1, a banda de valência é completamente preenchida, a qual é separada da banda de conducão por uma larga banda proibida. Neste caso, a aplicação de um campo elétrico não produz corrente elétrica.

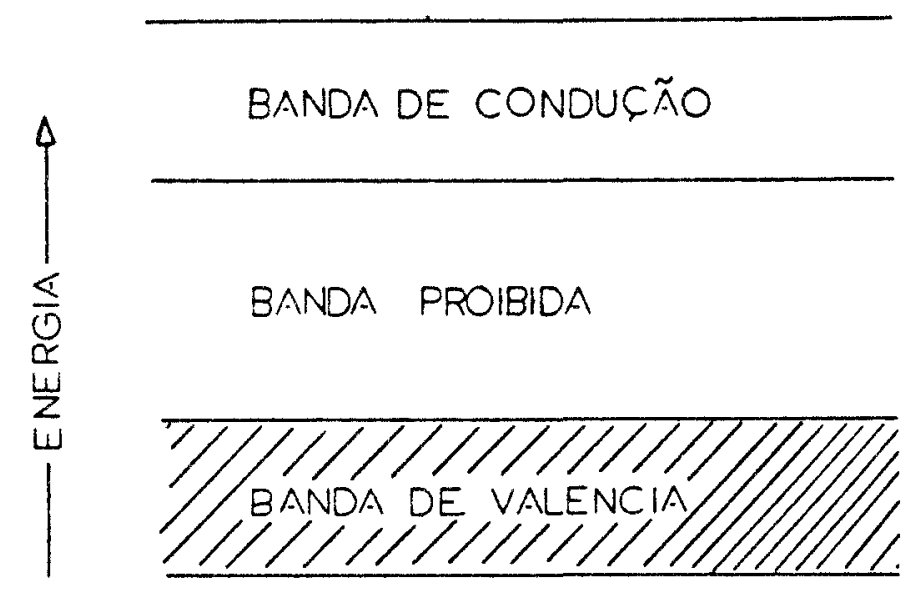

FIG. 1.I - Bandas de energia eletrônica de um isolante ou de um semicondutor. 


\section{b) Semicondutores}

Como vimos, a existência de bons condutores (metais) e maus condutores (isolantes) são explicados pela teoria de bandas. Existe uma classe de materiais, denominados semicondutores, que tem condutividade intermediária, e que o mecanismo de condução po de ser entendido pela mesma teoria.

Existem dois tipos de condução: intrínseca e extrínseca, podendo ambas ocorrer no mesmo semicondutor.

Há condução intrínseca em materiais cuja estrutura de ban das é similar aquela de isolantes (figura 1.1), mas com a diferen ça de que a largura da banda proibida é relativamente pequena (da ordem de $1,0 \mathrm{eV})$.

Quando a energia térmica é muito menor que a energia da banda proibida o material é isolante, mas em temperaturas da ordem ou maiores que a energia da banda proibida, elétrons são termicamente excitados a banda de condupão. Como os elétrons são transferidos da banda de valência para a banda de condufão, eles deixam na banda de valência níveis de energia disponíveis (lacunas) para os elétrons desta banda. Estes, então podem se movimentar para ocupar as lacunas criando por sua vez outras lacunas; este movimento corresponde a uma corrente de lacunas.

A corrente elétrica é então produzida tanto por elétrons na banda de conducão como por lacunas na banda de valência. Semicondutores em geral exibem conduqão intrínseca em temperaturas su ficientemente elevadas, mas tal mecanismo de conducão, entretanto, é de pequena importância na tecnologia de semicondutores.

Semicondutores extrínsecos também tem a mesma estrutura de bandas da figura 1.1. A conaucão extrínseca ocorre em virtude da presença de níveis adicionais de energia como resultado das im perfeifões da rede ou pela presenca de impurezas. Estes níveis adicionais situam-se na banda proibida e podem agir como doadores 
ou receptores de elétrons.

Um nivel extra age como doador se estiver preenchido no zeroabsoluto. Em temperaturas finitas uma impureza doadora pode doar um elétron 'a banda de condução. Uma impureza age como receptora se ela estiver vaga no zero absoluto; em temperaturas finitas este nivel extra pode receber um elétron da banda de valência, deixando assim um nível vago (lacuna), nesta banda. Condução na banda de valência é agora possível, visto que um elétron pode ser difundido a lacuna.

Em silício, germânio e outros semicondutores, o mecanismo principal de condufão é a extrínseca, visto que desejamos um grande número de portadores de um só tipo. Os elementos com que geralmente dopa-se silício agem como impurezas receptoras, enquanto que os elementos dopantes do Germânio agem como doadores.

A largura da banda proibida é de vários eletron-volts (da ordem de 5 a $10 \mathrm{ev}$ ) no caso de isolantes, mas é somente da ordem de 1 eV para semicondutores. Os niveis de energia das impurezas introduzidas nestes materiais, situam-se muito próximos $(0,1 \mathrm{eV})$ da banda, para a qual doam ou recebem elétrons. Assim, níveis doadores situam-se abaixo da banda de conducão, enquanto niveis receptores situam-se acima da banda de valência.

1.2.1. Distribuição de portadores em semicondutores

Como vimos anteriormente, no semicondutor intrínseco a conduçào é devida a elétrons e lacunas, enquanto no extrínseco é devido principalmente a elétrons, no caso em que a impureza é doadora, ou principalmente a lacunas quando o semicondutor contém impurezas receptoras; nestes casos o semicondutor é denominado "tipo-n" e "tipo-p", respectivamente.

Estes portadores são denominados portadores majoritários, 
mas qualquer semicondutor sempre contém portadores minoritários, os quais são lacunas no semicondutor tipo-n e elétrons no tipo-p. Naturalmente, suas concentrações são uma pequena fração das concentrações dos portadores majoritários.

o número de elétrons na banda de condução e de lacunas na banda de valência de um semicondutor é pequeno comparado ao número de níveis de energia destas bandas.

1.2.2. Retificação em um contato semicondutor-metal

Quando o contato de um semicondutor com um metal está no equilíbrio termodinâmico (18), o fluxo de elétrons do metal para - semicondutor equilibra o fluxo de elétrons em sentido oposto, e as correntes devido a eles, $i_{s_{1}} e i_{s_{2}}$ são iguais em módulo mas de sentidos opostos, como mostrado na figura 1.2.a. Então:

$$
i_{s_{1}}=i_{s_{2}}=i_{s}
$$

E a corrente resultante através do contato é:

$$
i=i_{s_{1}}-i_{s_{2}}=0
$$

Quando uma diferença de potencial externo $V$, é aplicada ao contato na direcão reversa, figura 1.2.b, o fluxo de elétrons do semicondutor para o metal diminui em proporcão a $e^{-V / k T}$, visto que o potencial da barreira aumentou de $v_{0}$ para $v_{0}+v$. On de $v_{0}$ é a altura da barreira de potencial no equilíbrio termodinâ mico, e a base do logarítmo neperiano, k a constante de Boltmann, $\mathrm{T}$ a temperatura do contato em graus Kelvin, $\ell$ a carga eletrônica e $V$ a diferenca de potencial externo aplicado ao contato. O fluxo 


\section{METAL SEMICONDUTOR}

(a)

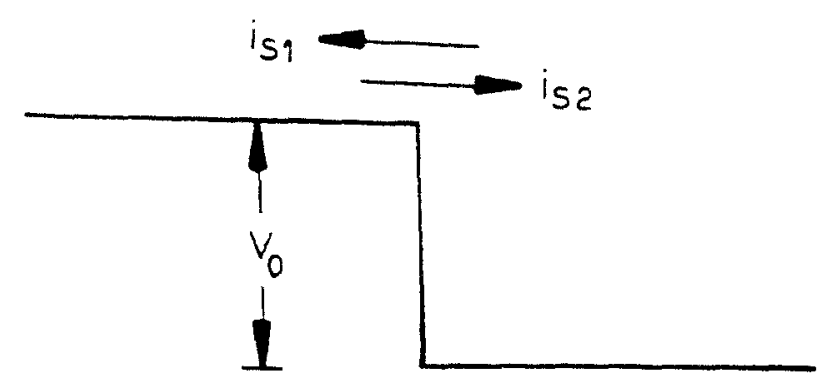

(b)
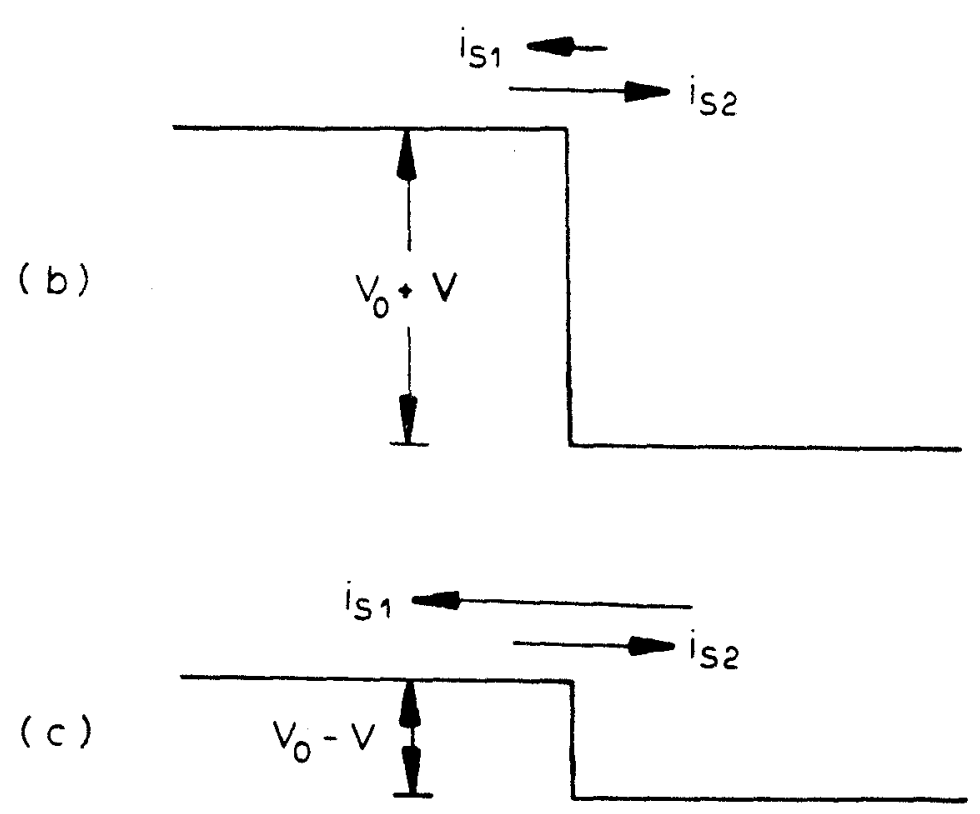

FIG.1.2 - Barreira de potencial formada pelo contato semicondutor-metal, (a) em equilíbrio termodinâmico, (b) com potencial externo aplicado na direção reversa, (c) mesmo potencial externo aplicado na direfão direta.

de elétrons do metal para o semicondutor permanece constante. 0 resultado é um fluxo líquido de elétrons na direcão reversa, chamado corrente reversa e expresso por:

$$
i_{r}=i_{S}\left(e^{-e V / k T}-1\right) \quad(1.2 .3)
$$


Quando a diferença de potencial é aplicada na direcão direta, figura l.2.c, a barreira de potencial diminui para o valor $\mathrm{V}_{0}-\mathrm{V}$ e o fluxo de elétrons no sentido semicondutor-metal aumenta em proporção a $e^{e V / k T}$, de acordo com a Lei de Boltzmann. Isto resultá em um aumento da corrente denominda direta, que é dada por:

$$
i_{d}=i_{s}\left(e^{e V / k T}-1\right)
$$

Combinando as equacões $(1.2 .3)$ e (1.2.4), obtemos:

$$
i=i_{s}\left(e^{ \pm 2 V / k T}-1\right) \quad(1.2 .5)
$$

Definindo:

$$
\alpha=\frac{e}{k T}
$$

cujo valor na temperatura ambiente é $\alpha \simeq 40 \mathrm{~V}^{-1}$, podemos reescrever $(1.2 .5)$ como:

$$
i=i_{s}\left(e^{ \pm \alpha V}-1\right)
$$

onde: i é a corrente através do contato e $\mathrm{V}$ a voltagem aplicada a ele.

A equação (1.2.7) descreve a característica estática VI do contato semicondutor-metal. Graficamente, esta característica é representada na figura 1.3, mostrando que tal contato produz uma barreira de potencial que possui praticamente uma condução unilateral. 


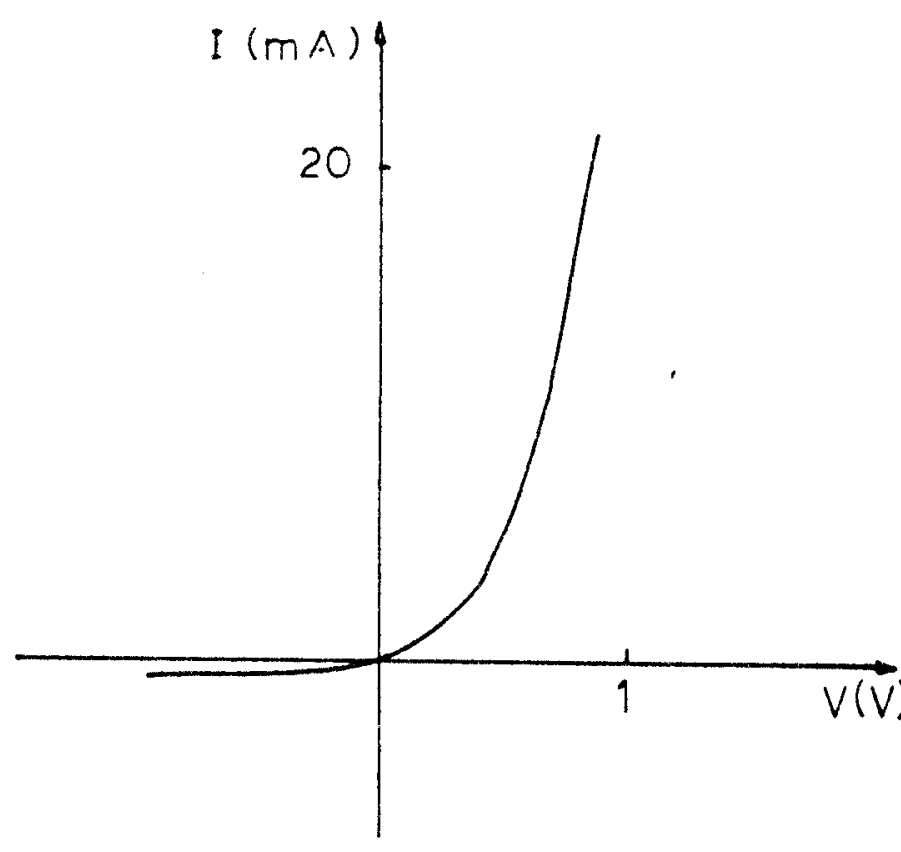

FIG. 1.3 - Característica V - I de um contato
semicondutor-metal.

Esta figura mostra que para uma mesma voltagem aplicada, a corrente na direção direta é muito maior que na direcão reversa. Se um sinal alternado for aplicado ao contato semicondutormetal ele será retificado, isto devido a característica do conta to.

1.2.3. O circuito equivalente do contato semicondutor-metal

o contato semicondutor-metal pode ser representado por um circuito equivalente. Tal circuito, facilita a compreensão do con tato quando analisado em termos de frequência.

Vemos que a equacão (1.2.7) que descreve a característica do contato, pode representar a resistência da barreira, que simbolizaremos por $R$. Notamos também que $R$ é não-linear, isto é evi denciado pela figura 1.3.

Existe ainda a capacitância C associada ao contato, que aparece devido ao armazenamento de cargas na fronteira da bar- 
reira. Esta capacitância é idêntica aquela de um capacitor de placas paralelas com o valor dado (18) por:

$$
C=S\left[\frac{2 \varepsilon_{0} n_{n_{0}}}{2\left(V_{0} \pm 2 V\right)}\right]^{\frac{1}{2}}
$$

onde: $\mathrm{S}$ é a área do contato, $\mathrm{K}$ a constante dielétrica do semicondutor, $\varepsilon_{0}$ a permitividade do vácuo, $l$ a carga eletrônica, $n_{n_{0}}$ a concentração de portadores majoritários no equilíbrio termodinâmico, $V_{0}$ a altura da barreira e $V$ a diferença de potencial aplicada ao contato.

A equacão (1.2.8) mostra a dependência não-linear desta capacitância em relacão a voltagem a ela aplicada.

Além destes dois parâmetros, devemos considerar a resistência do corpo do semicondutor, que designaremos por $r$.

Consequentemente, o circuito equivalente do contato semicondutor-metal é o mostrado na figura 1.4 .

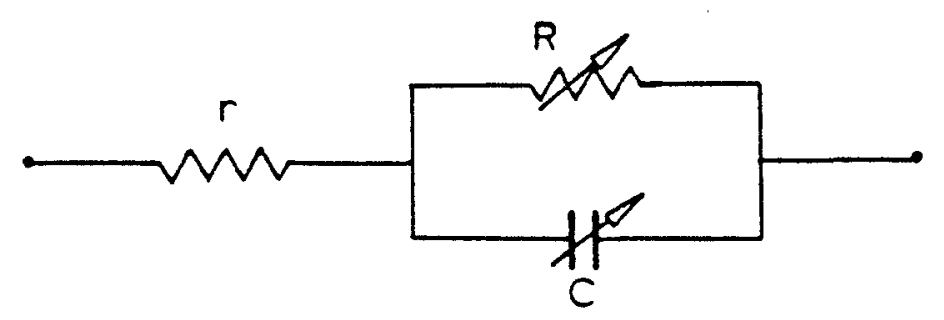

FIG.1.4 - Circuito equivalente do contato semicondutormetal

Analisemos o circuito equivalente do ponto de vista da frequência. A admitância deste circuito é:

$$
Y=\frac{1}{r}+\left(\frac{1}{R}+j \omega C\right)
$$


Para sinais de baixa frequência tal que:

$$
x_{C}=\frac{1}{\omega C}>R
$$

a admitância será:

$$
Y=\frac{1}{r}+\frac{1}{R}
$$

e o circuito equivalente para este caso é mostrado na figura 1.5 .

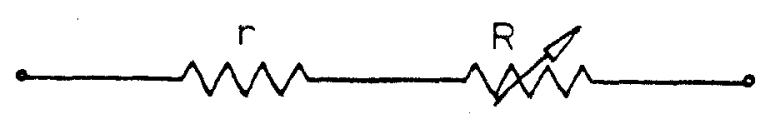

FIG.1.5 - Circuito equivalente do contato semicondutormetal para baixas frequencias.

Em altas frequências tal que:

$$
x_{C}=\frac{1}{\omega C} \ll R
$$

a admitancia do circuito torna-se:

$$
Y=\frac{1}{r}+j \omega C
$$

e o circuito equivalente é o mostrado na figura 1.6 .

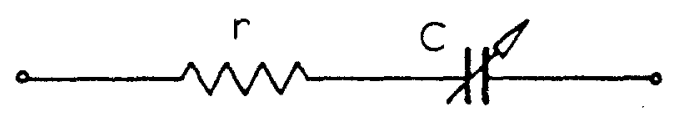

FIG.1.6 - Circuito equivalente do contato semicondutormetal para altas frequências 
Isto significa que sob estas condicões o contato perde todas as suas propriedades retificadoras.

A frequência na qual a impedância reativa do contato, $x_{C^{\prime}}$ é igual a resistência, $r$, do corpo do semicondutor é denomina da frequência de corte, $\omega_{c}$ e sua expressão é dada (18) por:

$$
w_{C}=\frac{1}{r C}
$$

Vemos em (1.2.14) que $\omega_{c}$ depende do produto $\mathrm{rC}$ e como a capacitância depende da área do contato, a solução é reduzir esta área, isto é conseguido utilizando-se um contato puntual. A finalidade de se reduzir o produto $r C$ e aumentar a frequência de corte, é que normalmente esta deve ser três vêzes maior que a frequência de trabalho do dispositivo.

A resistência r é dada (2) por:

$$
r=\frac{1}{4 \sigma a}
$$

onde $\sigma$ é a condutividade do semicondutor, a o raio do contato. Como a capacitância do contato é $c \sim a^{2}$ e $r \sim 1 / a$, então $r C \sim a$ e $\omega_{c} \sim 1 / a$. Assim, reduzindo-se a é possivel aumentar a frequência de corte e consequentemente extender a frequência de trabalho do dispositivo.

1.3. O gerador de harmônicos

Microondas e frequências mais altas são geradas em klystrons, magnetrons, etc, mas também é possível obtê-las através da geração de harmónicos de um sinal fundamental em um elemento nào-linear. 
Nesta seção discutiremos o processo de geração de harmônicos em um diodo a cristal (2) e a relacão entre as potências do sinal fundamental e aquela do n-ésimo harmônico. Descreveremos ainda a caracterização de tal dispositivo.

A figura 1.7 representa de forma esquematizada, um gerador de harmonicos que é um dispositivo de dois ou três terminais. As entradas para o sinal da frequência fundamental e corrente con tínua para polarização do diodo (quando houver), e a saída para os sinais das frequências harmônicas da fundamental.

1.3.1. A geraçăo de harmônicos em um diodo a cristal

Como já vimos anteriormente (secão 1.2.2), a relação entre a tensão aplicada e a corrente de saída em um diodo a cristal pode ser expressa convenientemente pela equação (1.2.7); a qual para maior clareza, reescrevemos abaixo:

$$
i=i_{s}\left(e^{ \pm \alpha V}-1\right)
$$

Expandindo esta equacão em uma série de potências, que é um dos métodos descritos por stokman (19), chegamos a expressão:

$$
i=\frac{i_{s}{ }^{\alpha}}{1 !} v+\frac{i_{s}{ }^{2}}{2 !} v^{2}+\ldots+\frac{i_{s}{ }^{n}}{n !} v^{n}
$$

ou

$$
i=k_{1} v+k_{2} v^{2}+\ldots+k_{n} v^{n}
$$

onde: $\quad k_{n}=\frac{i_{s} s^{n}}{n !}$ 


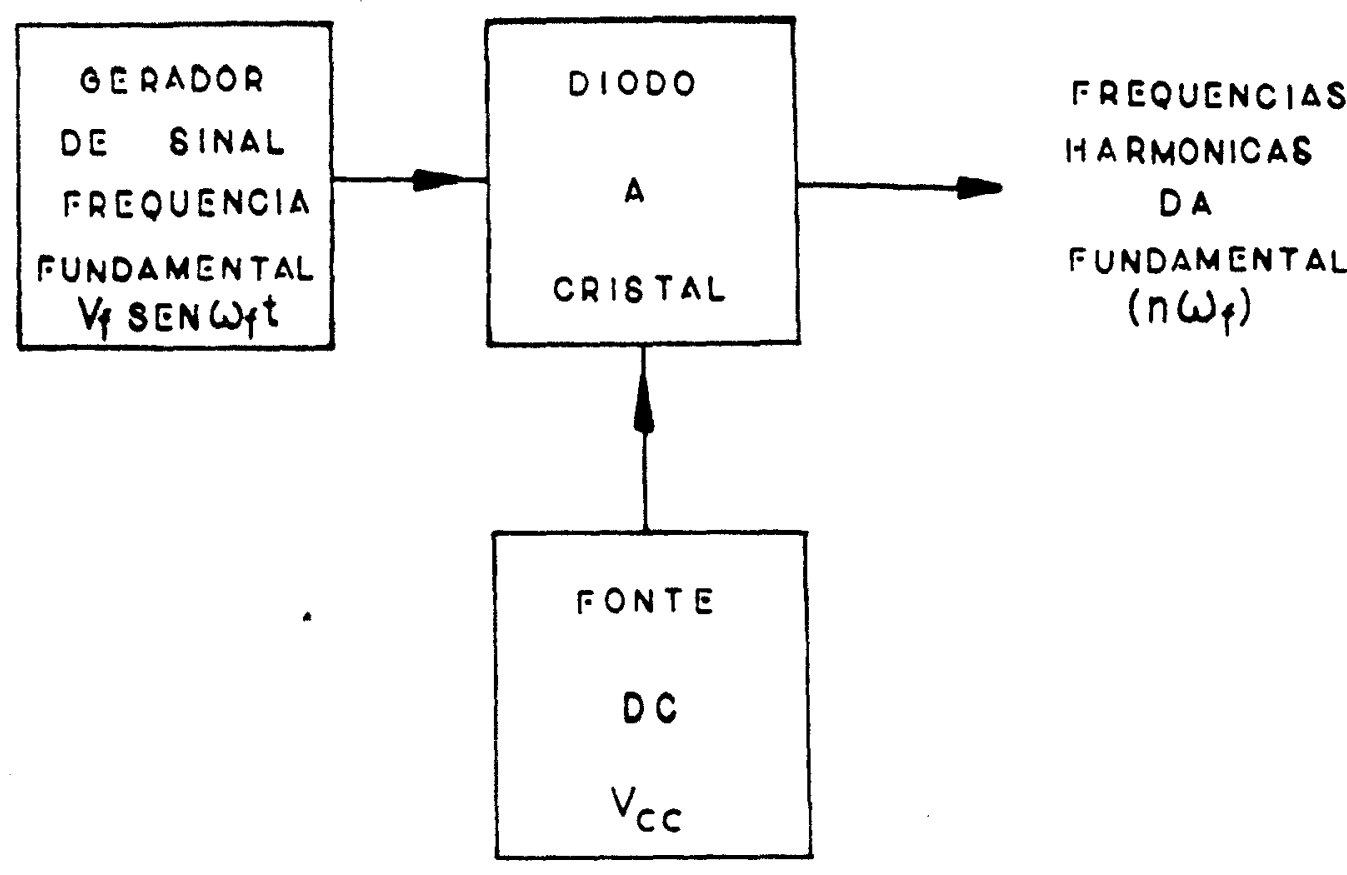

FIG.1.7 - Esquema simplificado de um gerador de harmônicos

A tensão aplicada no diodo a cristal é a soma dos sinais da frequência fundamental mais quaisquer outros que possam estar presentes. A equação (1.3.3) representa a voltagem aplicada ao diodo:

$$
v=v_{c c}+v_{f} \operatorname{sen} \omega_{f} t
$$

Substituindo (1.3.3) em (1.3.2), desenvolvendo até o termo de quinta ordem e agrupando, obtemos uma expressão, cujos termos são mostrados na tabela I.

Também podemos considerar o caso em que não haja tensão contínua aplicada ao diodo, isto é, $v_{c c}=0$; este caso também é mostrado na tabela $I$.

As componentes, na tabela I, representam as amplitudes dos vários harmônicos gerados até a quinta potência da frequên- 
TABELA I

Amplitude dos harmônicos até a quinta potência da frequência fundamental, com e sem polarizacão.

\begin{tabular}{|c|c|c|}
\hline COMPONENTE & $\begin{array}{l}\text { AMPLITUDE } \\
\text { COM } V_{C C} \neq 0\end{array}$ & $\begin{array}{l}\text { AMPLITUDE } \\
\text { COM } V_{C C}=0\end{array}$ \\
\hline CONTINUA & $\begin{array}{l}{\left[\left(K_{1} v_{c c}+k_{2} v_{c c}^{2}+k_{3} v_{c c}^{3}+\right.\right.} \\
\left.+K_{4} v_{c c}^{4}+K_{5} v_{c c}^{5}\right)+\frac{1}{2}\left(K_{2}+\right. \\
+K_{3} v_{c c}+6 K_{4} v_{c c}^{2}+ \\
\left.+10 K_{5} v_{c c}^{3}\right) v_{f}^{2}+ \\
\left.+3 / 8\left(K_{4}+5 K_{5} v_{c c}\right) v_{f}^{4}\right]\end{array}$ & $\frac{1}{2} K_{2} V_{f}^{2}+3 / 8 K_{4} v_{f}^{4}$ \\
\hline $\operatorname{sen}^{\operatorname{se}} \mathrm{f}^{t}$ & $\begin{array}{l}v_{f}\left[\left(K_{I}+2 K_{2} v_{C C}+3 K_{3} v_{C C}^{2}+\right.\right. \\
\left.+\frac{1}{4} V_{f}^{2}\right)+4 K_{4}\left(V_{C C}^{3}+\right. \\
\left.3 / 4 v_{C c} v_{f}^{2}\right)+5 K_{5}\left(V_{c c}^{4}+\right. \\
\left.\left.+3 / 2 v_{C C}^{2} v_{f}^{2}+1 / 8 v_{f}^{4}\right)\right]\end{array}$ & $\begin{array}{l}V_{f}\left(K_{1}+3 / 4 K_{3} v_{f}^{2}+\right. \\
\left.+5 / 8 K_{5} v_{f}^{4}\right)\end{array}$ \\
\hline $\cos 2 \omega_{E} t$ & 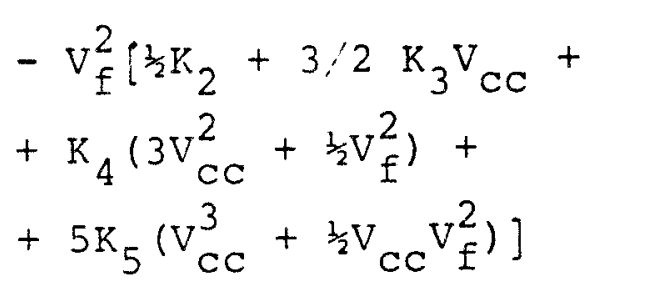 & $-v_{f}^{2}\left(\frac{1}{2} K_{2}+\frac{1}{2} K_{4} v_{f}^{2}\right)$ \\
\hline $\operatorname{sen} 3 \omega_{f} t$ & $\begin{array}{l}-\mathrm{v}_{\mathrm{f}}^{3}\left[\frac{13}{4} \mathrm{~K}_{3}+\mathrm{K}_{4} \mathrm{~V}_{\mathrm{cc}}+\right. \\
\left.5 \mathrm{~K}_{5}\left(\frac{1}{2} \mathrm{~V}_{\mathrm{cc}}^{2}+1 / 16 \mathrm{v}_{\mathrm{f}}^{2}\right)\right]\end{array}$ & $-v_{f}^{3}\left(\frac{13}{4} K_{3}+5 / 16 v_{f}^{2}\right)$ \\
\hline $\cos 4 \omega_{f} t$ & $1 / 8 \mathrm{v}_{\mathrm{f}}^{4}\left[\mathrm{~K}_{4}+5 \mathrm{~K}_{5} \mathrm{v}_{\mathrm{cc}}\right]$ & $I / 8 \mathrm{~K}_{4} \mathrm{~V}_{\mathrm{f}}^{4}$ \\
\hline $\operatorname{sen} 5 \omega_{f} t$ & $1 / 16 \mathrm{~K}_{5} \mathrm{~V}_{\mathrm{f}}^{5}$ & $1 / 16 \mathrm{~K}_{5} \mathrm{~V}_{\mathrm{f}}^{5}$ \\
\hline
\end{tabular}


cia fundamental, com e sem polarizacão, que aparecem na saida do dispositivo.

1.3.2. Caracterização do gerador de harmônicos

Para que possamos analisar as qualidades de qualquer dispositivo é necessário conhecer os diversos parâmetros que são indispensáveis a sua completa caracterizacão.

INo caso do gerador de harmônicos, existem parâmetros que são conhecidos na ocasião do projeto, são eles: faixa da frequência fundamental, ordem dos harmônicos de trabalho e faixa das frequências harmônicas. O parâmetro que deve ser obtido experimentalmente, o qual caracteriza o gerador de harmônicos em relaqão as potências fundamental e harmônica, é a perda de conversão, L, este fator mostra a qualidade do dispositivo e é definido pela expressão:

$$
{ }^{t} L(d B)=10 \log \frac{P_{f}}{P_{h}} .
$$

onde $P_{f}$ e $P_{h}$ são as potências dos sinais fundamental e harmônico. 1.3.3. Relação entre as potências fundamental e harmônica

Nas discussóes teóricas sobre geração de harmônicos, duas classes de elementos não-lineares foram anallsados, o diodo a cristal e o diodo "varactor". Nestas discussões, a barreira de po tencial do contato semicondutor-metal no diodo a cristal é representada exclusivamente por uma resistência não-linear, enquanto que a barreira de potencial da junção $p-n$ do diodo "varactor" é descrita unicamente por uma capacitância não-linear; sendo ambas 
as responsáveis pela geracão dos harmônicos.

A teoria para o diodo a cristal foi desenvolvida por Page $(20,21)$, o circuito equivalente proposto consiste numa resistência não-linear, que é definida como um dispositivo de dois terminais, através do qual flui uma corrente I. Esta é supos ta ser uma função não-decrescente da voltagem $V$ aplicada, com a condição: $I(0)=0$. O circuito idealizado por page é mostrado na figura 1.8. Este modelo apresenta uma expressão para a mínima

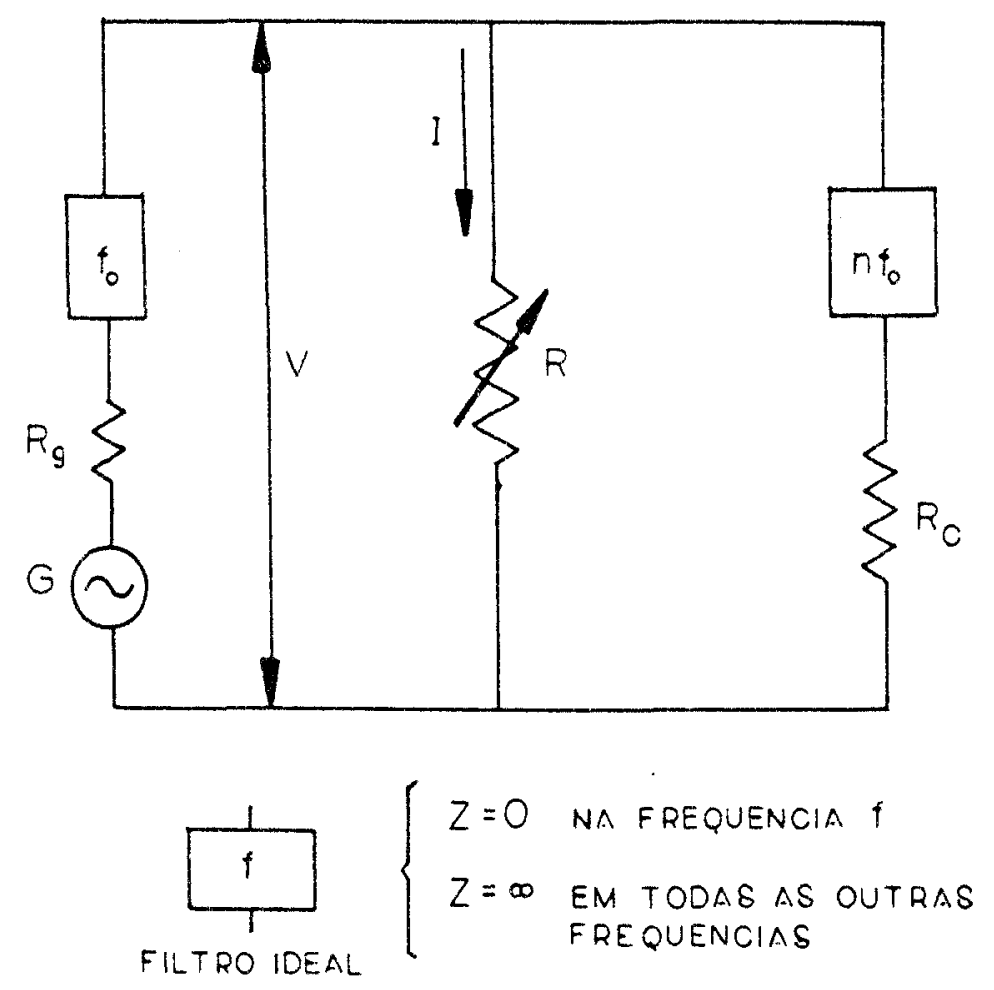

FIG. 1.8 - Circuito equivalente proposto por Page para o gerador de harmônicos.

peráa de conversão na geração de harmônicos que é mostrada na expressão abaixo:

$$
L(A B)=10 \log \frac{P_{f}}{P_{h}} \geqslant 10 \log n^{2}
$$

onde $\mathrm{P}_{\mathrm{h}}$ representa a potência desenvolvida no n-ésimo harmônico, $P_{E}$ é a potencia fundamental e $n$ é o número do harmônico. 
A equação (1.3.5) estabelece que se todà a potência funda mental é convertida no n-ésimo harmônico, a perda de conversão na geracão deste harmônico não é menor que $\mathrm{n}^{2}$.

Por outro lado, menores perdas de conversão devem ser esperadas de dispositivos que não retificam. Iva teoria de geração de harmônicos por capacitâncias não-lineares, Manley e Rowe (22), Leeson e Weinreb (23) e Utsunomiya e Yuan (24) mostram que a perda de conversão destes dispositivos aproxima-se de zero.

Outro resultado obtido por Page é que uma resistência não-linear não pode gerar sub-harmônicos (20). A teoria de Manley e Rowe prediz que uma capacitância não-linear gerará sub-harmônicos, o que foi confirmado experimentalmente por Leenov e Uhlir (25) .

1.4. O misturador de harmônicos

A técnica superheterodina de deteção de microondas é baseada em um processo de mistura de sinais. Potência do oscilador de microonas, chamadó oscilador-local (OL), é aplicado juntamen te com a potência do sinal que contém a informação, denominado rádio-frequência ( $R F$ ), em um elemento não-linear (diodo a cristal em nosso caso). A frequência que resulta da diferença produ zida pelo batimento das duas frequências de microonas citadas acima, e denominada frequência-intermediária (FI). Este processo é chamado mistura e ocorre em dispositivos deriominados misturadores. Podemos então definir o misturador como um dispositivo não-linear de três terminais, duas entradas para os sinais de OL e RF e uma saída para o sinal de FI.

Como o componente responsável pela conversão de frequências é não-linear, ele gerará uma ampla gama de frequências dos sinais aplicados; sendo assim o espectro de saida de tal dispo- 
sitivo conterá todas as misturas possiveis.

Quando a frequência-intermediária é a diferença entre as frequências dos sinais aplicados, o misturador é dito fundamental. o misturador de harmônicos é aquele em que a frequência-intermediária resulta da diferença entre harmônicos do sinal de oscilador-local e do sinal de rádio-frequência.

o misturador de harmônicos devido a sua característica é um misturador não-balanceado, isto é,o ruído do oscilador-local nào é cancelado, além disto opera com níveis de potência do oscilador-local bem acima daqueles que operam com a frequência fundamental (misturadores fundamentais), visto que ele deve ser um eficiente gerador de harmônicos.

o valor da frequência-intermediária é comumente 30 ou 60 MHz, sendo assim a FI pode ser amplificada e detetada utilizando-se técnicas comuns de baixa-frequência. Atualmente, com o desenvolvimento de amplificadores a estado sólido na região de microondas, existem misturadores cuja frequencia-intermediária e compreendida entre $\mathrm{I}$ e $5 \mathrm{GHz}$.

Idealmente, o misturador apenas transforma em frequência - sinal recebido, deixando todas as outras componentes (por exem plo: modulação) deste imutáveis.

A perda de conversão de tal dispositivo é bem mais alta que aquela de misturadores fundamentais. O acréscimo típico na perda de conversão é 3 ou 4 dB por harmônico $(11,27)$ e a esta deve ser somada a perda de conversão se o mesmo dispositivo operasse na frequência fundamental, sendo que esta pode ser de até $15 \mathrm{~dB}(27)$.

1.4.1. A mistura de frequências em um diodo a cristal 
blocos é mostrado na figura 1.9. O gerador de sinais de amplitude $\mathrm{V}_{\mathrm{RF}}$ e frequência ângular $\omega_{\mathrm{RF}}$, que simula o sinal recebido pela antena em um receptor de microondas, é combinado com o osciladorlocal, cuja amplitude é $V_{O L}$ e frequencia ângular 'wOL' em um mistú rador composto por um único diodo a cristal.

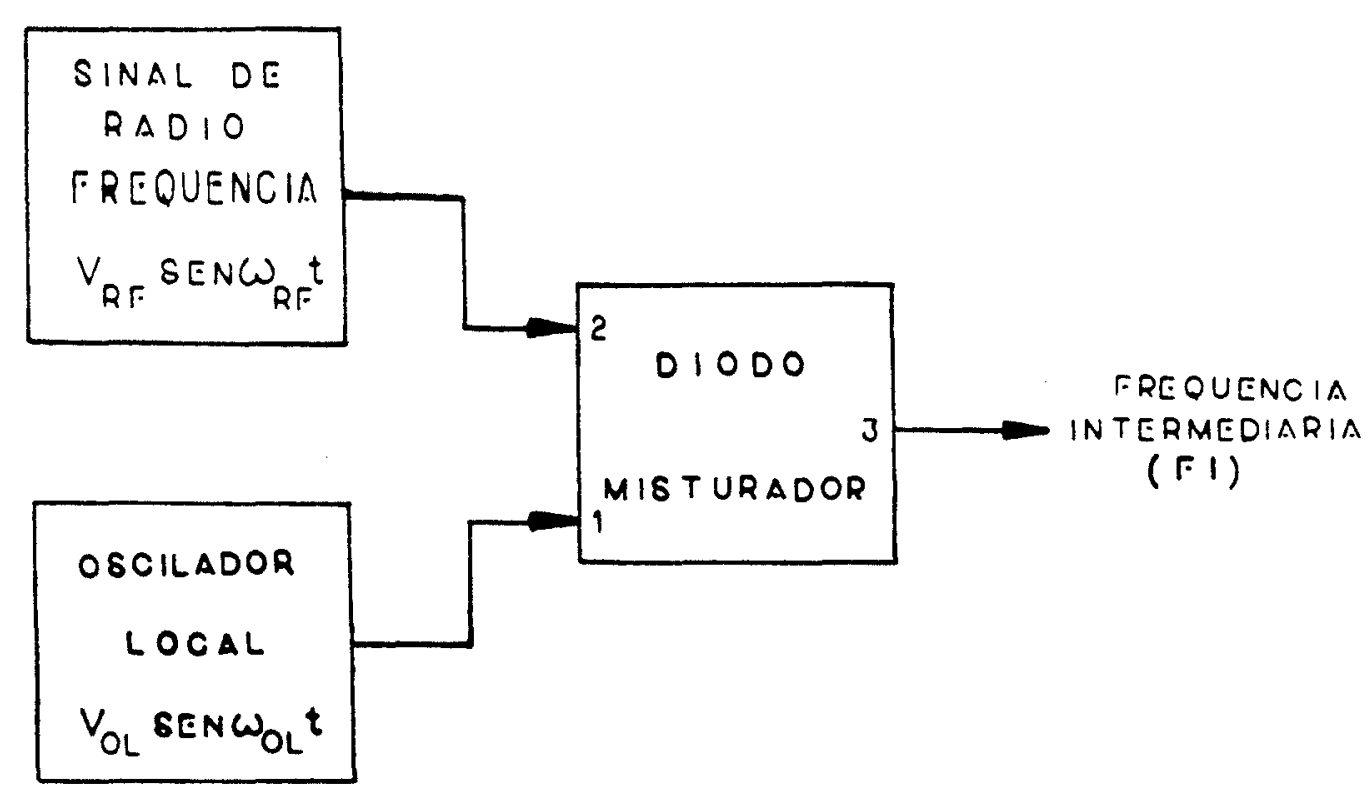

FIG.I.9 - Diagrama em blocos do conversor de frequências.

Desejamos observar que sinais estarão presentes na saída (FI) do misturador, como resultado do batimento das frequências do oscilador-local e sinal de RF no diodo a cristal. Como vimos (seção 1.3.1), a tensão e corrente no diodo estão relacionadas pela expressão:

$$
i=k_{1} v+k_{2} v^{2}+\ldots+k_{n} v^{n}
$$

A tensão aplicada no diodo, é a soma dos sinais de RF e do oscilador-local mais qualquer componente contínua $\left(V_{C c}\right)$ que possa estar presente. Esta tensão é representada pela equação $(1.4 .1)$. 
Amplitudes das várias componentes das frequências na saída do misturador.

\begin{tabular}{|c|c|c|}
\hline COMPONENTE & $\begin{array}{l}\text { AMPLITUDE } \\
\text { COM } V_{C C} \neq 0\end{array}$ & $\begin{array}{l}\text { AMPLITUDE } \\
\operatorname{COM} V_{C C} \neq 0\end{array}$ \\
\hline CONTINUA & $\begin{aligned} & \left(K_{1} V_{C C}+K_{2} V_{C C}^{2}+K_{3} V_{C C}^{3}+\right. \\
+ & \left.K_{4} V_{C C}^{4}+K_{5} V_{C C}^{5}\right)+ \\
+ & \frac{1}{2}\left(K_{2}+K_{3} V_{C C}+\right. \\
+ & \left.6 K_{4} V_{C C}^{2}+10 K_{5} V_{C C}^{3}\right) \\
& \left(V_{R F}^{2}+V_{O L}^{2}\right)+3 / 2\left(K_{4}+\right. \\
+ & \left.5 K_{5} V_{C C}\right) V_{O L}^{2} V_{R F}^{2}+ \\
+ & 3 / 8\left(K_{4}+5 K_{5} V_{C C}\right) \\
& \left(V_{C C}^{4}+V_{R F}^{4}\right)\end{aligned}$ & $\begin{array}{l}3_{2} K_{2}\left(V_{R F}^{2}+V_{O L}^{2}\right)+ \\
+3 / 2 K_{4} V_{O L}^{2} V_{R F}^{2}+ \\
+3 / 8 K_{4}\left(V_{O L}^{4}+V_{R F}^{4}\right)\end{array}$ \\
\hline $\cos 2 \omega_{R F}{ }^{t}$ & 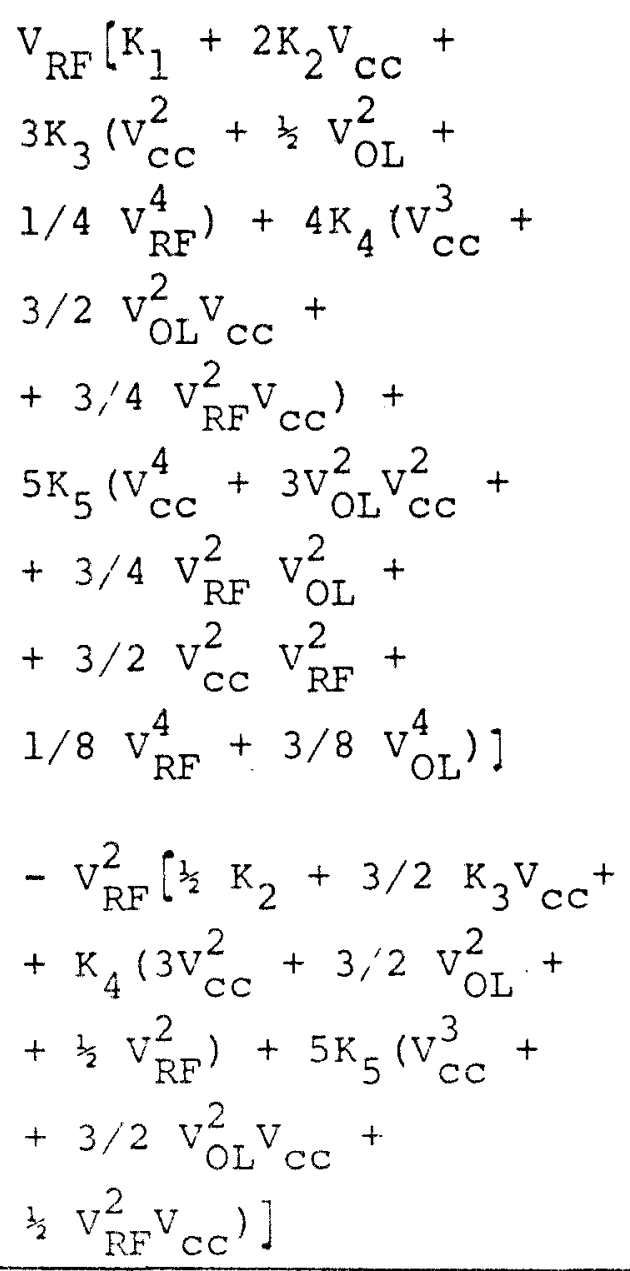 & $\begin{array}{l}\mathrm{v}_{\mathrm{RF}}\left[\mathrm{K}_{1}+3 \mathrm{~K}_{3}\left(\frac{1}{2} \mathrm{~V}_{\mathrm{OL}}^{2}+\right.\right. \\
\left.+\frac{1}{4} \mathrm{~V}_{\mathrm{RF}}^{2}\right)+ \\
+5 \mathrm{~K}_{5}\left(3 / 4 \mathrm{v}_{\mathrm{RF}}^{2} \mathrm{~V}_{\mathrm{OL}}^{2}+\right. \\
\left.\left.1 / 8 \mathrm{~V}_{\mathrm{RF}}^{4}+3 / 8 \mathrm{~V}_{\mathrm{CL}}^{4}\right)\right] \\
-\mathrm{v}_{\mathrm{RF}}^{2}\left[\frac{1}{2} \mathrm{~K}_{2}+\mathrm{K}_{4}\left(3 / 2 \mathrm{v}_{\mathrm{OL}}^{2}+\right.\right. \\
\left.\left.+\frac{3}{2} \mathrm{~V}_{\mathrm{RF}}^{2}\right)\right]\end{array}$ \\
\hline
\end{tabular}


COITT, TABELA II

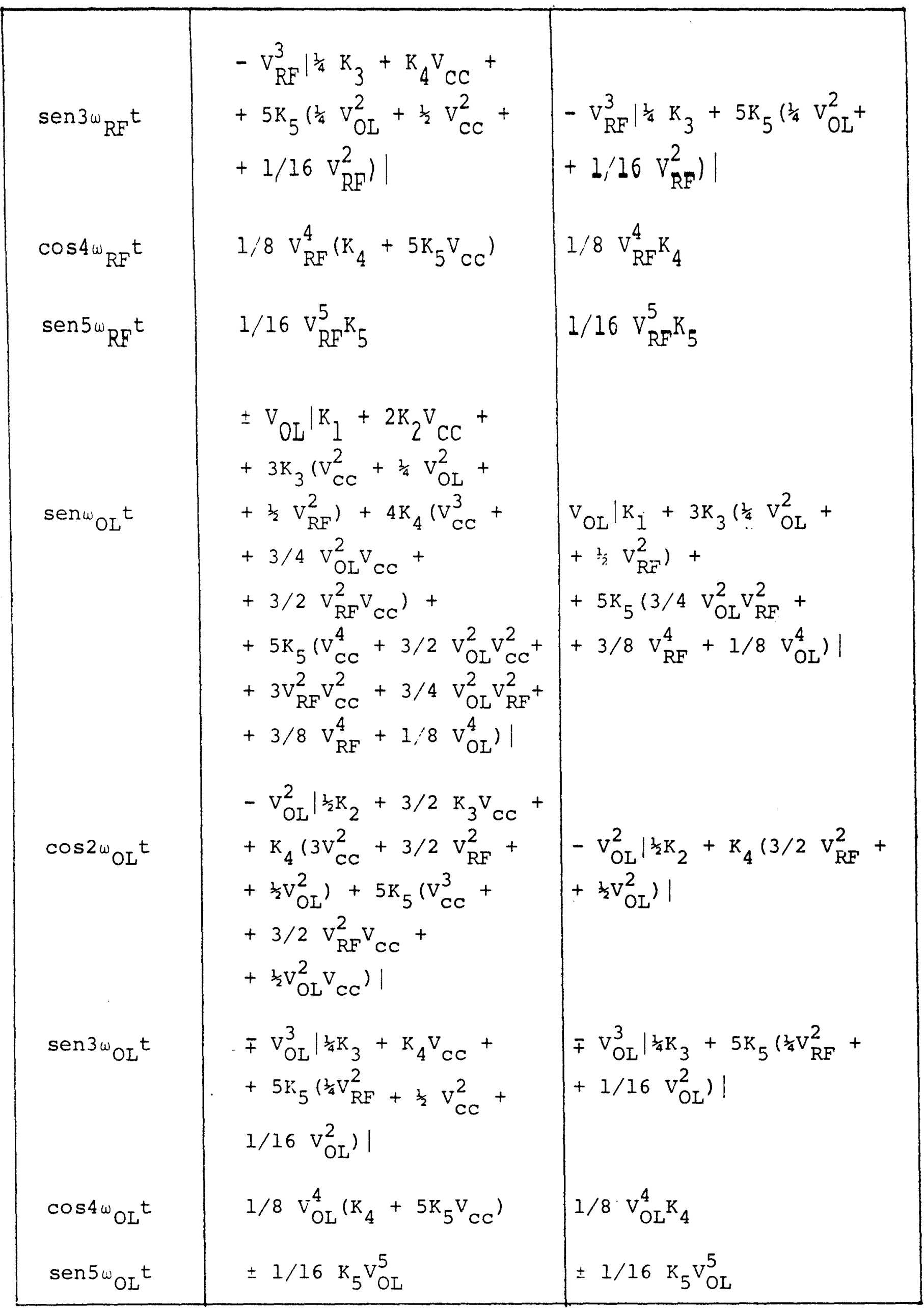


CONT. TABELA II

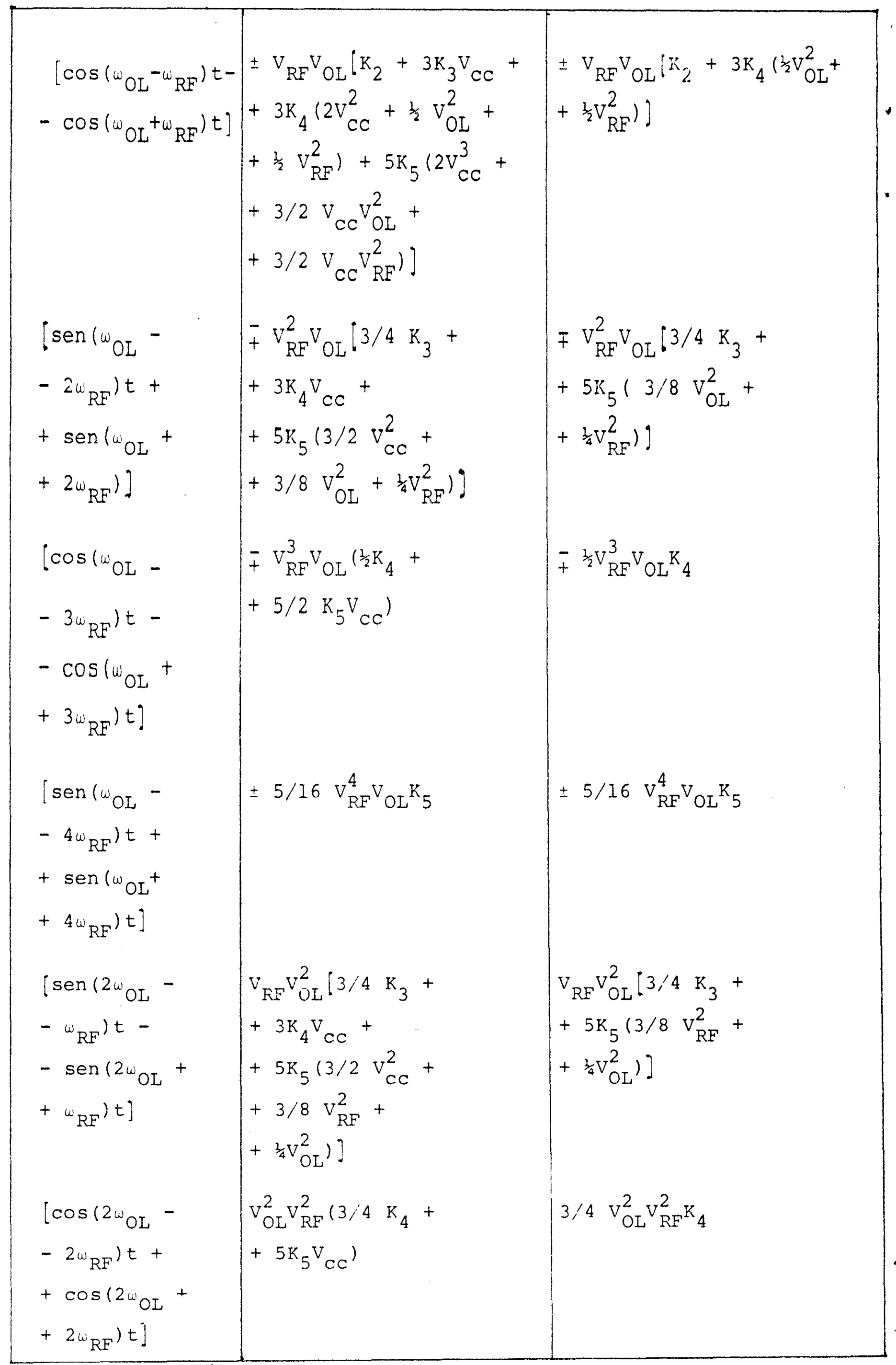


CONT. TABELA II

\begin{tabular}{|c|c|c|}
\hline $\begin{array}{l}{\left[\operatorname{sen}\left(2 \omega_{O L}-\right.\right.} \\
\left.-3 \omega_{R F}\right) t- \\
-\operatorname{sen}\left(2 \omega_{O L}+\right. \\
\left.\left.+3 \omega_{R F}\right) t\right] \\
{\left[\cos \left(3 \omega_{O L}-\right.\right.} \\
\left.-\omega_{R F}\right) t- \\
-\cos \left(3 \omega_{O I}+\right. \\
\left.\left.+{ }^{\omega_{R F}}\right) t\right] \\
{\left[\operatorname{sen}\left(3 \omega_{O L}-\right.\right.} \\
\left.-2 \omega_{R F}\right) t+ \\
+\operatorname{sen}\left(3 \omega_{O L}+\right. \\
\left.\left.+2 \omega_{K F}\right) t\right] \\
{\left[\operatorname{sen}\left(4 \omega_{O L}-\right.\right.} \\
\left.-\omega_{R F}\right) t- \\
-\operatorname{sen}\left(4 \omega_{O L}+\right. \\
\left.\left.+\omega_{R F}\right) t\right]\end{array}$ & $\begin{array}{l} \pm 5,8 \mathrm{v}_{\mathrm{RF}}^{2} \mathrm{v}_{\mathrm{OL}}^{3} \mathrm{~K}_{5} \\
-5 / 16 \mathrm{v}_{\mathrm{OL}}^{2} \mathrm{~V}_{\mathrm{RF}} \mathrm{K}_{5}\end{array}$ & $\begin{array}{c} \pm 5 / 8 \mathrm{v}_{\mathrm{RF}}^{2} \mathrm{~V}_{\mathrm{OL}}^{3} \mathrm{~K}_{5} \\
-5 / 16 \mathrm{~V}_{\mathrm{OL}}^{4} \mathrm{~V}_{\mathrm{RF}} \mathrm{K}_{5}\end{array}$ \\
\hline
\end{tabular}


$V=V_{C C}+V_{R F} \operatorname{sen} \omega_{R F} t \pm V_{O L} \operatorname{sen} \omega_{C L}{ }^{t}$

Substituindo a equação (1.4.1) na equação (1.3.2), desenvolvendo até a quinta potência e agrupando, obtemos uma expressão (26) cujas componentes são mostradas na tabela II.

o caso em que $V_{c c}=0$, isto é não há polarização aplicada, foi considerado e o resultado é mostrado na tabela II.

1.4.2. Caracterização de misturadores

Baseados no esquema do misturador mostrado na figura 1.9, definiremos alguns parâmetros que o caracterizam.

Definimos a perda de conversảo, L, como a razão entre a potência do sinal de $R F$ e a potência do sinal da frequência-inter mediária, isto é:

$$
I(\mathrm{~dB})=10 \log \frac{\mathrm{P}_{\mathrm{RF}}}{\mathrm{P}_{\mathrm{FI}}}
$$

Se todo o sinal de RF fosse convertido em sinal de FI, a perda de conversão do misturador seria zero; mas em virtude da geração de harmônicos dos sinais de RF e OL e consequentemente da mistura que acontece entre eles e como a energia nunca é trans ferida com rendimento unitário, a perda de conversão ocorre.

Um outro parâmetro pertinente aos níveis dos sinais é a isolação entre os terminais. O interesse é determinar a quantidade de um sinal que entrando em um terminal aparece em outro, isto é, medir a fuga de potência dos sinais e que não são utilizadas.

A isolacão, I, entre os terminais do oscilador-local e 
frequência-intermediária é definido pela expressão:

$$
I_{1,3}=10 \log \frac{\mathrm{P}_{\mathrm{OL}_{1}}}{\mathrm{P}_{\mathrm{OL}_{3}}}
$$

onde $\mathrm{P}_{\mathrm{OL}_{1}}$ é a potência do OL que é introduzido em seu próprio terminal e $\mathrm{P}_{\mathrm{OL}_{3}}$ a potência do OL que aparece no terminal de FI. Analogamente,

$$
I_{2,1}=10 \log \frac{{ }_{R F_{2}}}{P_{R F_{1}}}
$$

esta expressão define a isolação entre os terminais de RF e OL.

\subsection{Propagação de microondas}

Existe um número infinito de modos, ou configuracões de campo, através dos quais energia pode ser transmitida em linhas de transmissão e guias de onda. Em linhas coaxiais, o modo de pro pagação usado é o denominado modo principal e simbolizado por TEM, no qual os campos elétrico e magnético tem somente componentes que sãonormais a direção de propagação. Este modo principal requer dois condutores separados, e portanto não pode existir em guias de onda. Em guias de onda a energia se propaga somente em modos de ordem mais alta, e isto requer que o guia exceda certas dimensões mínimas para permitir a transmissão de sinais de um dado comprimento de onda.

os vários modos de propagação em guias de onda podem ser divididos em duas classes. Em uma destas o campo elétrico tem somente componentes que são normais a direção de propagação; estas ondas são denominadas TE ou H. Analogamente, ondas TM ou E são aquelas em que o campo magnético tem somente componentes normais a 
direção de propagação.

Nesta seção os principios de linhas de transmissão e guias de onda (retangular) e uma análise de seus diversos parâmetros são apresentados.

\subsubsection{Linhas de transmissão}

Uma linha de transmissão é construida com dois condutores separados por um dielétrico. Ela tem uma indutância distribuida, I, por unidade de comprimento e uma capacitância distribuida, C, por unidade de comprimento. As perdas são representadas por uma resistência distribuida, $R$, por unidade de comprimento em série e pela condutância distribuida, G, por unidade de comprimento em paralelo. o circuito equivalente da linha de transmissão é mostra do na figura 1.10. As relações entre a voltagem (V) e a corrente

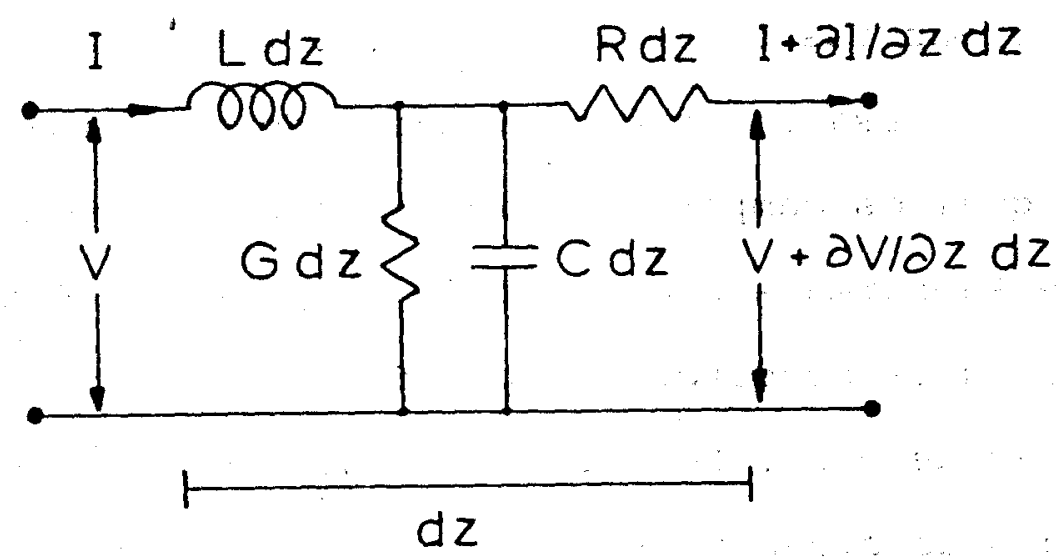

FIG. 1.10 - Circuito equivalente da linha de transmissao.

(I), que são assumidas terem uma dependência senoidal no tempo, são dadas pelas seguintes expressões:

$$
\frac{d V}{d z}=-(R+j \omega L) I
$$


e

$$
\frac{d I}{d z}=-(G+j \omega C) V
$$

Podemos eliminar $V$ ou I destas equações pela diferenciação em relacão a $z$ e seguida pela necessária substituição, isto leva ao resultado:

$$
\frac{d^{2} v}{d z^{2}}=\gamma^{2} v
$$

e

$$
\frac{d^{2} I}{d z^{2}}=\gamma^{2} I
$$

onde a constante de propagacão $\gamma$ é definida em termos da constante de atenuação $\alpha$ e a constante de fase $B$, isto é:

$$
\gamma=\alpha+j \beta=[(R+j \omega L)(G+j \omega C)]^{\frac{1}{2}}
$$

A solução geral de (1.5.3) é:

$$
V=v_{1} e^{-\gamma z}+v_{2} e^{\gamma z}
$$

e substituindo esta solução em (1.5.2), obtemos para a corrente:

$$
I=\frac{I}{Z_{0}}\left(V_{1} e^{-\gamma z}-V_{2} e^{\gamma z}\right)
$$

onde $z_{0}$ é a impedância característica da linha de transmissão e sua expressão é: 


$$
z_{0}=[(R+j \omega L) /(G+j \omega C)]^{\frac{1}{2}}(1.5 .8)
$$

A impedância de entrada da linha em qualquer ponto, digamos $z=z$, é a impedância de entrada da seção de linha a direita de $z=z$, no esquema mostrado na figura 1.11, e é dada por:

$$
z_{E N}=\frac{V}{I}=z_{0} \frac{v_{1} e^{-\gamma z}+v_{2} e^{\gamma z}}{v_{1} e^{-\gamma z}-v_{2} e^{\gamma z}}
$$

em particular para $z=\ell$, temos:

$$
z_{L}=z_{0} \frac{v_{1} e^{-\gamma \ell}+v_{2} e^{\gamma \ell}}{v_{1} e^{-\gamma l}-v_{2} e^{\gamma \ell}}
$$

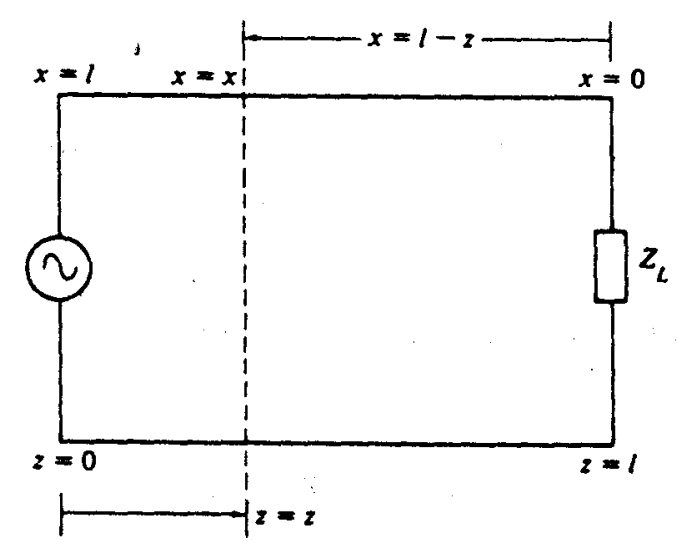

FIG. 1.11 - Esquema da linha de tranßmissão onde são mostrados os sistemas de referência.

O coeficiente de reflexão de voltagem, $\Gamma$, é definido como a razão entre as voltagens das ondas incidente e refletida, na carga $z_{L}$, isto é: 


$$
I_{L}=\frac{v_{2} e^{\gamma \ell}}{V_{1} e^{-\gamma \ell}}=\frac{v_{2}}{V_{1}} e^{2 \gamma \ell}
$$

onde $\Gamma_{L^{\prime}}$ o qual geralmente é complexo, é o coeficiente de reflexão de voltagem. Em termos de $\Gamma_{L}$ a equação prévia torna-se:

$$
z_{L}=z_{0} \cdot \frac{1+\Gamma_{L}}{1-\Gamma_{L}}
$$

Resolvendo esta pra $\Gamma_{L}$, obtemos:

$$
\Gamma_{L}=\frac{z_{L}-z_{0}}{z_{L}+z_{0}}
$$

Analisaremos a equação (1.5.13) considerando alguns casos especiais:

a) $z_{L} \rightarrow \infty$ (circuito aberto), $\Gamma_{L}=1$, e a voltagem da onda refletida tem o mesmo módulo e fase da onda incidente. A corrente da onda refletida tem o mesmo módulo da onda incidente, mas as fa ses são opostas.

b) $z_{L}=a z_{0} \operatorname{com} l<a<\infty$, então $0<\Gamma_{L}<1$. A voltagem $e$ a corrente da onda refletida tem um valor menor que 0 da onda incidente; as fases das voltagens e correntes são iguais e opostas respectivamente.

c) $z_{L}=z_{0}$, não ha reflexão, $\Gamma_{L}=0$ e a linha de transmissão é dita "casada" a carga e equivale a uma linha de comprimento infinito.

d) $z_{L}=a z_{0} \operatorname{com} 0<a<1$, então $-1<\Gamma_{L}<0$. A voltagem e corrente da onda refletida tem amplitude menor que a da onda incidente, as fases das voltagens e correntes são opostas e iguais, respectivamente. 
e) $z_{L}=0$ (curto circuito), $I_{L}=-1$. Os módulos das voltagens e correntes das ondas refletida e incidente são iguais, a fase da voltagem da onda refletida e oposta a da incidente e as fases são iguais para as correntes das ondas refletida e inciden te.

Desejamos encontrar uma expressão para a impedância de entrada, $Z_{E N}$, que não dependa explicitamente de $V$ e I, para isto vamos trocar a variável $z$ pela variável $x$, de modo que $z=\ell-x$, assim as equações $(1.5 .6)$ e $(1.5 .7)$ podem ser reescritas como:

$$
V=V_{I} e^{-\gamma \ell}\left(e^{\gamma x}+\Gamma_{L} e^{-\gamma x}\right)
$$

e

$$
I=\frac{v_{1}}{z_{0}} e^{-\gamma \ell}\left(e^{\gamma x}-\Gamma_{L} e^{-\gamma x}\right)
$$

Substituindo as expressões acima na equacão (1.5.9), encontramos:

$$
z_{E N}=z_{0} \frac{z_{L}+z_{0} \operatorname{tgh} \gamma x}{z_{0}+z_{L} \operatorname{tgh} \gamma x}
$$

Esta é a expressão geral para a impedância de entrada $z_{E N}$ a uma distância $x$ da carga $z_{L}$.

Se a Iinha é um circuito aberto, $z_{L} \rightarrow \infty$ a equaqão (1.5.16) se reduz a :

$$
z_{E N}=z_{0} \operatorname{cotgh} \gamma x
$$

Se a linha é curto-circuitada, $z_{L}=0$, e (1.5.16) torna-se: 


$$
z_{E N}=z_{0} \operatorname{tgh} \gamma x
$$

Vamos agora considerar o caso em que não há perdas, isto é, $R=G=\alpha=0$ e $\beta=2 \pi / \lambda$, onde $\lambda$ é 0 comprimento de onda; com estas condições a linha é denominada ideal. Assim as equações $(1.5 .5),(1.5 .6),(1.5 .7)$ e $(1.5 .8)$ se reduzem a:

$$
\begin{aligned}
& \gamma=j \beta=j \omega(L C)^{\frac{1}{2}} \\
& V=v_{1} e^{-j \beta z}+v_{2} e^{j \beta z} \\
& I=\frac{1}{z_{0}}\left(v_{1} e^{-j \beta z}-v_{2} e^{j \beta z}\right)
\end{aligned}
$$

e

$$
\begin{aligned}
& z_{0}=(L / C)^{\frac{1}{2}} \\
& \text { A impedância de entrada } z_{E N}(1.5 .16) \text {, torna-se: } \\
& z_{E N}=z_{0} \frac{z_{L}+j z_{0} \operatorname{tg} \beta x}{z_{0}+j z_{L} \operatorname{tg} \beta x} \\
& \text { pois: } \quad \operatorname{tgh\gamma x}=\frac{\operatorname{tgh} \alpha x+j \operatorname{tg} \beta x}{1+j \operatorname{tgh} \alpha \operatorname{tg} \beta x} \\
& \text { As equações }(1.5 .17) \text { e (1.5.18) reduzem-se a: } \\
& z_{E N}=-j z_{0} \operatorname{cotg} \beta x \\
& z_{E N}=j z_{0} \operatorname{tg} \beta x
\end{aligned}
$$


Em uma linha de transmissão ideal a voltagem varia entre um máximo e um mínimo, isto é, há pontos onde $v_{1}$ e $v_{2}$ se adicionam e outros em que se subtraem, isto é:

$$
\mathrm{v}_{\mathrm{MAX}}=\left|\mathrm{v}_{1}\right|+\left|\mathrm{v}_{2}\right|
$$

e

$$
v_{\text {MIN }}=\left|v_{1}\right|+\left|v_{2}\right|
$$

A razão de voltagem de onda estacionária (RVOE) é definida como:

$$
\text { RVOE }=\frac{V_{M A X}}{V_{M I N}}=\frac{1+\left|\Gamma_{L}\right|}{1-\left|\Gamma_{L}\right|}
$$

que pode ser reescrita como:

$$
\left|\Gamma_{L}\right|=\frac{\text { RVOE }-1}{\text { RVOE }+I}
$$

Se a linha de transmissão é "casada", não há reflexão e a RVOE é unitária. Assim a quantidade pela qual a RVOE excede a uni dade é uma medida da qualidade do "casamento".

\subsubsection{Linhas coaxiais}

As linhas coaxiais foram desenvolvidas para transmissão de sinais de microondas com o objetivo de evitar perdas por radiação. Elas são construidas com dois condutores cilíndricos coaxiais separados por um dielétrico. Os parâmetros. deste tipo de linha dados por (28) são: 


$$
L=0,4605 \mu \log (b / a) \cdot 10^{-6}
$$

e

$$
C=\frac{0,241 \varepsilon}{\log \left(\frac{b}{a}\right)} \cdot 10^{-10}
$$

onde $\mu$ e $\varepsilon$ são a permeabilidade e a constante dielétrica do meio, $\mathrm{a} e \mathrm{~b}$ são os raios externo (condutor interno)e interno (condutor externo).

A impedância característica de uma linha coaxial de baixas perdas (29) é:

$$
z_{0}=138(\mu / \varepsilon)^{\frac{1}{2}} \log (b / a)
$$

o modo principal de transmissão em uma linha coaxial é aquele em que os campos elétrico e magnético são ortogonais a dire ção de propagação e denominado TEM. A configuração deste é mostrada na figura 1.12 .

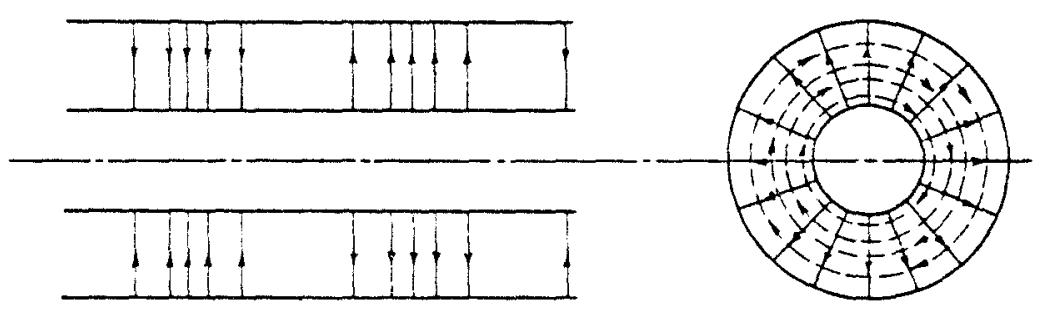

FIG. 1.12 - O modo TEM de propagação.

Nesta figura as linhas sólidas indicam o campo elétrico e as tracejadas o campo magnético. As seguintes equações (28) dão a distribuifão dos campos: 


$$
\begin{array}{ll}
\mathrm{H}_{\mathrm{r}}=0 & E_{r}=377(\mu / \varepsilon)^{\frac{1}{2}} \frac{I_{0}}{2 \pi r} e^{j \omega t}-\gamma z \\
\mathrm{H}_{\theta}=\frac{I_{0}}{2 \pi r} e^{j \omega t-\gamma z} & E_{\theta}=0 \\
H_{z}=0 & E_{z}=0
\end{array}
$$

onde $I_{0}$ é a amplitude da corrente de condução ao longo do condutor interno e $a \leqslant r \leqslant b$.

Em linhas coaxiais as fontes de atenuacão são as perdas ohmicas devido a resistência dos condutores e as perdas dielétri cas resultantes das imperfeiçoes do dielétrico que separa os doj condutores. A atenuação em $\mathrm{dB} / \mathrm{m}$ devido as perdas ohmicas é dada (28) por:

$$
\alpha_{c}=13,6 \frac{\delta}{b \lambda}(1+b / a) \frac{(\varepsilon)^{\frac{1}{2}}}{\log (b / a)}
$$

a expressão (29) do "skin dept" $\delta$ em metros é:

$$
\delta=\frac{1}{\left(\pi f_{\mu \sigma}\right)^{\frac{1}{2}}}
$$

onde $f$ e $\lambda$ são a frequência e o comprimento de onda e $\sigma$ a condutividade do metal.

Em frequências de microondas, a corrente de condução est concentrada em uma camada superficial. A corrente é máxima na superfície e decresce exponencialmente no interior do condutor. A profundidade na qual a corrente decresce l/e de seu valor na superfície é denominada "skin dept".

As perdas dielétricas podem ser calculadas assumindo-se que a constante dielétrica é complexa. Esta pode ser escrita como: 


$$
\varepsilon=\varepsilon^{\prime}-j \varepsilon^{\prime \prime}
$$

e a tangente de perdas é definida como:

$$
\operatorname{tg} \delta=\frac{\varepsilon^{\prime}}{\varepsilon^{\prime \prime}}
$$

A atenuação em $\mathrm{dB} / \mathrm{m}(28)$ resultante das perdas dielétricas é:

$$
\alpha_{d}=27,3 \frac{\left(\varepsilon^{\prime}\right)^{\frac{1}{2}}}{\lambda} \operatorname{tg} \delta
$$

\subsubsection{Guias de onda}

O método para a determinacão dos modos de propagacão de ondas eletromagnéticas em um guia de onda de particular secção transversal é conseguir-se a solução das equações de onda descritas abaixo, que são obtidas a partir das equações de Maxwell:

$$
\begin{aligned}
& \nabla^{2} \overrightarrow{\mathrm{E}}=-\omega^{2} \mu_{0} \varepsilon_{0} \overrightarrow{\mathrm{E}} \\
& \nabla^{2} \overrightarrow{\mathrm{H}}=-\omega^{2} \mu_{0} \varepsilon_{0} \overrightarrow{\mathrm{H}}
\end{aligned}
$$

e que devem satisfazer as condições de contorno impostas pela seç ção transversal.

Nas equações $(1.5 .39)$ e $(1.5 .40), \mu_{0}$ e $\varepsilon_{0}$ são respectivamente a permeabilidade e a permitividade do vácuo, $\omega$ é a frequência angular da onda e os campos: elétrico $\vec{E}$ e magnético $\vec{H}$ são assumidos variarem harmonicamente no tempo, isto é: 


$$
\begin{aligned}
& \vec{E}=\vec{E}_{0} e^{j \omega t} \\
& \vec{H}=\vec{H}_{0} e^{j \omega t}
\end{aligned}
$$

A notação aplicada 'a guias de onda retangulares é ilustra da figura 1.13.

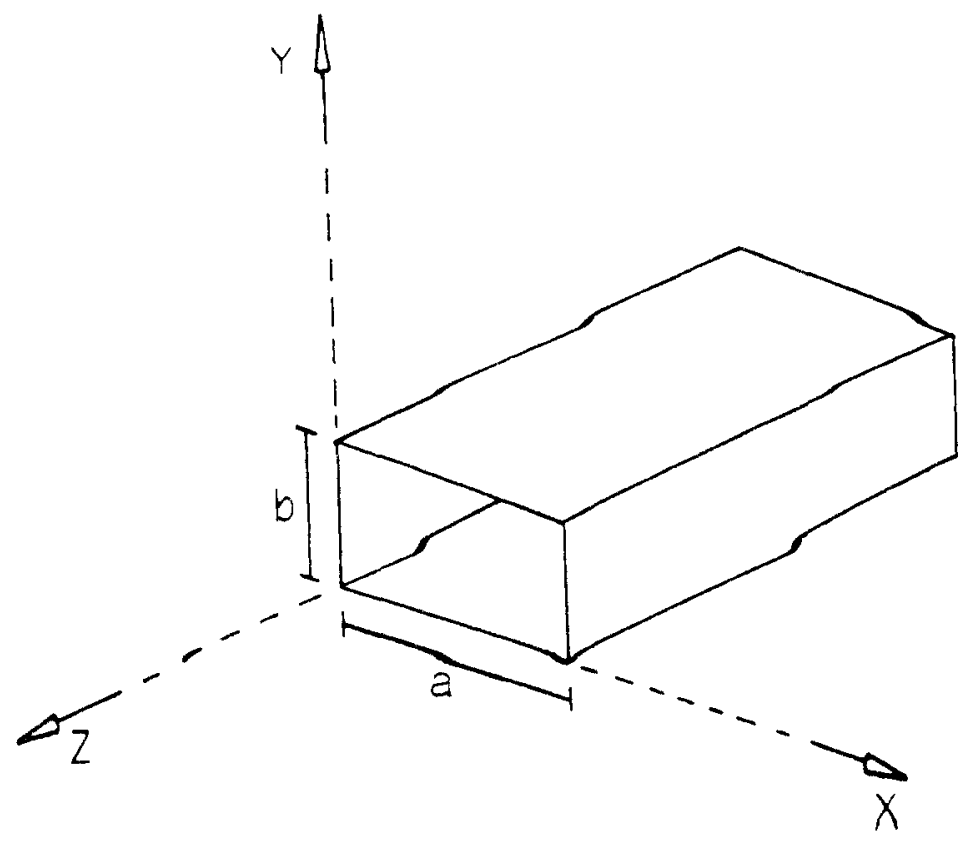

FIG. 1.13 - Sistema de referência e dimensões do guia de onda retangular.

O modo de transmissão dominante em guias de onda retangulares é o $\mathrm{TE}_{1,0}$. A distribuição de campo deste modo é mostrada na figura 1.14, e as equações dos campos (28) são:

$$
\begin{aligned}
& E_{z}=E_{x}=H_{y}=0 \\
& E_{y}=B \frac{\mu_{0} \omega \pi}{k^{2} a} \operatorname{sen} \frac{\pi x}{a} \operatorname{sen}(\omega t-\beta z)
\end{aligned}
$$




$$
\begin{aligned}
& \mathrm{H}_{z}=-B \cos \frac{\pi x}{a} \cos (\omega t-\beta z) \\
& H_{x}=B \frac{\beta \pi}{k^{2} a} \operatorname{sen} \frac{\pi x}{a} \operatorname{sen}(\omega t-\beta z)
\end{aligned}
$$

onde $B$ é uma constante arbitrária de amplitude. A constante de fa se $B$, em geral e dada (28) por:

$$
\beta_{m, n}^{2}=\frac{w^{2}}{c^{2}}-\pi^{2}\left(\frac{m^{2}}{a^{2}}+\frac{n^{2}}{b^{2}}\right)
$$

que para 0 modo $\mathrm{TE}_{10}$ se reduz a:

$$
\beta_{10}^{2}=\frac{\omega^{2}}{c^{2}}-\frac{\pi^{2}}{a^{2}}
$$
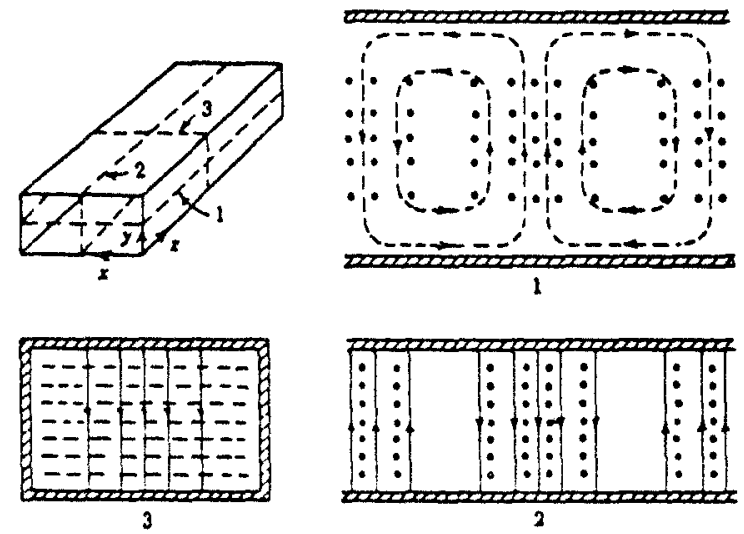

FIG. 1.14 - Configuração dos campos elétrico (linhas sólidas) e magnético (linhas tracejadas) do modo $\mathrm{TE}_{10^{\circ}}$ 
A quantidade $k$ é definida pela expressão:

$$
\mathrm{k}^{2}=\frac{\omega^{2}}{c^{2}}-\beta^{2}
$$

Modo dominante significa o modo com maior comprimento de onda de corte, isto é, o maior comprimento de onda que pode se pro par em um guia de onda. Em guias de onda retangulares, o primeiro e segundo subscritos são a medida do número de variaçóes de meia onda da intensidade do campo transversal ao longo das dimensões $x$ e y do guia, respectivamente. Por exemplo, no modo dominante, $\mathrm{TE}_{10}$, há uma variação do campo transversal ao longo do eixo $\mathrm{x} e$ não há variação do campo transversal ao longo do eixo y. As configurações de alguns modos de propagação de ordem mais alta são mostrados na figura 1.15, e as correspondentes equações dos campos (28) são:

$$
\begin{aligned}
& E_{z}=A \operatorname{sen} \frac{n \pi y}{b} \operatorname{sen} \frac{m \pi x}{a} \cos (\omega t-\beta z) \\
& E_{y}=A \frac{\beta}{k^{2}} \frac{n \pi}{b} \cos \frac{n \pi y}{b} \operatorname{sen} \frac{m \pi x}{a} \operatorname{sen}(\omega t-\beta z) \\
& E_{x}=A \frac{\beta}{k^{2}} \frac{m \pi}{a} \operatorname{sen} \frac{n \pi y}{b} \cos \frac{m \pi x}{a} \operatorname{sen}(\omega t-\beta z) \\
& H_{z}=0 \\
& H_{y}=-A \frac{\varepsilon 0^{\omega}}{k^{2}} \frac{m \pi}{a} \operatorname{sen} \frac{n \pi y}{b} \cos \frac{m \pi x}{a} \operatorname{sen}(\omega t-\beta z) \\
& H_{x}=A \frac{\varepsilon 0^{\omega}}{k^{2}} \frac{n \pi}{b} \cos \frac{n \pi y}{b} \operatorname{sen} \frac{m \pi x}{a} \operatorname{sen}(\omega t-\beta z)
\end{aligned}
$$


Nestas equações, A é uma constante arbitrária de amplitude, Be $\mathrm{k}$ foram definidos previamente.
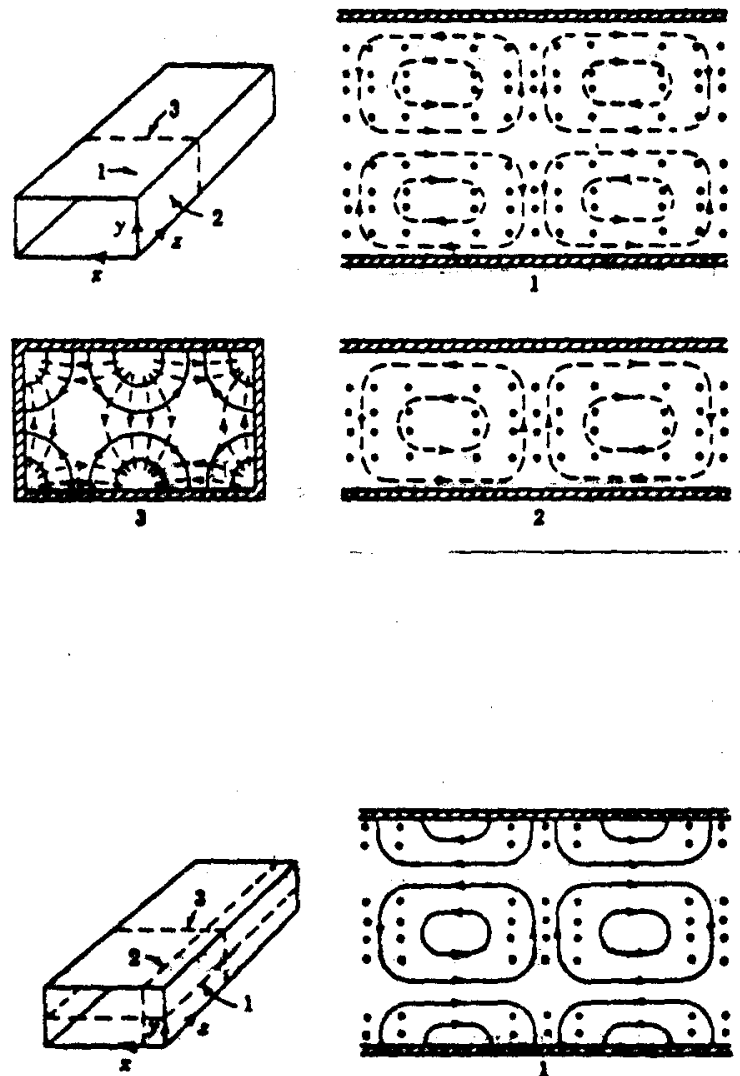

:02:

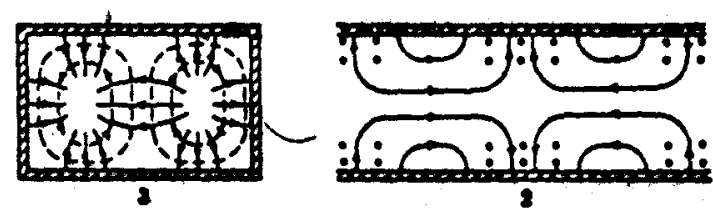

FIG. 1.15 - Modos de transmissão de ordem mais alta.

$T E_{m, n}$

$E_{z}=0$

$E_{y}=-B \frac{\omega \mu_{0}}{k^{2}} \frac{m \pi}{a} \cos \frac{n \pi y}{b} \operatorname{sen} \frac{m \pi x}{a} \operatorname{sen}(\omega t-B z)$ 


$$
\begin{aligned}
& E_{x}=B \frac{\omega H_{0}}{k^{2}} \frac{n \pi}{b} \operatorname{sen} \frac{n \pi y}{b} \cos \frac{m \pi x}{a} \operatorname{sen}(\omega t-\beta z) \\
& H_{z}=-B \cos \frac{n \pi y}{b} \cos \frac{m \pi x}{a} \cos (\omega t-\beta z) \\
& H_{y}=B \frac{\beta}{k^{2}} \frac{n \pi}{b} \operatorname{sen} \frac{n \pi y}{b} \cos \frac{m \pi x}{a} \operatorname{sen}(\omega t-\beta z) \\
& H_{x}=B \frac{\beta}{k^{2}} \frac{m \pi}{a} \cos \frac{n \pi y}{b} \operatorname{sen} \frac{m \pi x}{a} \operatorname{sen}(\omega t-B z)
\end{aligned}
$$

Os modos de ordem mais alta não são frequentemente usados como o modo dominante, em vista da dificuldade de excitar um deles sem excitar outros. Nos guias de onda padronizados, suas dimensöes são calculadas de tal maneira que os modos de ordem mais alta são rapidamente atenuados com a distância, podendo propagar apenas o modo dominante.

1.5.4. Comprimentos de onda em guias de onda

Um guia de onda age como um filtro passa-alta, e transmitirá ondas eletromagnéticas em um dado modo somente quando o comprimento de onda do sinal é menor que o comprimento de onda de corte. Este depende do modo de transmissão e é dado (28) para guias de onda retangulares por:

$$
\lambda_{c}=\frac{2}{\left[\left(\frac{m}{a}\right)^{2}+\left(\frac{n}{b}\right)^{2}\right]^{\frac{1}{2}}}
$$


do sob consideração e $\lambda_{c}$ é o comprimento de onda limite que se propaga pelo guia de onda. Esta equação é válida para ambos os mo dos (TE e TM) de propagação.

Em guias de onda, o comprimento de onda no guia, ${ }^{\prime} g$ ' sempre excede o comprimento de onda no espaço livre, $\lambda$. Como a frequência é invariável, isto parece indicar que a velocidade de propagação de ondas em um guia de onda excede a velocidade da luz. A velocidade de fase $v_{f}$ em um guia preenchido com ar é dada pela equação:

$$
v_{f}=f \lambda_{g}
$$

e maior que a velocidade da luz pelo fator $\lambda g / \lambda$. Mas a taxa de propagação de energia é a velocidade de grupo $\mathrm{v}_{\mathrm{g}}$; esta é relacionada a velocidade de fase por:

$$
v_{g}=\frac{c^{2}}{v_{f}}
$$

onde $f$ e $c$ são a frequência e a velocidade da luz.

o comprimento de onda $\lambda_{g}$ é relacionado ao comprimento de onda de corte $\lambda_{c}$ e ao comprimento de onda no espaço livre $\lambda$, (28) pela equação:

$$
\lambda_{g}=\frac{\lambda}{\left[1-\left(\frac{\lambda}{\lambda_{c}}\right)^{2}\right]^{\frac{1}{2}}}
$$

- comprimento de onda no guia é sempre maior que o comprí mento de onda no espaço livre, e quando este se aproxima do comprimento de onda de corte do guia, tende ao infinito. A equaça (1.5.52) é mostrada na figura 1.16. Nesta a razão $\lambda / \lambda g$ é grafica- 
¿a versus a razão $\lambda / \lambda_{C^{\prime}}$ e a relação entre as duas é um quarto de circunferência de raio unitário.

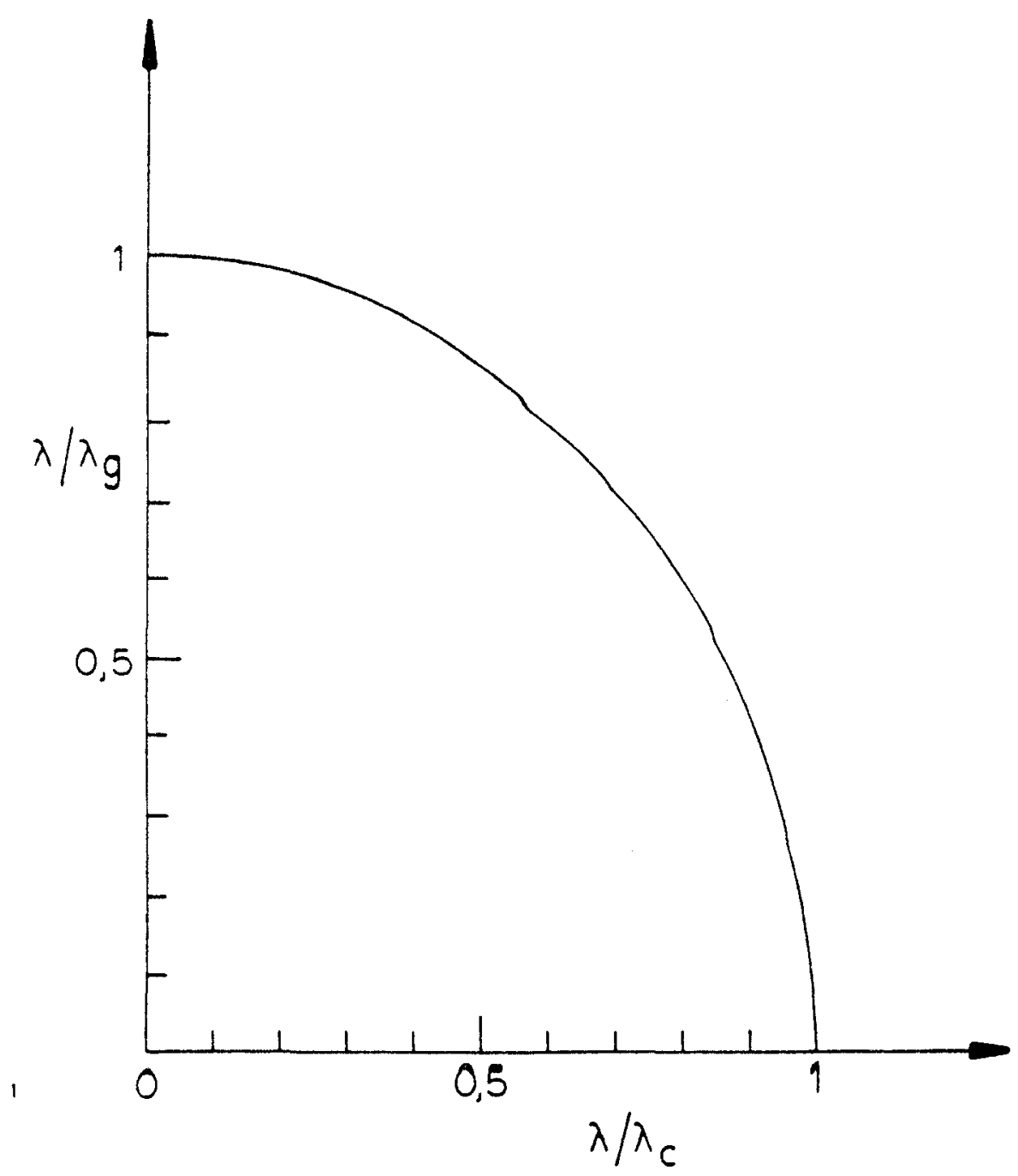

FIG. 1.16 - Relação entre comprimentos de onda em um guia de onda.

1.5.5. Atenuação em guias de onda

Nas seções anteriores, assumimos que as paredes do guia de onda eram condutores perfeitos, isto é, sua condutividade era infinita e que o guia era preenchido com um dielétrico perfeito. Em guias de onda reais, a condutividade das paredes é finita e co mo resultado a onda é parcialmente atenuada em virtude das perdas no metal. Além disto, se algum dielétrico diferente do ar é usado no interior do guia, as perdas no dielétrico podem resultar em 
uma atenuação muito rápida da onda transmitida.

Como resultado das perdas ohmicas nas paredes condutoras do guia de onda a potência da microonda é atenuada pelo fator $\exp \left(-\alpha_{c} z\right)$. A constante de atenuação $\alpha_{c}$ em $d B / m$ para o modo $\mathrm{TE}_{10}$ é dada (29) por:

$$
\alpha_{c}=\frac{8,686 R_{s}}{377 b}\left[\frac{1+\frac{2 b}{a}\left(\frac{\lambda}{2 a}\right)^{2}}{\left[1-\left(\frac{\lambda}{2 a}\right)^{2}\right]^{\frac{1}{2}}}\right]
$$

a resistência superficial $R_{s}$ em ohm.m e:

$$
R_{S}=\frac{\pi f \mu}{\sigma}^{\frac{1}{2}}
$$

Em um guia de onda preenchido com material dielétrico, ha verá perdas devido as imperfeicões do dielétrico. Se um dielétrico ideal de constante $\varepsilon$ é assumido, o comprimento de onda de corte $\lambda_{c}^{\prime}$ no guia preenchido com o dielétrico (28) será:

$$
\lambda_{c}^{\prime}=(\varepsilon)^{\frac{1}{2}} \lambda_{c}
$$

onde $\lambda_{c}$ é o comprimento de onda de corte no mesmo guia quando preenchido com ar.

o comprimento de onda no guia preenchido com dielétrico ideal é dada (28) por:

$$
\lambda_{g}=\frac{\lambda}{\left[\varepsilon-\left(\frac{-\lambda}{\lambda_{c}}\right)\right]^{2}}
$$

onde $\lambda$ é o comprimento de onda no espaço livre e $\lambda_{c} \circ$ comprimento de onda de corte do guia quando preenchido com ar. Se o dielétri- 
co nào é perfeito, o comprimento de onda no guia (28) é:

$$
\lambda_{g}=\frac{\lambda}{\left[\varepsilon^{\prime}-\left(\frac{\lambda}{\lambda_{c}}\right)^{2}\right]^{\frac{1}{2}}} \frac{1}{\left[\frac{1}{2}+\frac{1}{2}\left[\frac{\varepsilon^{\prime \prime}}{\left[\varepsilon-\left(\frac{\lambda}{\lambda_{c}}\right)^{2}\right]^{2}}+1\right]^{\frac{1}{2}}\right]^{\frac{1 / 2}{2}}}
$$

A atenuação $\alpha_{\mathrm{d}}$ em $\mathrm{dB} / \mathrm{m}$ num guia de onda preenchido com dielétrico imperfeito é dada (30) por:

$$
\alpha_{d}=\frac{4,343 \omega\left(\mu_{0} \varepsilon_{0}\right)^{\frac{1}{2}}\left(\varepsilon^{\prime \prime} / \varepsilon^{\prime}\right)}{\left[1-(\lambda / 2 a)^{2}\right]^{\frac{1}{2}}}
$$

A corrente de condução em um guia de onda é confinada a superfície interna do guia; a profundidade de penetracão é determinada pelo "skin dept", como mostrado na secão 1.5.2. As linhas de corrente fluem nas paredes do guia e são mostradas na figura 1.17. A direção do fluxo de corrente é ortogonal a direção do campo magnético na superfície interna do guia.

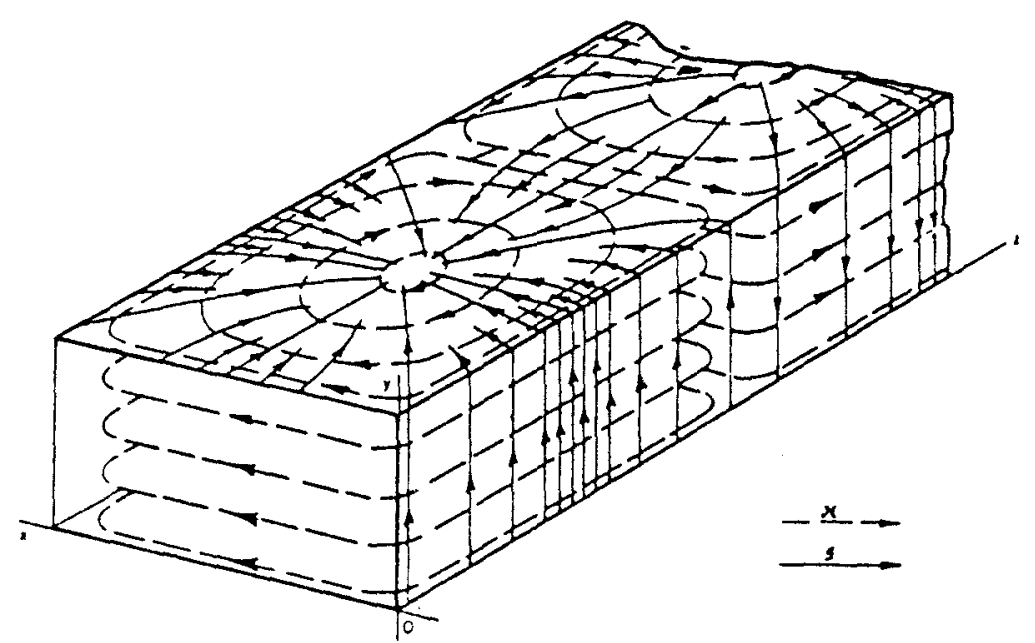

FIG. 1.17 - Distribuição de corrente do modo $\mathrm{TE}_{10}{ }^{\circ}$ 
1.5.6. Atenuação abaixo do corte em um guia de onda

Se um possível modo de propagação é excitado em um guia de onda que está abaixo do corte para aquele particular modo, não haverá propagação real de energia. A impedância de entrada será uma reatância pura, se perdas na parede são negligenciadas e os campos que são excitados no guia decrescerão exponencialmente com a distancia do ponto de excitação.

o campo elétrico como função da distância é:

$$
E=E_{0} e^{-\alpha z}
$$

onde $\mathrm{E}_{0}$ é a amplitude ínicial da excitação. A atenuação a em $a B / m(28)$ é:

$$
\alpha=8,686\left[\left(\frac{2 \pi}{\lambda_{c}}\right)^{2}-\left(\frac{2 \pi}{\lambda}\right)^{2}\right]^{1 / 2}(1.5 .60)
$$

Quando o comprimento de onda no espaço livre torna-se muito maior que o comprimento de onda de cortes a atenuação $\alpha$ torna-se independente de $\lambda(28)$ e tende ao limite:

$$
\alpha=\frac{54,6}{\lambda_{c}}
$$

Na figura 1.18 é mostrado um gráfico da atenuacão como função de $\lambda$ para um dado $\lambda c^{\cdot}$

1.5.7. Impedância característica do guia de onda

A impedância característica de um guia de onda pode ser definida de diversas maneiras. No tratamento realizado por 


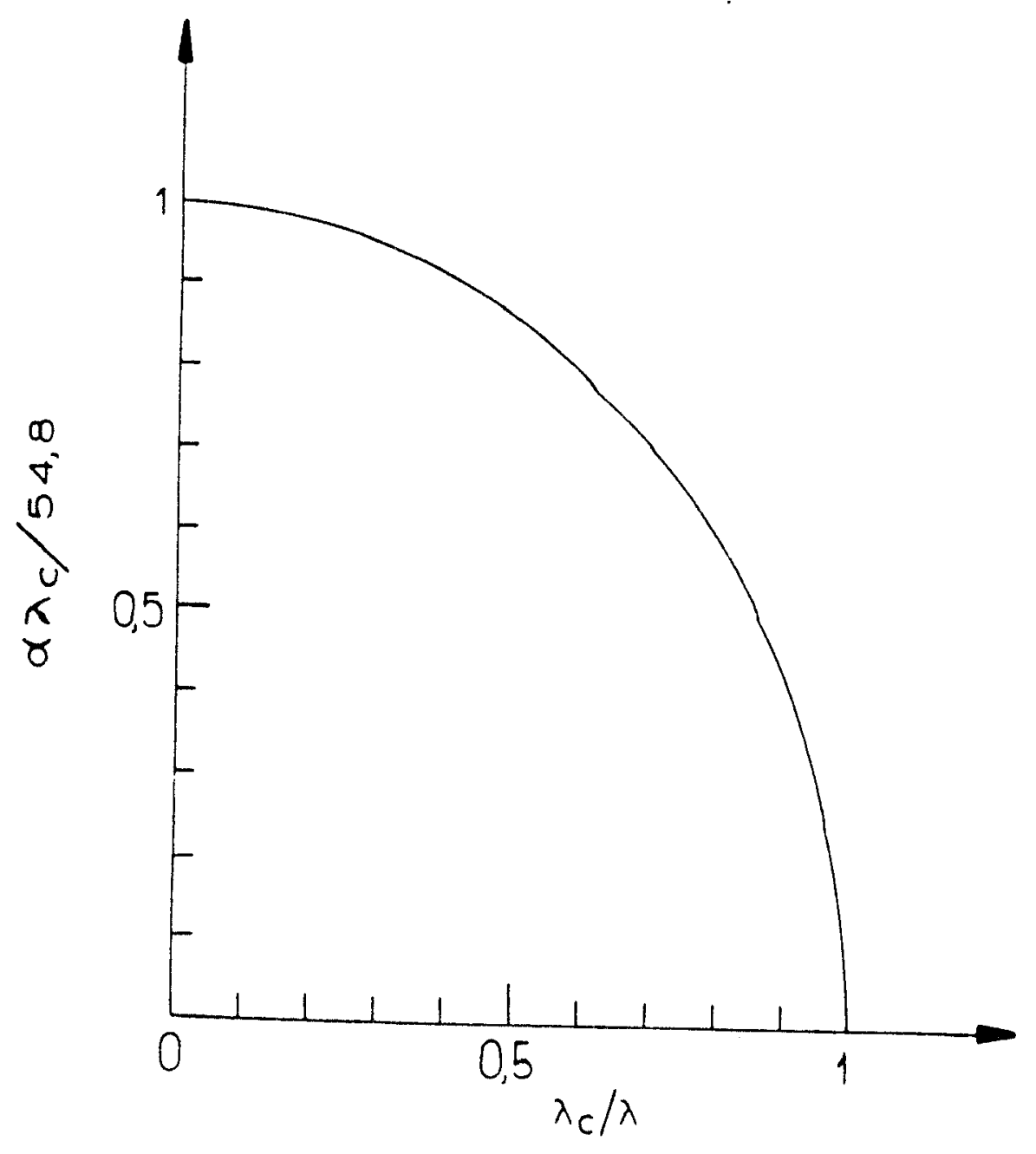

FIG. 1.18 - Atenuação abaixo do corte em um guia de onda

Reich (29), O modo de propagação $\mathrm{TE}_{10}$ é assumido e a impedância em um ponto qualquer do guia de onda é definida como:

$$
z_{0}=377 \frac{b}{a(\varepsilon)^{\frac{1}{2}}} \frac{1}{\left[1-\left(\frac{f_{c}}{f}\right)^{2}\right]^{\frac{1}{2}}}
$$

onde a e b são as dimensões do guia de onda, $\varepsilon$ a constante dielétrica, $f_{c}$ a frequência de corte e $f$ a frequência no espaço livre.

\subsection{Componentes de microondas}

O propósito desta seção é descrever os principios de operação e aplicações práticas de alguns componentes de microondas 
que foram usados no decorrer deste trabalho.

Os componentes de microondas são tratados e analisados como consistindo de várias secções curtas de linhas de transmissão (31). As voltagens e correntes destas linhas de transmissão são tratadas da mesma forma como foram discutidas na seção 1.5.1. Muitas das informaçōes aqui contidas podem ser encontradas com mais detalhes nos volumes $6,7,8,9,10,11$ e 14 do MIT Radiation Laboratory Series, Reich (29), Poole (30), Ishii (31) e VHF techniques (32).

\subsubsection{Atenuadores e Terminações}

o atenuador é um elemento que, quando inserido entre o gerador e a carga, reduz a amplitude e a variacão de fase do sinal de microondas incidente na carga.

A perda de insercão, L, que é um dos parâmetros que descrevem a qualidade de um componente passivo, é definida em termos da potência $P_{1}$ entregue por um gerador de impedância interna arbitrária a uma carga arbitrária; dividida pela potência $\mathrm{P}_{2}$ entregue pelo mesmo gerador a mesma carga quando um dispositivo, neste caso um atenuador, é inserido entre eles. Sua expressão (30) é:

$$
L(d B)=10 \log \frac{P_{1}}{P_{2}}
$$

A atenuação $A$ em db é a perda de inserção medida quando o gerador e a carga tem impedâncias casadas. Sob estas condicões $P_{1}$ é a máxima potência disponível do gerador e $\mathrm{P}_{2}$ é a potência entre gue a carga através do atenuador. A expressão para a atenuação A è:

$A(d B)=10 \log \frac{P_{1}}{P_{2}}$ 
Os atenuadores são de dois tipos: fixos e variáveis, sendo ambos construídos em guias de onda e linhas coaxiais. No tipo variável um dial pode ser deslocado para uma atenuacão pré-determinada. Este dial pode estar calibrado em dB ou uma curva (dB $X$ deslocamento) é fornecida pelo fabricante. Ho tipo fixo a atenuação é fixa, sendo comercializado com diversos valores de atenucação.

o principio de funcionamento é o mesmo em ambos os tipos. No atenuador variável uma placa é recoberta com material de alta resistividade, mica, carbono, etc, o deslocamento do dial faz com que esta placa se mova no interior do guia de onda e a microonda é atenuada devido as perdas ohmicas. No tipo fixo esta placa é posicionada de tal maneira, que a microonda é atenuada sempre pela mesma quantidade.

As terminações são usadas para terminar uma linha de transmissão ou guia de onda. O significado físico desta terminacão é que ela proporciona o casamento de impedâncias, isto é, ela dissipa toda a potência incidente sem produzir reflexão. Além disto, é utilizada pára medidas do coeficiente de reflexão; neste caso ela é construía de maneira que uma reflexão conhecida ocorra.

O material absorvedor de potência é usualmente um composto contendo carbono e grafite. Ele é construido de tal forma e co locado em tal posicão no interior do guia de onda, que a impedância da terminação é a mesma do guia de onda.

\subsubsection{Isoladores}

Ferrite (17) é o nome de uma familia de materiais magnet cos cuja fórmula molecular é $\mathrm{MO} . \mathrm{Fe}_{2} \mathrm{O}_{3}$, onde $\mathrm{M}$ é um íon metálico divalente. 
Quando uma placa de ferrite é colocada em um guia de onda e um campo magnético DC é plicado, o guia de onda mostra uma característica de transmissão não-recíproca. Um isolador $(33,34,35)$ é um componente que utiliza o efeito Faraday para permitir transmissão com baixas perdas em uma direção e absorver a potência na direçào oposta.

o isolador é usualmente colocado entre ogerador de microondas e a outra parte do sistema para evitar a instabilidade de frequência do gerador que é causada por ondas refletidas.

1.6.3. Acopladores direcionais

O acoplador direcional é um componente de quatro terminais, comomostrado na figura 1.19. Ele consiste da linha primá-

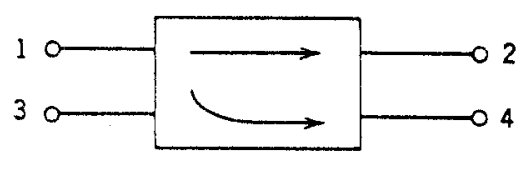

FIG. 1.19 - Esquema geral do acoplador direcional.

ria 1 - 2 e da linha secundária 3 - 4. Quando potência é transmitida ao terminal 1 , parte desta é transmitida ao terminal 2 da 1 i nha principal. Mas potência também é acoplada na linha secundária, e a maior parte desta é transmitida ao terminal 4. Se potência é transmitida na direção reversa da linha principal, isto é do ter minal 2 para $\circ$ l, a maior parte da potência acoplada pela linha secundária será transmitida ao terminal 3. As características co acoplador direcional podem ser expressas em termos dos seguintes 
parâmetros $(31,32)$, assumindo propagação do terminal 1 para $\circ 2$ na linha primária:

$$
C(d B)=10 \log \frac{\mathrm{P}_{1}}{\mathrm{P}_{4}}
$$

e

$$
D(d B)=10 \log \frac{P_{4}}{P_{3}} \quad(1.6 .4)
$$

onde $\mathrm{P}_{1}, \mathrm{P}_{3}$ e $\mathrm{P}_{4}$ são as potências nos terminais 1,34 respectiva mente.

- fator de acoplamento, C, que caracteriza a quantidade de potência que é extraída pela linha secundária da principal. A diretividade $D$ e a medida de rejeição entre os terminais 3 e 4 .

o acoplador direcional é utilizado geralmente para monitorar a potência incidente ou refletida pelo sistema, através da extração de uma pequena quantidade desta.

1.6.4. Curto móvel

Curtos móveis são construidos de dois tipos: contato e não-contato. No tipo contato existe uma conexão entre o curto e e o guia de onda ou linha coaxial. Na estrutura do curto são feitas ranhuras axiais que formam tiras metálicas, estas agem como molas que pressionam as paredes do guia ou linha coaxial. Este tipo de curto móvel tem diversas desvantagens:

1) Desgaste e oxidação produzem un contato de comportamento irregular. 2) As mesmas causas juntamente com partículas metálicas produzem ruído e sintonia irregular. Estas dificulades podem ser contornadas pelo uso do curto móvel tipo não-contato.

No tipo de curto móvel do tipo não-contato, como explica - próprio nome, não existe contato entre o curto e a estrutura 
ondé montado.

o curto do tipo não-contato mais simples é um anel cilínarico parà linhas coaxiais e um paralelepipedo para guias de onda retangulares; nestes estas estruturas preenchem a maioria do espa co. Este tipo é denominado curto capacitivo, pois os efeitos capa citivos são predominantes.

Se a parte posterior do curto capacitivo é cortada, um curto tipo "choke" é formado. Um curto tipo "bucket" é construido cortando-se a face anterior do curto capacitivo. Ambos tem as mes mas características e são superiores ao tipo capacitivo. A referência (32) mostra de forma detalhada uma discussão sobre estes tipos de curtos móveis para linhas coaxiais.

Um outro tipo de curto, cujas características são superiores aos apresentados, é aquele formado colocando-se um curto tipo "bucket" emediatamente após o curto tipo "choke". As faces anterior e posterior são unidas através de uma parede comum. Este curto é denominado tipo "s". Uma discussão bem detalhada sobre este tipo de curto para linhas coaxiais foi feita por Huggins (37) e uma forma resumida deste trabalho pode ser encontrada nas referências (29) e (32).

Os quatro tipos de curto apresentados são mostrados na figura 1.20 .

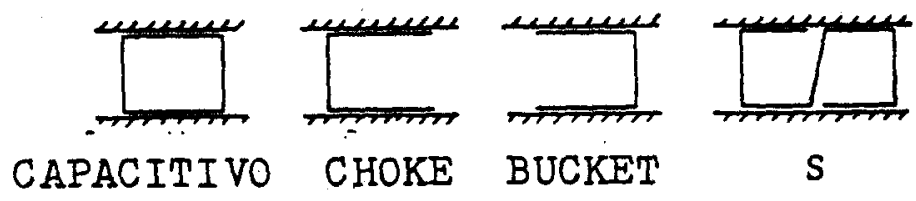

FIG. 1.20 - Tipos de curtos móveis não-contato. 
Se um guia de onda é curto-circuitado por um curto movel, a uma distância $\ell$ de um plano de referência, como mostrado na figura 1.21, a voltagem deve ser zero em $x=l$, para que a condicão de contorno do campo elétrico no curto seja respeitada. Desejamos saber que condiçōes $\ell$ deve satisfazer para tenhamos um guia em curto circuito, ou seja o coeficiente de reflexão da voltagem, • $\Gamma=-1$, ou a impedância de entrada, $z_{E N}=0$.

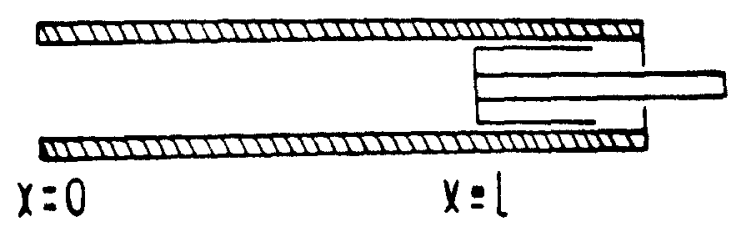

\footnotetext{
FIG. 1.21 - Sistema de referência de um guia de onda curto-circuitado.
}

A distribuição de voltagem ao longo do guia pode ser expressa (31) por:

$$
V(x)=v_{0} \operatorname{sen} \frac{2 \pi(\ell-x)}{\lambda_{g}}
$$

onde $V_{0}$ é o valor máximo da voltagem e $\mathrm{x}$ é qualquer posição ao longo do guia.

A corrente em $x=\ell$ deve ser máxima e sua distribuição ao longo do guia é:

$$
I(x)=j I_{0} \cos \frac{2 \pi(l-x)}{\lambda_{g}} \quad(I .6 .6)
$$

onde $I_{0}$ é o máximo valor da corrente.

A impedância de entrada em $x=0$ é, portanto:

$$
z_{E N}=\frac{V(0)}{I(0)}=j z_{0} \operatorname{tg} \frac{2 \pi l}{\lambda_{g}}
$$


onde $z_{0}$ é a impedância característica do guia de onda.

Um gráfico da equação $(1.6 .7)$ é mostrado na figura 1.22 .

Podemos concluir que: quando $\ell=n \lambda / 2$, onde $n$ é um inteiro, a impedância de entrada $\mathrm{z}_{E N}=0$; quando $\ell=(2 n+1)\left(\lambda_{\mathrm{g}} / 4\right), \mathrm{z}_{\mathrm{EN}} \rightarrow \infty$.

Assim, o curto móvel pode ser usado como uma reatância va riável. A impedância de entrada é puramente reativa e varia com o comprimento $\ell$.

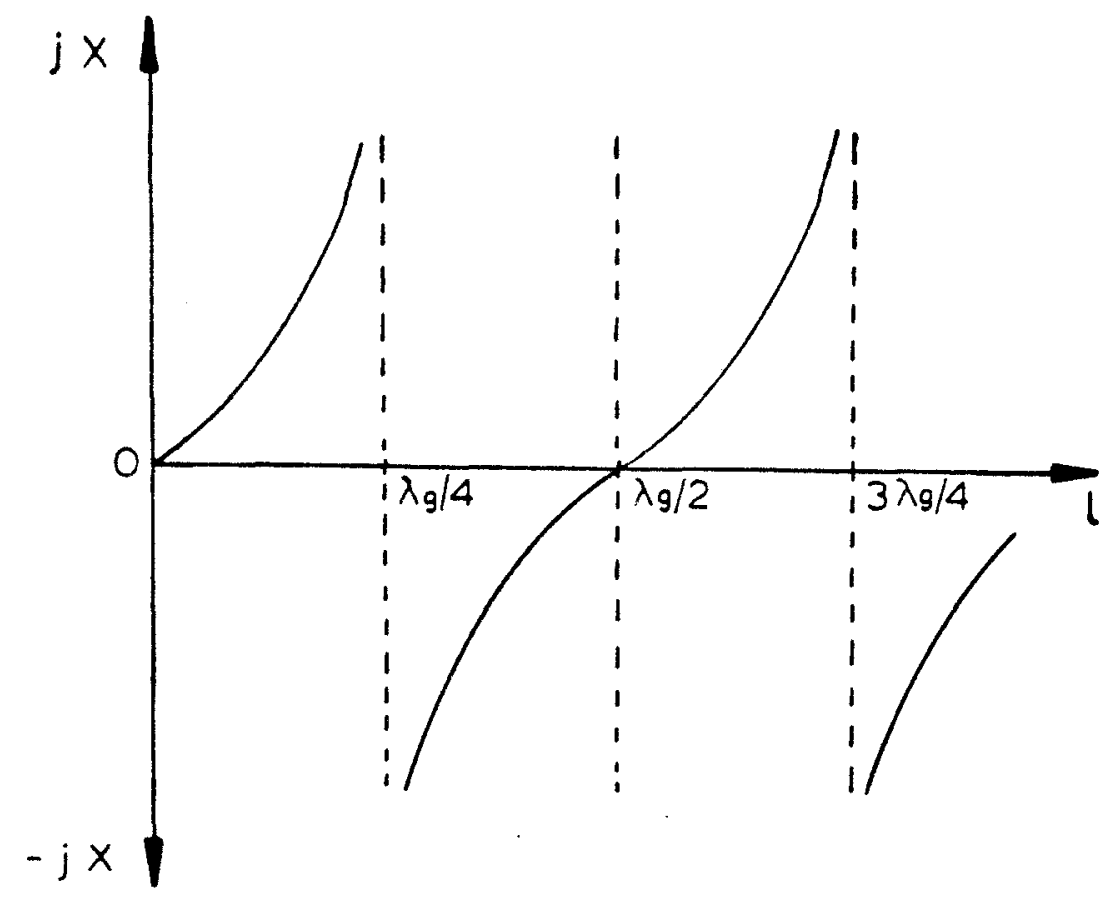

FIG. 1.22 - Impedância de entrada de um guia de onda curto-circuitado.

No curto móvel não-contato mostrado na figura 1.23, cada seç̧ão tem comprimento $\lambda_{g} / 4$, onde $\lambda_{g}$ é o comprimento de onda no guia no centro da banda de trabalho. Os espaços entre as faces de maior dimensão do guia de onda e do curto móvel agem como secções de quarto de onda de impedância, característica mais baixa que aquela do guia de onda principal.

Para prevenir a possibilidade de ressonância na "cavidade" constituida pela seção do guia de onda após o curto, esta secção 
tem impedância característica $\mathrm{z}_{0^{\circ}}$

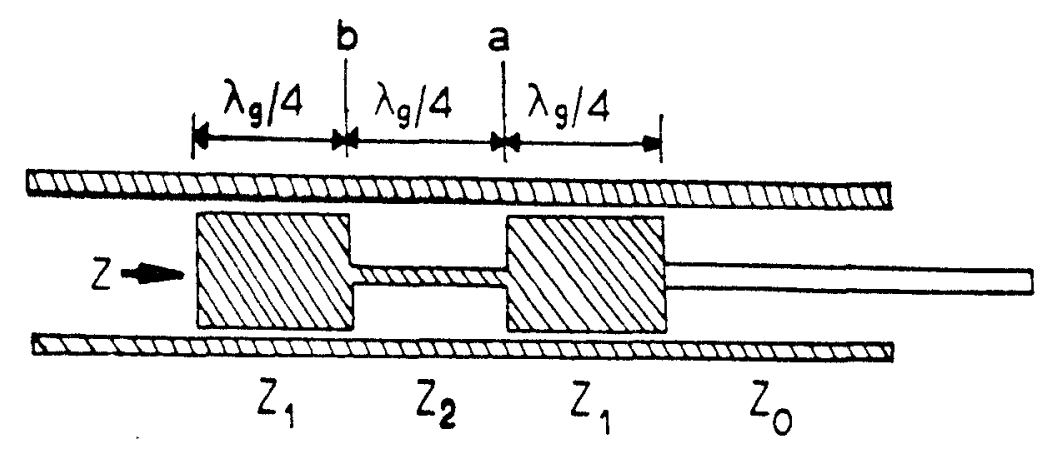

FIG. 1.23 - Curto móvel tipo quarto de onda não-contato.

Na figura acima, a impedância de entrada $z_{a}$ olhando para a direita através do terminal a, foi dicutida na seção 1.5.1, e é dada por:

$$
z_{a}=z_{1} \frac{z_{0}+j z_{1} \operatorname{tg}\left(2 \pi l / \lambda_{g}\right)}{z_{1}+j z_{0} \operatorname{tg}\left(2 \pi l / \lambda_{g}\right)}
$$

como $\ell=\lambda_{g} / 4$, esta expressão se reduz a:

$$
z_{a}=\frac{z_{1}^{2}}{z_{0}}
$$

onde $z_{1}$ é a impedância característica da secção de linha constituída pelos espaços entre as paredes do guia e a última secção do curto móvel.

Analogamente,

$$
\mathrm{z}_{\mathrm{b}}=\frac{\mathrm{z}_{2}^{2}}{\mathrm{z}_{\mathrm{a}}}
$$

onde $z_{b}$ é a impedância de entrada no terminal $b, z_{2}$ a impedância 
característica da secção de linha formada pelo espaço entre o guia e a secção central do curto móvel.

e

$$
z=\frac{z_{1}^{2}}{z_{b}}
$$

onde $z$ é a impedância de entrada na face do curto móvel. Combinando as equações $(1.6 .9),(1.6 .10)$ e $(1.6 .11), \mathrm{ob}-$ temos a relação:

$$
z=\frac{z_{1}^{4}}{z_{2}^{2} z_{0}}
$$

Como a razão de impedâncias $\mathrm{z}_{1} / \mathrm{z}_{2}$ pode ser reduzida variando-se as alturas das seções central e lateral do curto móvel, a impedância de entrada $z$ pode aproximar-se de zero e o curto aproxima-se de um curto circuito ideal.

o curto movel é um dispositivo frequentemente usado como casador de impedâncias e é utilizado também para sintonizar cavidades ressonantes.

\subsubsection{Poste indutivo}

Um fio cilindrico metálico que se extende através do guia de onda, paralelo ao campo elétrico, como mostrado na figura 1.24

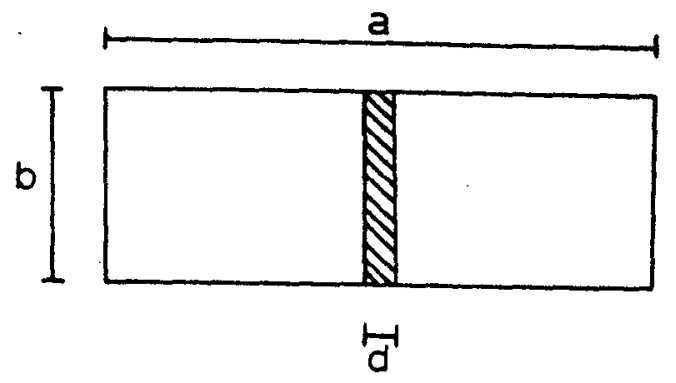

FIG. 1.24 - Poste indutivo. 
é denominado poste indutivo. Uma susceptância indutiva em paralelo com o guia é introduzida por este elemento, devido a corrente de condução que existe através dele.

A magnitude desta susceptância depende do diâmetro do pos te e sua expressão para d $<$ a é dada (28) por:

$$
B=-\frac{2 \lambda g}{a} \frac{1}{\ln \left(\frac{4 a}{\pi d e^{2}}\right)}
$$

onde dé o diâmetro do poste, a é a largura do guia de onda e e é a base do logaritmo neperiano $(e=2,718)$. Um gráfico da suscep tância $B$ versus d/a é mostrado na figura 1.25 .

Este dispositivo é utilizado para acoplar dispositivos a terminais situados nas faces opostas do guia de onda e pode ser utilizado na construção de um bolômetro, o qual é usado para medidas de potência de microondas (36). Neste caso o poste é construido com um fio de alta resistencia e seu raio deve ser compara vel ao "skin dept". 


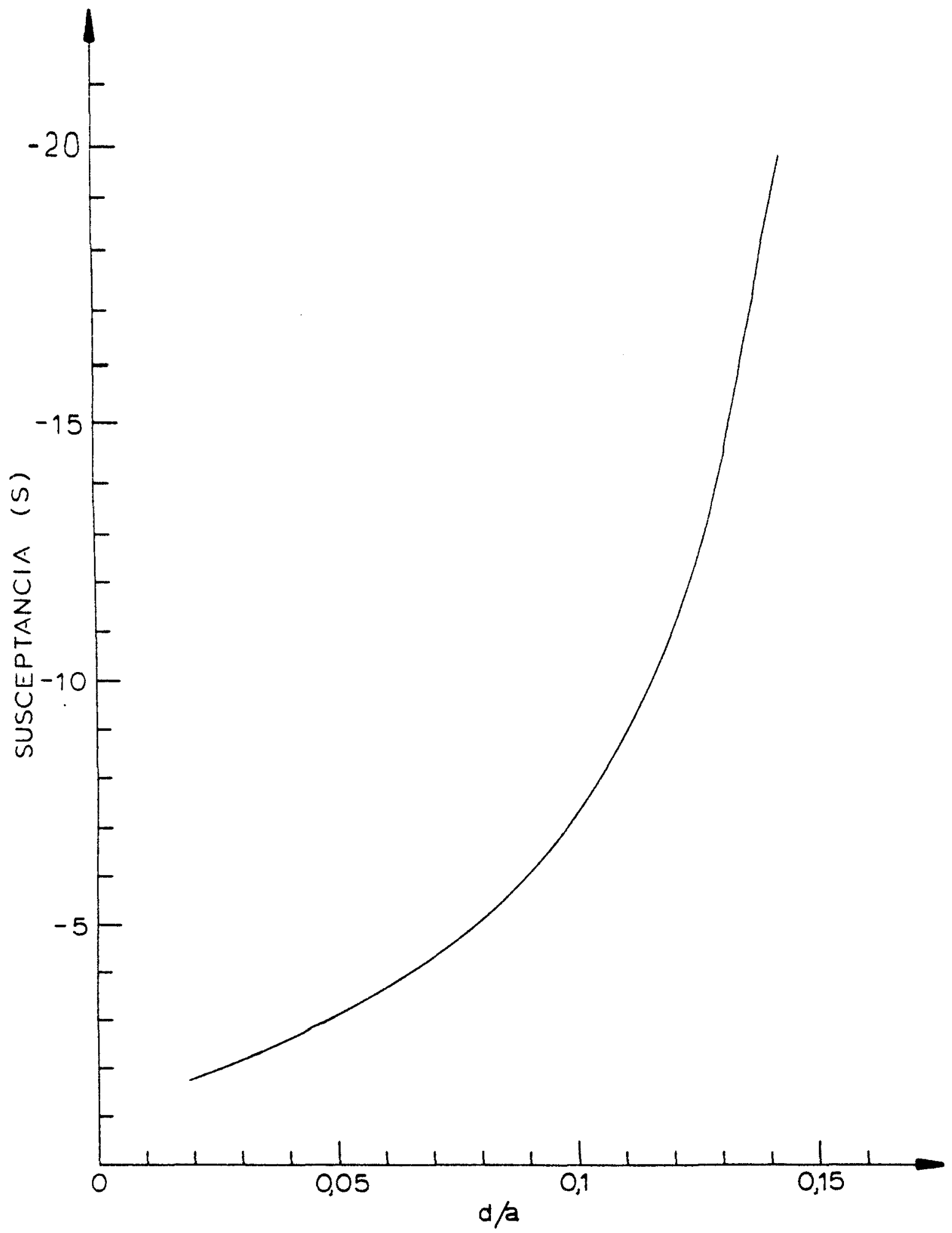

FIG. 1.25 - Susceptancia de um poste indutivo em um guia de onda. 
PROJETO DO GERADOR E MISTURADOR DE HARMÔNICOS

\subsection{Introdução}

Um diodo a cristal produz frequências harmônicas do sinal a ele aplicado, podendo então ser utilizado na construcão de um gerador de harmônicos, isto é, de uma fonte de microondas de alta frequência, estável e monocromática, sua estabilidade e monocroma ticidade dependem esssencialmente da fonte do sinal fundamental.

o processo de mistura de frequências também ocorre em um diodo a cristal e sua aplicação imediata é na construção de misturadores quer fundamentais quanto de harmónicos.

Baseados nas aplicações do diodo a cristal resumidas acima, construimos um dispositivo que pode ser utilizado como gerador e misturador de harmônicos de frequências da Banda-X. Como gerador de harmônicos pode sér usado para gerar o terceiro e o quarto har mônico das frequências compreendidas entre 8,2 e 12,4 GHz. Quando utilizado como misturador, a frequência de rádio-frequência deverá estar compreendida entre 24,6 e 37,2 GHz para o terceiro harmô nico e no intervalo $32,8-49,6 \mathrm{GHz}$ para o quarto harmônico.

\subsection{O gerador de harmónicos}

o funcionamento do diodo a cristal como elemento nãolinear foi discutido no capítulo I e notamos que é posssível obter, em virtude de sua característica exponencial, todos os harmônicos. Assim, alimentando-se um diodo com uma fonte de micro-

ondas, é possível recolher, em um guia de onda excitado pelo mes mo diodo, todos os harmônicos, selecionando-se aqueles de interes 
se através de filtros.

Quando um diodo a cristal é usado para gerarem-se os harmônicos, é posssível utilizar-se até o quinto harmônico de uma frequencia fundamental de $10 \mathrm{GHz}$, em virtude das elevadas (acima de $30 \mathrm{~dB}$ ) perdas de conversão que ocorrem em harmônicos de ordem mais alta.

Num gerador de harmônicos com diodo a cristal, há sempre uma perda de potência entre a frequência fundamental e o harmônico obtido. Assim, em condições de ótimo casamento de impedâncias, um gerador de terceiro e quarto harmônicos é esperado ter uma per da de conversão de 15 a $16 \mathrm{~dB}$ e 21 a $22 \mathrm{~dB}$ (5), respectivamente.

Em resumo, basicamente um gerador de harmônicos é constituido dos seguintes elementos:

- Guia de onda para a introdução do sinal fundamental.

- Montagem para o diodo a cristal.

- Guia de onda para a saída dos sinais harmônicos.

- Acoplador entre o diodo e os guias de onda.

- Elementos reguláveis para o casamento de impedâncias.

- Filtro para a seleção do harmônico desejado.

2.3. O misturador de harmônicos

Num diodo a cristal ocorre o processo de mistura de frequências. No caso do misturador de harmônicos, a frequência intermediária (FI) é a soma ou a diferenca do batimento que ocorre entre os harmônicos do sinal do oscilador-local (OL) e o sinal de rádio-frequência (RF).

Em virtude disto desejamos obter a maior potência possível do harmónico de interesse, portanto o misturador de harmônicos de ve também ser um eficiênte gerador de harmônicos. Tal misturador é do tipo não-balanceado, visto ser esta a única configuração pos 
sivel para este tipo de misturador (27).

A perda de conversão de um misturador de harmônicos é aquela do mesmo misturador, se operasse na frequência fundamental cujo, valor pode chegar a $15 \mathrm{~dB}(27)$, somada a perda de conversão da própria mistura de harmônicos, que pode ser considerada como 3 ou 4 dB por harmônico.

Sendo assim, a perda de conversão de um misturador do ter ceiro ou quarto harmônico, é esperada ser em torno de 21 e $27 \mathrm{~dB}$, respectivamente. Aqui estamos considerando que não há perdas devido ao descasamento de impedâncias.

Tanto no caso do misturador. fundamental como no de harmônicos, o arranjo deve conter os seguintes elementos:

- Guia de onda para a entrada do sinal do osciladorlocal.

- Montagem para o diodo a cristal.

- Guia de onda para a entrada do sinal de rádio-frequência.

- Terminal para a frequência-intermediária.

- Acoplador éntre o diodo, os guias de onda e o terminal de frequência-intermediária.

- Elementos reguláveis para o casamento de impedâncias.

- Dispositivos que permitam isolar os terminais entre si.

2.4. O gerador e misturador de harmônicos

Nas seções anteriores discutimos os esquemas básicos do gerador e misturador de harmônicos. Uma comparação entre eles mos tra que as diferencas consistem na existencia do terminal de FI e - acoplamento entre este e o diodo.

Fundamentados na semelhança existente entre estes esquemas, propomos um que realiza ambas as funções, o qual foi baseado 
ros geradores de harmônicos descritos por Nethercot (4) e Johnson $(6)$.

o dispositivo proposto é mostrado na figura 2.1 e sua ope ração como gerador e misturador de harmônicos, bem como a função de cada elemento, descrita abaixo.

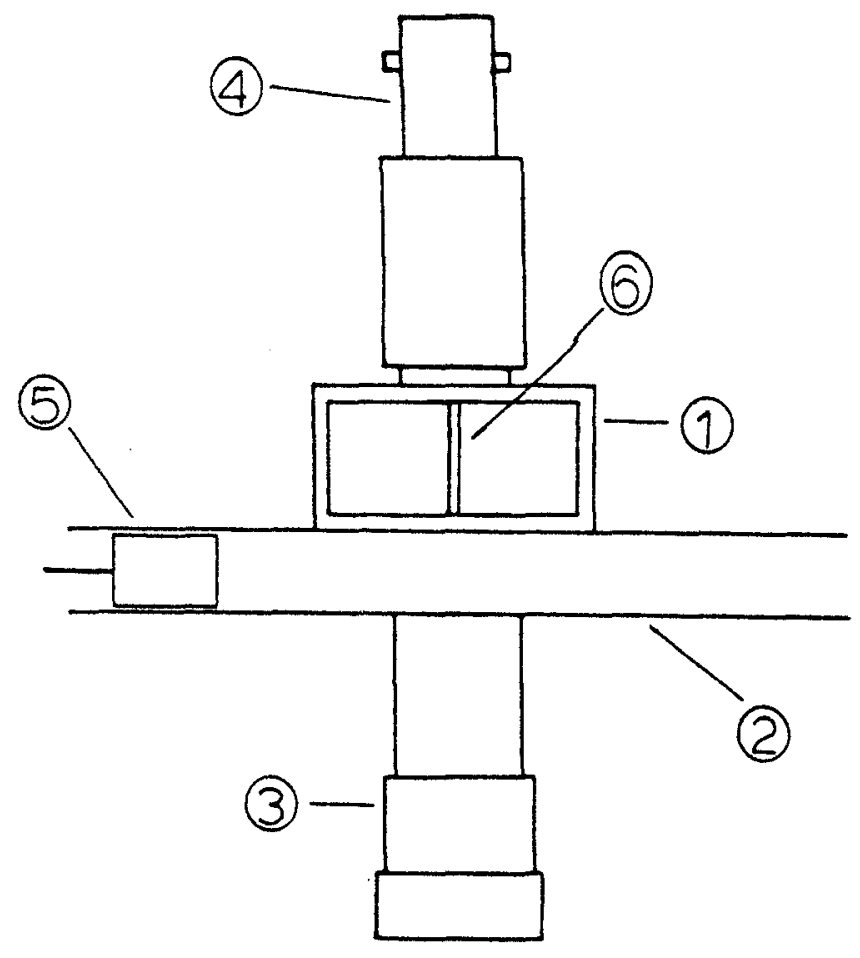

FIG. 2.1 - Esquema do gerador e misturador de harmônicos. (1) Guia de onda fundamental, (2) Guia de onda secundário, (3) Montagem do diodo a cristal, (4) Terminal da FI, (5) Curto móvel, (6) Acoplador entre o diodo, guias de onda e terminal de FI.

Na utilização do dispositivo como gerador de harmônicos, a energia produzida pelo gerador de microondas é conduzida pelo guia de onda fundamental e transferida ao diodo pelo acoplador tipo "poste".

o acoplador tipo "poste" é constituido por um fino cilín- 
metálico, paralelo ao campo elétrico em ambos os guias de onda e é o condutor central da linha coaxial que suporta o diodo.

A corrente resposta do diodo é conduzida pelo mesmo acoplador e excita o guia de onda secundário.

- guia de onda secundário, tem também a função de filtrar os harmônicos de ordem mais baixa que o desejado. Sendo assim, es te guia deve ser escolhido de tal maneira, que seu comprimento de onda de corte seja menor. que o comprimento de onda do harmônico anterior ao desejado.

Os guias de onda fundamental e secundário são terminados por curtos móveis que são utilizados para casar a impedância do acoplador com a do guia de onda.

Quando operamos este dispositivo como misturador de harmônicos, o sinal do oscilador-local é aplicado ao guia de onda fundamental, enquanto que o sinal de $R F$ é introduzido no guia de onda secundário.

o acoplador conduz ambos os sinais ao diodo onde ocorre a mistura. A correnté da frequência-intermediária é conduzida pelo mesmo acoplador ao terminal deste sinal.

2.5. O projeto do gerador e misturador de harmônicos

Nossa proposta de trabalho era a construção de um gerador e misturador de quarto harmônico de Banda-X $(8,2-12,4 \mathrm{GHz})$. Isto significa que deveríamos ter condiçōes de retirar e aplicar sinais cujo intervalo de frequências é $32,8-49,6 \mathrm{GHz}$. Como as possíveis aplicações do dispositivo não necessitavam de sinais puros, isto é, não estivessem contaminados com sinais dos harmônicos superiores ao quarto, os quais tem potência bem abaixo (6) daquela do harmônico de interesse. Sendo assim nos preocupamos em filtrar a fundamental $(8,2-12,4 \mathrm{GHz})$, o segundo harmônico 
$(16,4-24,8 \mathrm{GHz})$ e o terceiro harmônico $(24,6-37,2 \mathrm{GHz})$, os quais tem maior potência (quando propriamente sintonizados) que - quarto harmônico.

Podemos então utilizar a propriedade de que o guia de onda é um filtro passa-alta, assim devemos escolher um guia de on da que por sua própria natureza filtre até o terceiro harmônico. Se o dispositivo for aplicado em experimentos que necessitem de um sinal puro, um filtro passa-baixa ou passa-banda deve ser acoplado ao guia de onda. Um filtro deste tipo não foi construido por nao dispormos de um guia de onda de Banda-Q.

o guia de onda fundamental utilizado é um RG52/U que opera em toda a Banda-X e cuja frequência de corte para o modo $\mathrm{TE}_{10}$ é $6,56 \mathrm{GHz}$. A flange usada neste guia é do tipo UG135/U.

Como guia de onda secundário utilizamos um RG96/U que opera em toda a Banda-Ka. Este era o guia de onda de mais alta frequência de corte disponível, o valor desta para o modo $\mathrm{TE}_{10}$ é 21,09 GHz. Este guia filtra a fundamental, o segundo harmônico do intervalo $8,2-10,95 \mathrm{GHz}$, mas não filtra o terceiro harmônico. Para filtrar este harmônico, utilizaremos o próprio guia de onda da estrutura do frequencímentro de Banda-Q. Este guia de onda, RG97/U, tem uma frequência de corte para o modo TE 10 igual a $26,3 \mathrm{GHz}$, sendo assim possibilita filtrar o terceiro harmônico da frequência fundamental compreendida entre 8,2 e 8,76 GHz.

As dimensões dos guias de onda são mostradas na figura 2.2, estas foram calculadas para não termos um nó de voltagem nas flanges, nas frequências inferiores da banda de trabalho dos guias de onda. As outras dimensões $(57,5$ e $115,2 \mathrm{~mm})$ permitem que os curtos móveis sejam movimentados em uma distância maior que $\lambda_{\mathrm{g}} / 2$ calculada na frequência inferior da banda.

Ambos os guias de onda foram terminados com curtos móveis do tipo não-contato, que possibilitam o necessário casamento de 


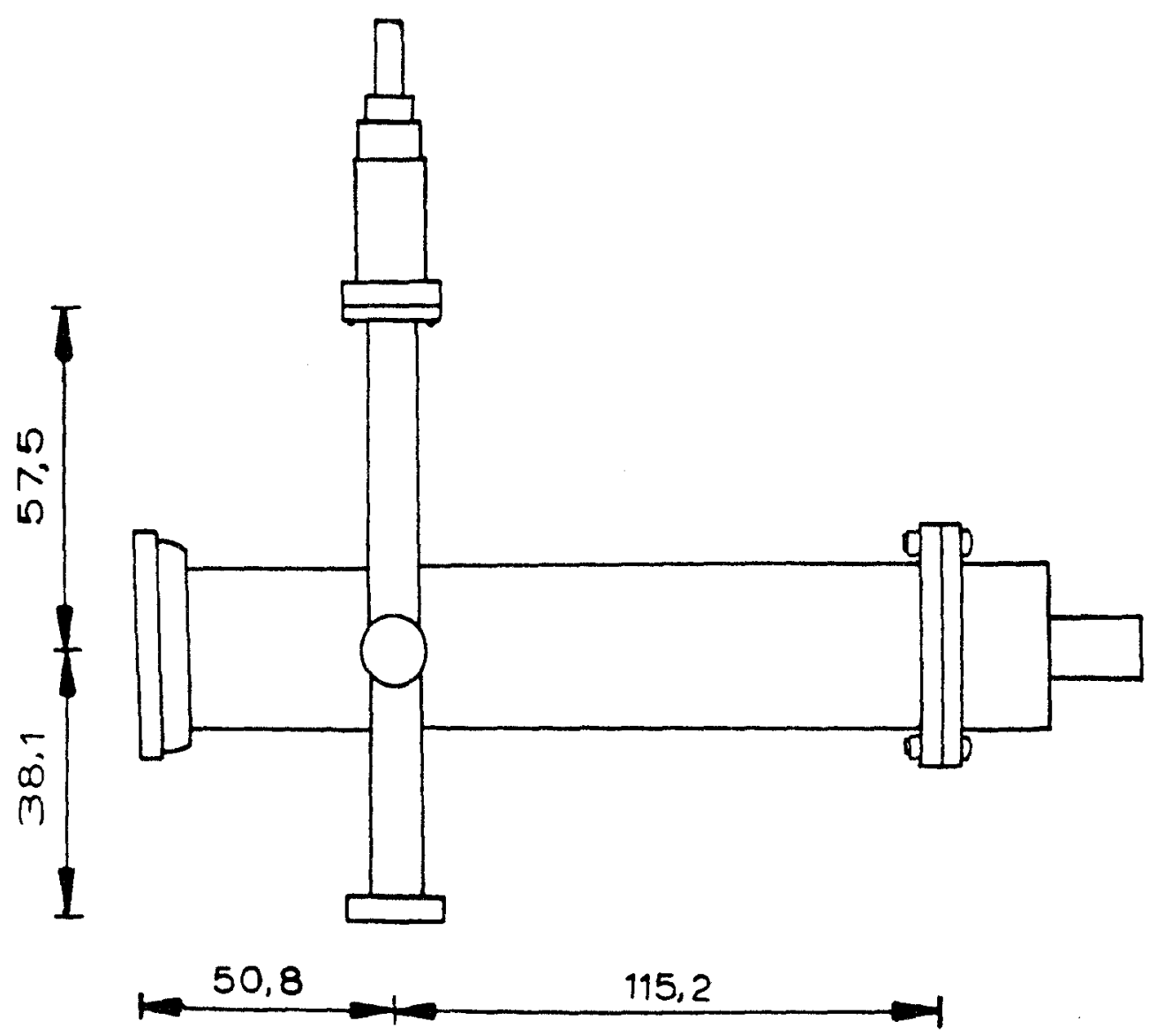

FIG. 2.2 - Vista de topo do gerador e misturador de harmônicos mostrando as dimensões dos guias de onda. 
impedâncias. O de Banda-X foi baseado em um modelo da HewlettPackard e suas dimensões mostradas na figura 2.3 , enquanto o de Banda-Ka baseado num modelo da Demornay-Bonardi e é mostrado na figura 2.4

Uma vista em explosão que mostra as dimensões da montagem do diodo e do terminal de FI é vista na figura 2.5. A montagem do diodo é uma linha coaxial de impedância $120 \Omega$, o diodo é colocado nesta montagem e seu condutor central é embutido no acoplador tipo "poste" que atravessa ambos os guias de onda e continua até o terminal de FI.

o diodo utilizado, procedente da indústria Microwave Associates, e o modelo 1N53B que opera na Banda-Ka, sendo que sua impedância de FI varia de 400 a $800 \Omega$.

o acoplador tipo "poste" é um cilindro construido de latão, como todas as outras partes, é banhado a ouro para diminuir as perdas devido a resistência superficial. o capacitor coaxial que permite isolar o terminal de FI dos terminais de OL e RF, está situado no terminal de FI e foi baseado em um modelo da Demornay-Bonardi. Para isolar o condutor central e o capacitor coaxial do condutor externo utilizamos lucite e teflon, respectivamente.

Uma vista em explosão do dispositivo mais detalhada é mostrada na figura 2.6 .

Como a impedância de FI do diodo é diferente da impedância $(50 \Omega)$ dos instrumentos de medidas a serem utilizados, é necessário construir um casador de impedâncias. o esquema deste, Przedpelski (38) é mostrado na figura 2.7 , onde $R_{i}$ e $R_{0}$ são os valores dás impedâncias a serem casadas, $x_{0}$ é um capacitor de $100 \mathrm{pF}$ que será utilizado para bloquear o sinal DC (resultante da retificąão do sinal de OL e RF), $x_{a}$ e $x_{b}$ são os componentes que possibilitam o casamento. As equações para $x_{a}$ e $x_{b}$ são: 

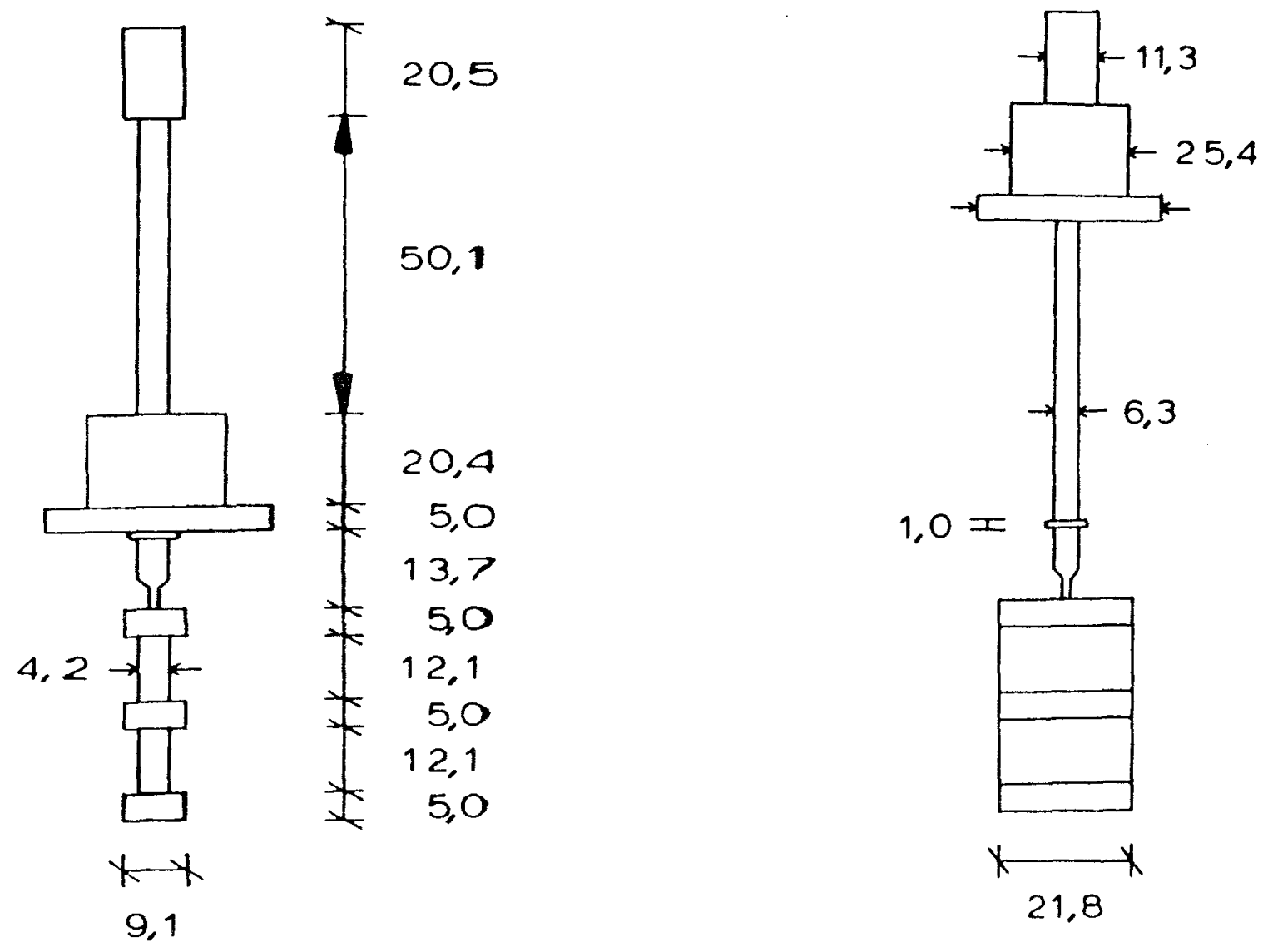

FIG. 2.3 - Vista de topo e de lado do curto móvel do tipo nãocontato do guia de onda de Banda-x, onde são mostradas as suas dimensões. 

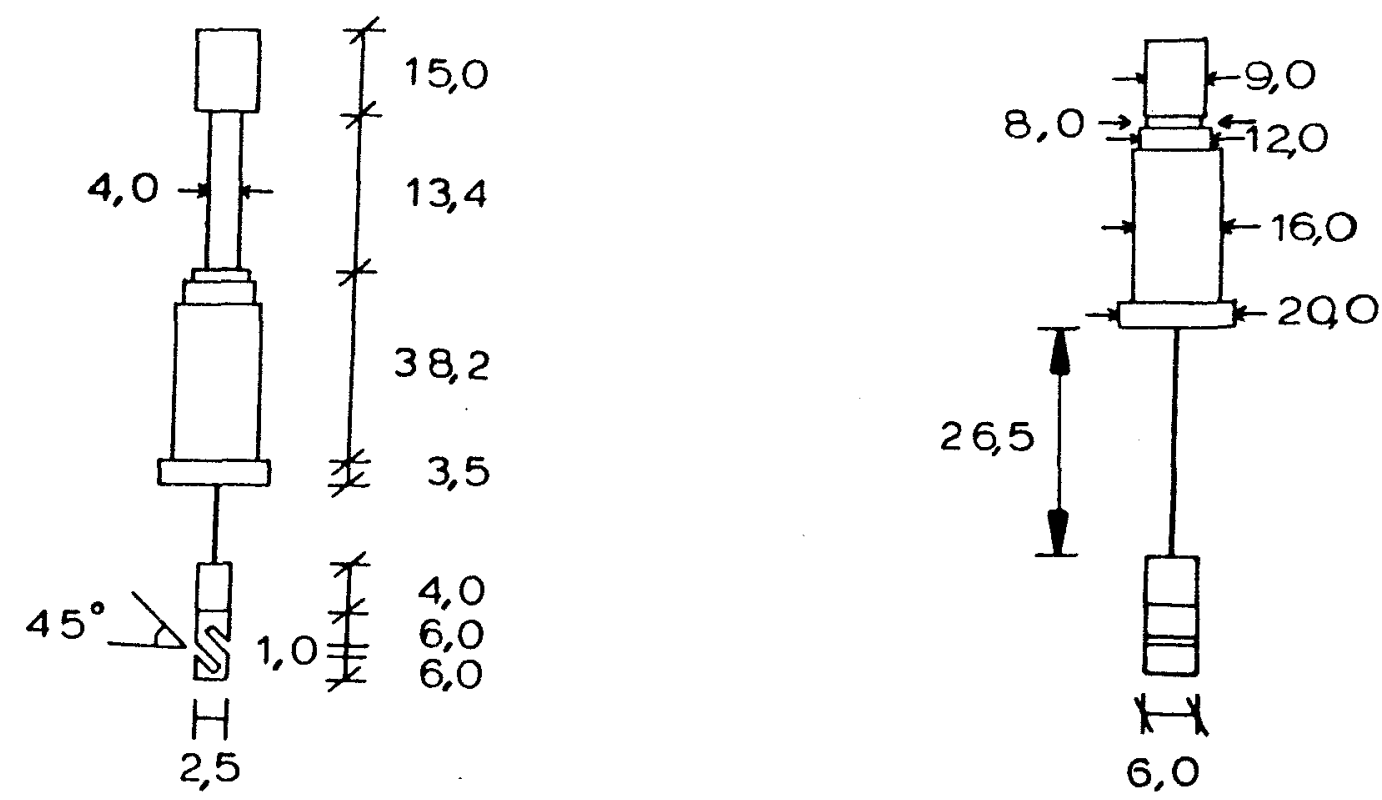

FIG. 2.4 - Vista de topo e de lado do curto móvel do tipo-s nãocontato do guia de onda de Banda-Ka, onde são mostradas as suas dimensões. 

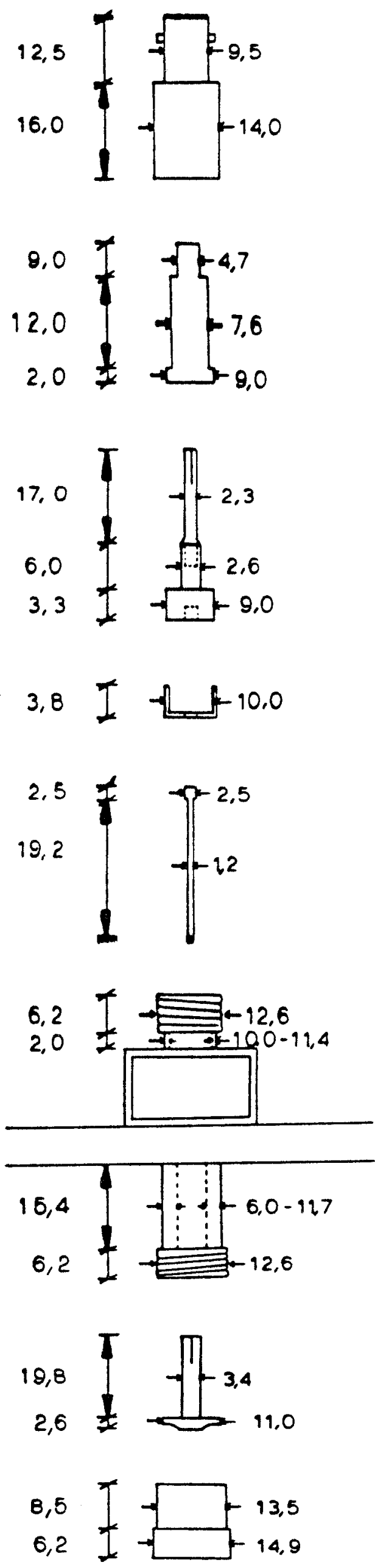

FIG. 2.5. Vista em explosão do dispositivo mostrando as dimensoẽs da montagem do diodo e do terminal de frequência-intermediária. 

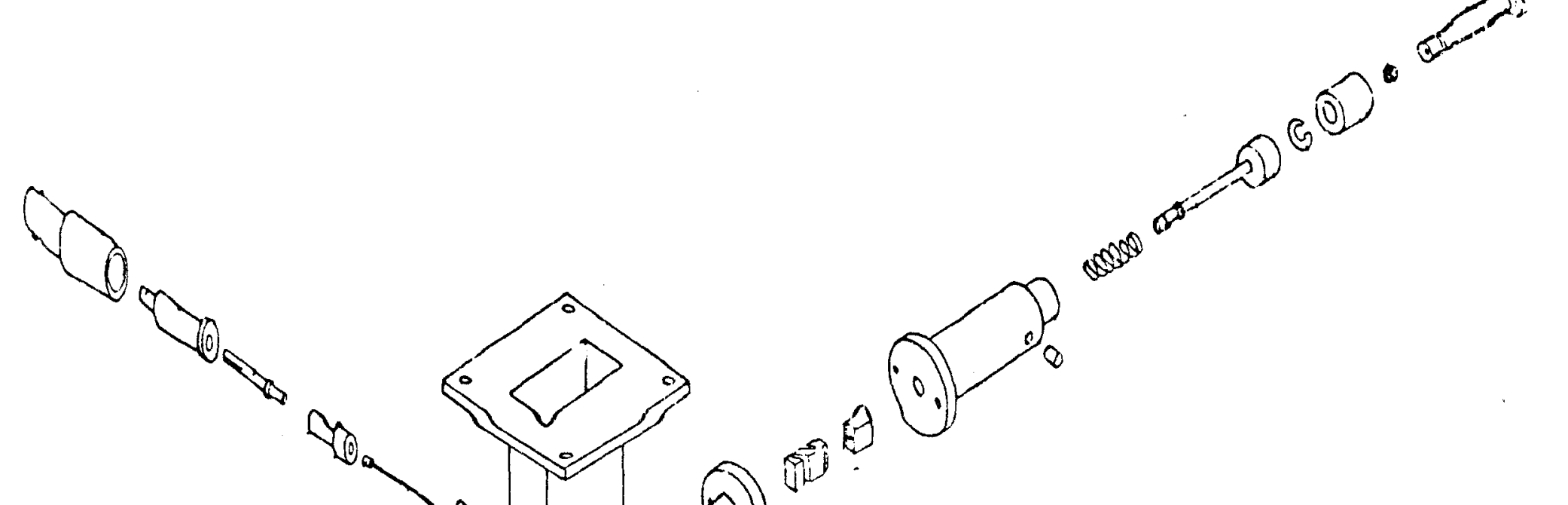


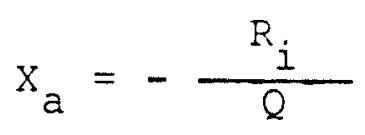

e $Q$ é dado por:

$$
Q=\left(\frac{R_{i}}{R_{0}}-1\right)^{1 / 2}
$$

e

$$
X_{b}=Q R_{0}-X_{0}
$$

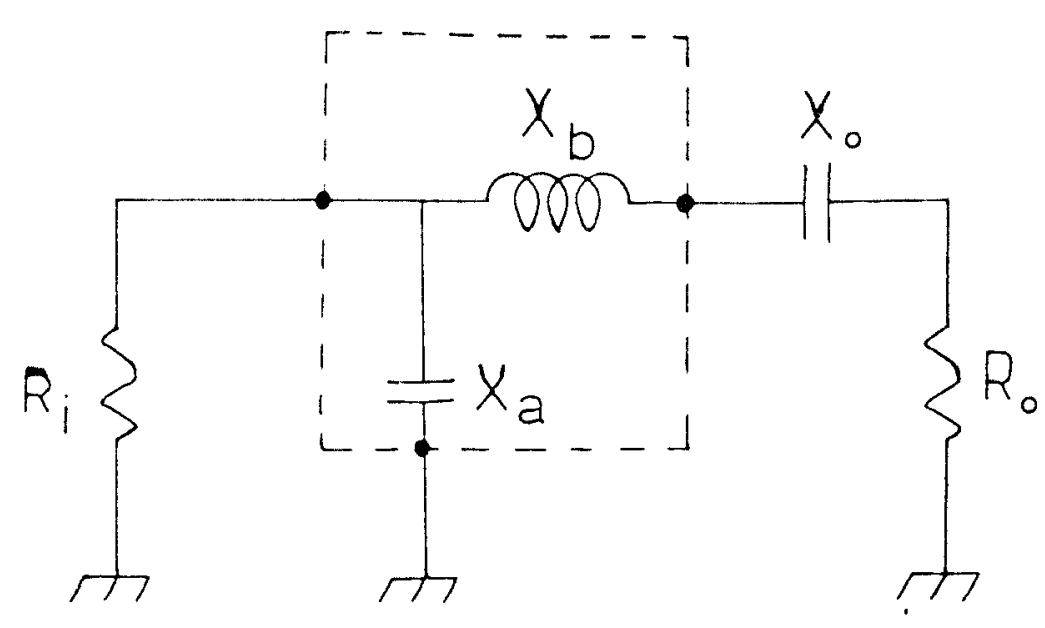

FIG. 2.7 - Cicuito equivalente do casador de impedâncias.

iós consideramos o valor médio da impedância de FI, assim $R_{i} 600 \Omega, R_{0}=50 \Omega$ e as frequências 30 e $60 \mathrm{MHz}$. Com estes valores, obitivemos os seguintes resultados:

$\begin{array}{ccc}F(\mathrm{MHz}) & \mathrm{C}(\mathrm{pF}) & \mathrm{L}(\mathrm{nH}) \\ 30 & 29,4 & 881 \\ 60 & 14,7 & 440\end{array}$


ciá (39) e os valores dos capacitores utilizados são: 29 e 15 pF. Em resumo o dispositivo projetado e construido consiste de duas seç̧ões de guias de onda ortogonais que tem uma parede em comum. Curtos móveis em cada guia de onda facilita o casamento de impedâncias. o diodo é localizado em uma montagem coaxial, cujo condutor central é perpendicular ao plano de interseção dos guias de onda e passa por um orifício no centro da parede comum e é conectado a um capacitor coaxial e ao terminal (BNC) de FI. o dispositivo, em virtude de não dispormos de filtros adequados, opera também como gerador e misturador do terceiro harmônico, além de operar como gerador e misturador do quarto harmônico. Suas bandas de frequências são: $37,2-24,6 \mathrm{GHz}$ (gerador e misturador do terceiro harmônico) e 49,6 - 32,8 (gerador e misturador do quarto harmônico). 


\section{CARACTERIZACÃO E APLICAÇÃO DO GERADOR E MISTURADOR DE HARMÔNICOS}

\subsection{Introdução}

Neste capítulo descrevemos os arranjos e procedimentos experimentais utilizados na caracterização e aplicação do dispo sitivo. Também é apresentado um breve comentário sobre o equipa mento usado.

As qualidades do dispositivo construído (descrito no capitulo II) podem ser avaliadas principalmente pela medida dos seguintes parâmetros:

1. Perda de conversão quando usado como gerador de harmônicos.

2. Perda de conversão e isolacão quando utilizado como misturador.

Estes parâmetros foram definidos no capitulo I e sua im portância discutida.

Um dos possíveis usos do dispositivo é a calibração de frequencimetros de diferentes bandas, quando não dispomos de equipamento apropriado.

Com esta aplicação, calibramos um frequencímentro de Banda-Q $(33,0-50,0 \mathrm{GHz})$, no intervalo de 33,4 a $40,0 \mathrm{GHz}$.

3.2. Medida da perda de conversão do gerador de harmônicos

No uso do gerador de harmónicos é importante conhecer a potência que será possivel obter, ou seja a perda de conversão do dispositivo. 
Como foi definido no capitulo I, perda de conversão é o quociente entre as potencias dos sinais fundamental $\left(P_{f}\right)$ e harmonica $\left(P_{h}\right)$, isto é:

$$
L=10 \log \frac{P_{E}}{P_{h}}
$$

Sendo assim a montagem experimental para a obtenção da perda de conversão, deve permitir a medida simultânea destas po tencias. o arranjo que foi utilizado nas medidas da perda de conversão e mostrado na figura 3.1 .

Neste esquema, o gerador de microondas utilizado 'é um klystron de Banda-X $(8,2-12,4 \mathrm{GHz})$, Varian $V-58$, que oscila entre 8,5 e $10,0 \mathrm{GHz}$ sendo sua potência máxima $500 \mathrm{~mW}$. Suas outras características são: Voltagem de Feixe $=500 \mathrm{~V}$, corrente Máxima de Feixe $=70 \mathrm{~mA}$ e Voltagem do Refletor $=-350 \mathrm{a}-525 \mathrm{~V}$. Este klystron é alimentado por uma fonte HP - modêlo - 716B.

A seguir um isolador de ferrite (Narda - modêlo - 1210) com isolação de $30 \mathrm{~dB}$, permite proteger o klystron das ondas re fletidas pelo sistema e não desejadas, permitindo uma maior estabilidade do gerador de microondas. Uma parte desta potência (20 $\mathrm{dB}$ ) é desvidada pelo acoplador direcional (Sivers Lab modêlo - PM 7250X) para medirmos a frequência da microonda. Essa frequência é lida no contador eletrônico (HP - modêlo - 5245L) que possui uma unidade conversora de frequência (HP - modêlo $5255 \mathrm{~A})$, ○ que permite medir frequencias de $20 \mathrm{~Hz}$ a $12,4 \mathrm{GHz} \mathrm{com}$ um erro de uma parte em $10^{5}$.

A potência do sinal é controlada através de um atenuador (Sivers Lab - modêlo - PM 7101X), que permite uma atenuação de 0 a $60 \mathrm{~dB}$ do sinal incidente com uma precisão de 0,1 dB entre 0 e $10 \mathrm{~dB} ; 1 \%, 2 \frac{8}{8}$ e $3 \%$ da leitura nos intervalos de 10 a $40 \mathrm{~dB}$, 40 a $50 \mathrm{~dB}$ e 50 a $60 \mathrm{~dB}(40)$. 


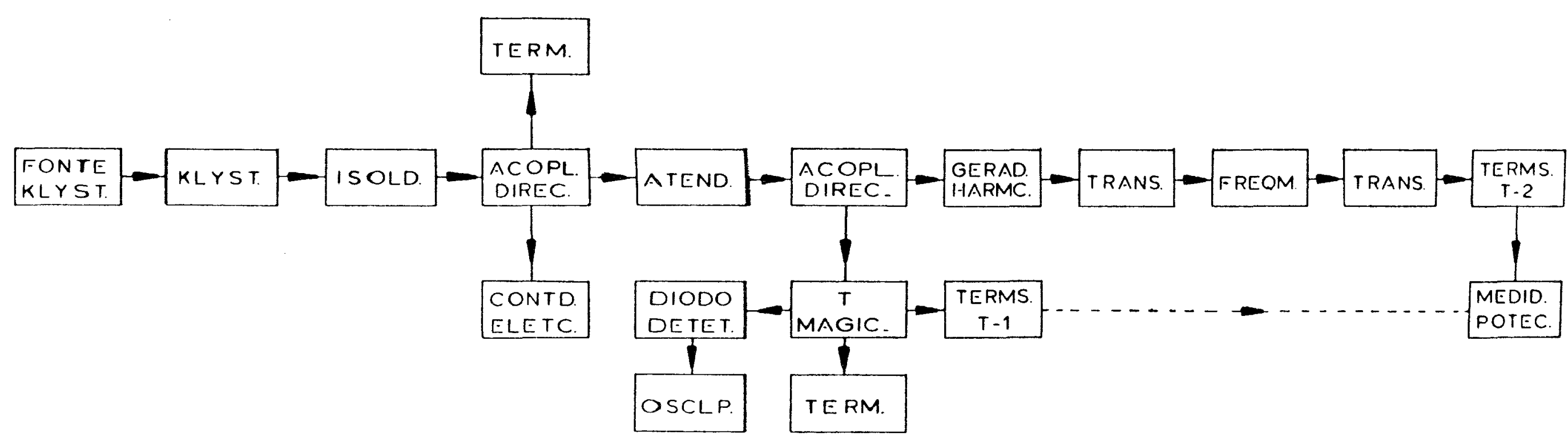

FIG. 3.1 - Diagrama em blocos do arranjo experimental empregado nas medidas da perda de conversão do gerador de harmônicos e na calibração do frequencímetro. 
A seguir uma fração do sinal $(10 \mathrm{~dB})$ é desviada por um acoplador direcional (Narda - modêlo - 1070-10) para um T-Mágico (DMB - modêlo - DBG-650). Este é usado para dividir a potência do sinal, de maneira que podemos medi-la, através do termistor $\left(\mathrm{T}_{1}\right)$ (HP - modêlo - X486A), no medidor de potência (HP - modêlo 432A) e observá-la no osciloscópio (Tektronix - modêlo - 7603), através do diodo detetor (Sivers Lab - modêlo - PM 7195X).

o sinal propaga-se pelo guia de onda fundamental (Banda-X) do gerador de harmônicos e é transferido, através de um acoplador tipo "poste" ao diodo onde os harmônicos são gerados. Estes são conduzidos pelo mesmo acoplador ao guia de onda secundário (Banda-Ka), no qual a fundamental e o segundo harmônico são filtrados, visto que suas frequências estão abaixo da frequência de corte deste guia de onda.

Os sinais harmônicos restantes (terceiro, quarto e etc) propagam-se pela transicão (DMB -modêlo - DBCD-018) existente entre os guias de onda Ka e Q. A seguir o terceiro harmônico e filtrado pelo guia de onda de Banda-Q (que faz parte do frequencímetro da mesma banda) e os sinais do quarto harmônico e os de ordem superior são conduzidos por uma transição idêntica à primeira ao termistor $\left(\mathrm{T}_{2}\right)$ (HP - modêlo - R486A) e sua potência medida no medidor de potência.

O medidor de potência utilizado permite medir potências de $1,0 \mu W$ a $10 \mathrm{~mW}$ com precisão de $1 \%$ do fundo de escala em todas elas (41).

O frequencímetro (DMB - modêlo - DBC 715-2) de Banda-Q usado é do tipo absorção, que através de seu guia de onda filtrava o terceiro harmônico e além disto confirmava o quarto harmônico mesmo sem estar calibrado.

Como o guia de onda secundário do gerador de harmônicos e o termistor $\left(\mathrm{T}_{2}\right)$ são de Banda-Ka e o Erequencímetro é de 
Banda-Q, foi necessário utilizar transições entre estes guias de onda.

Para evitarmos reflexões devido a terminais em aberto, utilizamos terminações (PRD - modelo - 1l6A), que absorvem a energia incidente com um minimo de reflexões.

\subsubsection{Procedimento experimental}

o primeiro passo é o ajuste do gerador de harmônicos para obter-a maior potência do harmônico. Este ajuste é feito através dos curtos móveis existentes em ambos os guias de onda. o quarto harmônico é confirmado através do frequencímetro de Banda-Q, o qual absorve potência de sinais cuja frequência esteja compreendida entre 33,0 e 50,0 GHz. A potência lida no medidor de potência passa por um mínimo, visto que o frequencímetro, quando sintonizado na frequência do sinal aboorve potên cia do mesmo.

As potências dos sinais fundamental e harmônico foram medidas através dos termistores e do medidor de potência, e com estes dados a perda de conversão calculada.

Para verificação o procedimento foi repetido e assim o valor médio das potências, e consequentemente o da perda de conversão; como também sua repetitividade obtidos.

Foram tomadas precaucões para evitarmos problemas de instabilidade em frequência e potência, o klystron era energizado três horas antes das medidas serem realizadas. Durante os testes se ocorria algum deste tipo de instabilidade, ela era contornada através do controle manual da voltagem do refletor do klystron. Este procedimento foi realizado para frequências entre 8,5 e $8,7 \mathrm{GHz}$ e diversos níveis de potência do sinal fundamental. 
Ós resultados são vistos nos gráficos: Potência Fundamental X Perda de Conversão e Potência Fundamental X Potência do Quarto Harmônico, que são mostrados no capitulo IV.

3.3. Medidas de isolação e perda de conversão do misturador de harmônicos.

o misturador é utilizado principalmente como conversor de frequências em receptores de microondas, sendo então necessárioconhecer a relação entre os sinais de Oscilador-Local (OL), Rádio-Frequência (RF) e Frequência-Intermediária (FI).

Como foi definido no capitulo I, o parâmetro isolação determina a quantidade de potência de um sinal que incidindo em um terminal é detetado em outro terminal, assim a isolafão entre os terminais oL e FI é dada por:

$$
I_{\mathrm{OL}-\mathrm{FI}}=10 \log \frac{\mathrm{P}_{\mathrm{OL}}}{\mathrm{P}_{\mathrm{OL}}}
$$

onde $\mathrm{P}_{\mathrm{OL}_{1}}$ é a potência do oscilador-localincidente em seu próprio terminal e $\mathrm{P}_{\mathrm{OL}_{3}}$ a potệncia do oscilador-local detetada no terminal de frequência-intermediária.

No caso do misturador a perda de conversão relaciona as potências de RF e FI, e é dada por:

$$
L=10 \log \frac{\mathrm{P}_{\mathrm{RF}}}{\mathrm{P}_{\mathrm{FI}}}
$$

- arranjo experimental usado para a medida destas quantidades é mostrado na figura 3.2 , e seus componentes e funçóes descritos abaixo. 


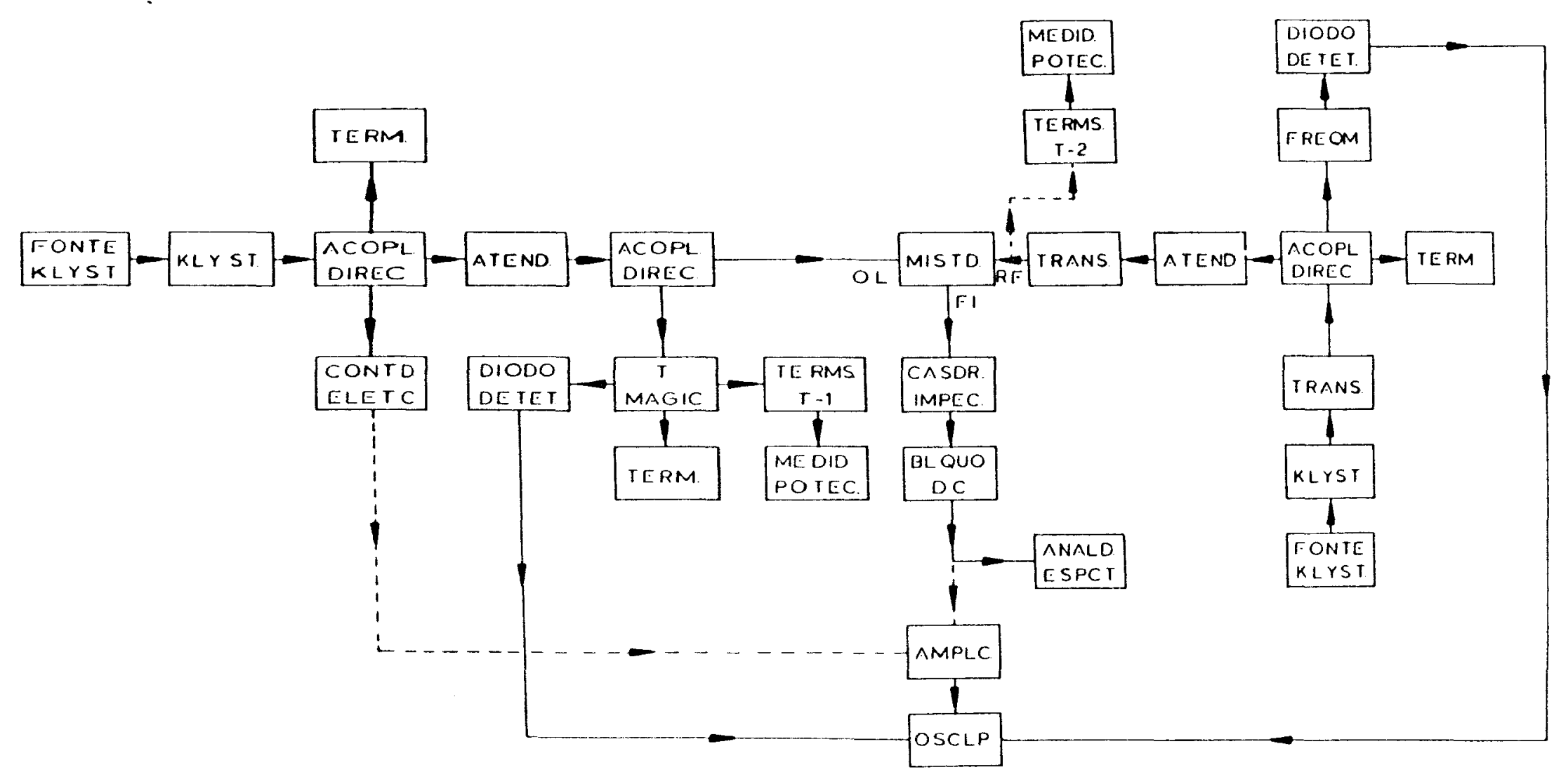

FIG. 3.2 - Diagrama em blocos do arranjo experimental para medidas da perda de conversão e isolação do misturador de harmô nicos e na calibracão do frequencímetro. 
o equipamento da Banda-X, que neste caso será considerado como oscilador-local do misturador, foi descrito na secão anterior e também mostrado na figura 3.1.

o sinal de RF é gerado num klystron de Banda-Ka, Varian $\mathrm{V}-97$, que oscila entre 34,0 e $35,6 \mathrm{GHz}$ sendo sua potência máxima $10 \mathrm{~mW}$. A voltagem de feixe é $400 \mathrm{~V}$, a corrente maxima de feixe $50 \mathrm{~mA}$ e a voltagem do refletor varia de -75 a $-225 \mathrm{~V}$. A fonte usada é uma HP - modêlo - 716B.

A seguir uma parte da potência $(20 \mathrm{~dB})$ é desviada pelo acoplador direcional (DMB - modêlo - DBC - 630), a qual é controlada por um atenuador (DMB - modêlo - DBC - 430) que permite uma atenuaçào máxima de $20 \mathrm{~dB}$.

Este sinal é introduzido no terminal de RF (guia de onda de Banda-Ka) do misturador, o qual é transmitido ao diodo através do acoplador.

$\mathrm{N}$ ○ diodo, são gerados os harmônicos dos sinais do OL e $\mathrm{RF}$ e também um batimento entre eles ocorre. Assim, o sinal de FI que é resultante do batimento entre o quarto harmônico do oscilador-local e do sinal de RF é conduzido ao seu terminal através do mesmo acoplador.

A potência do sinal de FI foi medida com o analisador de espectro (HP - modêlo - 141T), que permite visualizar sinais cuja frequência esteja situada entre 0 e $1,25 \mathrm{GHz}$ e com potências compreendidas entre 10 e $-72 \mathrm{dBm}$ com precisão de 1,75 dB. Com - analisador tambem foi possível observar a pureza espectral do sinal. O medidor de potência (HP - modêlo - 432A) não pode ser usado, visto que ele mede até $1,0 \mu \mathrm{W}$, enquanto que a potência do sinal de FI é da ordem de $0,01 \mu \mathrm{W}$.

A impedância do diodo na frequência de FI foi casada com - analisador de espectro através do casador de impedâncias descrito no capítulo II. O sinal DC, resultante da retificação 
dos sinais do oscilador-local e rádio-frequencia, foi bloqueado através de um capacitor cerâmico de 100 pF. Como a potência do sinal de FI e pequena, utilizamos um amplificador (Anzac modelo - 108) com a banda passante de 5 a 300 MHz com 28 dB de ganho, para amplificar este sinal antes de introduzi-lo no contador eletronico ou no osciloscópio.

ras medidas de potencias do oscilador-local no terminal FI foi usado um termistor (HP - modêlo - 8478B) cuja montagem e do tipo coaxial.

3.3.1. Procedimento experimental

A maior potência do sinal de FI e obtida através do ajuste dos curtos móveis.

A potência do sinal de FI foi obtida com o analisador de espectro, enquanto que as potências dos sinais de RF e OL foram medidas com os termistores e o medidor de potência. Com os dados das potências de RF e FI a perda de conversão foi calculada.

Os dados obtidos foram verificados através da repetifão do procedimento, e assim, o valor médio a repetitividade das medidas foram conseguidos.

Para evitarmos instabilidades de frequência e potência, ambos os klystrons eram energizados três horas antes das medidas serem efetuadas. Durante estas, a potência e a frequência foram monitoradas através do osciloscópio e do contador eletrónico.

A verificação da ocorrência de algua deslocamento na frequência de FI, seu sinal era amplificado e lido no contador eletrônico; isto foi feito antes e após cada medida, sendo que o deslocamento máximo observado entre elas foi de 1,0 $\mathrm{MHz}$, sua correcão era realizada através do controle manual da voltagem do refletor fo klystron do sinal de RF. 
A medida de isolação entre os terminais do OL e FI, foram realizadas com o sinal de $\mathrm{RF}$ totalmente atenuado. Medidas de potencia nos terminais de OL e FI foram realizadas com termistores e medidor de potência.

A isolação entre os terminais de oL e RF é infinita, visto que a frequência do ol está abaixo da frequência de corte do guia de onda do sinal de $\mathrm{RF}$, o recíproco pode não ser verdadeiro, mas como não tinhamos uma transifão entre os guias de onda de Bandas X e Ka não pudemos comprovar. Também não foi possível medir a isolação entre os terminais de RF e FI, por não termos uma transição coaxial-guia de onda de Banda-Ka que possibilite medir a potência de RF no terminal de FI.

A linearidade entre as potências dos sinais de RF e FI foi verificada, a potência do ol foi mantida constante, enquanto a potência do sinal de RF variada. O procedimento deste caso é o mesmo da medida da perda de conversão.

Os resultados são vistos nos gráficos: Potência Fundamen tal X Perda de Conversão, Frequência Fundamental X Isolação e Potência de RF X Potência de FI, que são mostrados no capítulo IV.

3.4. Aplicação - Calibração de um frequencímetro de Banda-Q

Este frequencímetro descrito na seção 3.2 não estava calibrado, isto é, não sabiamos a que frequência correspondia a leitura no micrômetro.

Com o gerador de quarto harmônico de Banda-X foi possivel calibrá-1o no intervalo entre 33,4 e $40,0 \mathrm{GHz}$, visto que estas frequências são o quarto harmônico do intervalo 8,35 - 10,0 GHz. Com o misturador do quarto harmônico foi possível comprovar alguns pontos da calibração obtida com o gerador de harmônicos. 
3.4.1. Procedimento experimental

o arranjo experimental utilizado para calibrar o frequen címetro usando o gerador de harmônicos é o mesmo mostrado na figura 3.1. Para obtermos frequencias compreendidas entre $8,35 \mathrm{e}$ $8,5 \mathrm{GHz}$ o klystron $\mathrm{V}-58$ foi substituído por um outro, também Varian VA-217H que oscila entre 8,3 e $9,6 \mathrm{GHz}$ e com potência máxima de $500 \mathrm{~mW}$.

o klystron de Banda-X era colocado para oscilar em determinada frequência, a qual era lida no contador eletrônico, o gerador de harmônicos era sintonizado até que o medidor de potên cia indicasse potência máxima. A cavidade do frequencímetro era então movimentada através do micrômetro e quando passavamos por sua frequência de ressonância esta absorvia potência do sinal do quarto harmônico, esta absorção era medida no medidor de potência, e a leitura efetuada no micrômetro. A confirmação desta leitura foi conseguida com a repetição do procedimento. A frequência harmônica era aquela lida no contador eletrônico multiplicada por quatro, isto significa que o erro cometido nesta frequência é de 4 partes em $10^{5}$.

Para frequências acima de $8,8 \mathrm{GHz}$ o terceiro harmônico também está presente, sendo assim a potência medida é composta dos sinais dos terceiro e quarto harmônicos, mas a cavidade do frequencímetro absorve apenas potência do quarto harmônico e da mesma maneira a absorção da potência era confirmada.

Com o procedimento exposto acima foi possível calibrar - frequencímetro, de 33,4 a $40,0 \mathrm{GHz}$, com intervalos de $200 \mathrm{MHz}$.

A calibração efetuada com o gerador de harmônicos foi comprovada no intervalo compreendido entre 34,0 e $35,6 \mathrm{GHz}$ com a utilizacao do misturador. o arranjo experimental usado é aquele mostrado na figura 3.2 . 
Neste procedimento, o sinal de FI era obtido da mesma forma que o apresentado na seção 3.3 , este sinal era amplificado e introduzido no contador eletronico. A voltagem do refletor do klystron de Banda-Q era regulada até que o contador indicasse uma frequência de FI igual a zero $\mathrm{Hz}$, portanto a frequência deste klystron era igual a do quarto harmonico do de Banda-X, isto é noscalibravamos a frequência do sinal de $R F$ através daquela do sinal do oscilador-local.

o sinal de RF era detetado pelo diodo detetor e visualizado no osciloscópio, portanto uma variação deste sinal era observada quando sintonizávamos o frequencímetro em sua frequência de ressonância, a leitura do micrômetro era feita no mínimo desta variacão.

Para confirmar a leitura do micrômetro, o procedimento foi repetido a a frequência da FI observada continuamente no con tador eletrônico para a verificação de algum desvio.

Os resultados obtidos são mostrados em um gráfico: Leitura do Micrômetro X Frequência que é mostrado no capítulo IV.

A figura 3.3 mostra o equipamento de microondas utilizado na caracterizacão do gerador e misturador de harmônicos construído, como também na aplicação efetuada.

\subsection{Comentário sobre as medidas realizadas com o terceiro harmônico de Banda-X}

Neste trabalho também realizamos medidas de potência com - gerador do terceiro harmônico de Banda-X, que são frequências compreendidas entre 24,6 e 37,2 GHz. Como o klystron de Banda-X utilizado opera entre 8,5 e $10,0 \mathrm{GHz}$, a banda do terceiro harmônico é reduzida para o intervalo $25,5-30,0 \mathrm{GHz}$. Em virtude de 


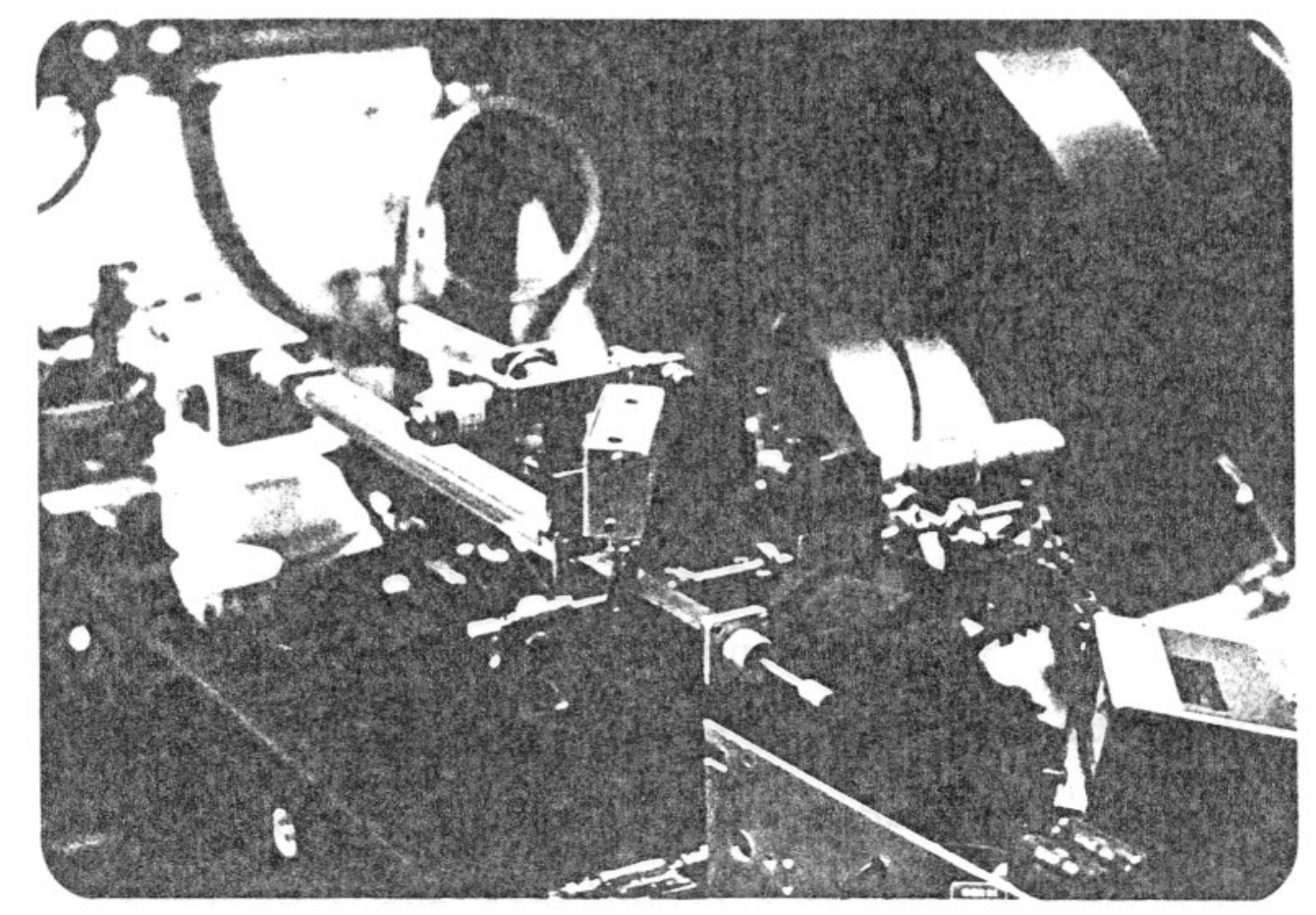

FIG. 3.3 - Equipamento de microondas utilizado na caracterizaçáo do gerador e misturador de harmônicos que é visto em primeiro plano. 
não dispormos de um klystron ou outra fonte que operasse nestas frequências e que simulariam o sinal de $F F$, medidas com o misturador do terceiro harmônico nao foram efetuadas.

o procedimento experimental é o mesmo descrito para o quarto harmônico na seção 3.2. No arranjo experimental mostrado na figura 3.1, retiramos as transições e o frequencímetro de Banda-Q e montamos o termistor $\mathrm{T}_{2}$ diretamente no guia de onda secundário (Banda-Ka).

Salientamos que estas medidas não são absolutas, visto que o quarto harmônico está presente. Podemos afirmar que a potência deste é baixa, pois quando sintonizamos os curtos móveis para obtermos maior potência de um harmônico os outros são desintonizados e consequentemente suas potências são diminuidas. Se tivéssemos um filtro passa-baixa ou um filtro passabanda, por exemplo uma cavidade ressonante do tipo transmissão, um destes seria montado na saída do guia de onda secundário e as medidas obtidas seriam absolutas.

os resultados conseguidos são vistos nos gráficos: Potência Fundamental X Perda de Conversão e Potência Fundamental X Potência do Terceiro Harmônico, mostrados no capítulo IV. 


\section{RESULTADOS E CONCLUSÕES}

\subsection{Introdução}

Neste capitulo expomos os resultados experimentais da caracterizacão do gerador de terceiro e quarto harmônicos e mistura dor do quarto harmônico de Banda-X, como também da aplicação efetuada.

As curvas de potência e perda de conversão do terceiro e quarto harmônicos versus potência da fundamental, bem como a curva de isolação (OL-FI) versus frequência da fundamental foram ajustadas pelo método dos mínimos quadrados.

Nossos resultados são confrontados e discutidos com aqueles existentes na literatura e concluimos que o gerador do terce ro e quarto harmônicos, como também o misturador do quarto harmônico de Banda-X construido é comparável aqueles.

4.2. Potência do terceiro e quarto harmônicos e perda de conversão do gerador de harmônicos

Nas figuras 4.1 e 4.2 , respectivamente, estão representados os valores da potência e da perda de conversão do terceiro harmônico, ambos em função da potência do sinal fundamental.e ten do como parâmetro a frequência da fundamental.

Na figura 4.1, a curva correspondente a frequencia $8,8 \mathrm{GHz}$ tem equação: $P_{3}=1,01 \mathrm{P}_{f}^{1,3}$, enquanto que a curva cuja frequência é $10 \mathrm{GHz}$ tem equação: $\mathrm{P}_{3}=0,71 \mathrm{P}_{f} 1,4$. A tangente destas curvas concordam com o resultado $\left(P_{3} \propto P_{f}{ }^{1,3}\right)$ de Richardson (42). Nestas equações $P_{3}$ é a potência do terceiro harmônico em $\mu \mathrm{W}$ e $\mathrm{P}_{\mathrm{f}}$ a potên 


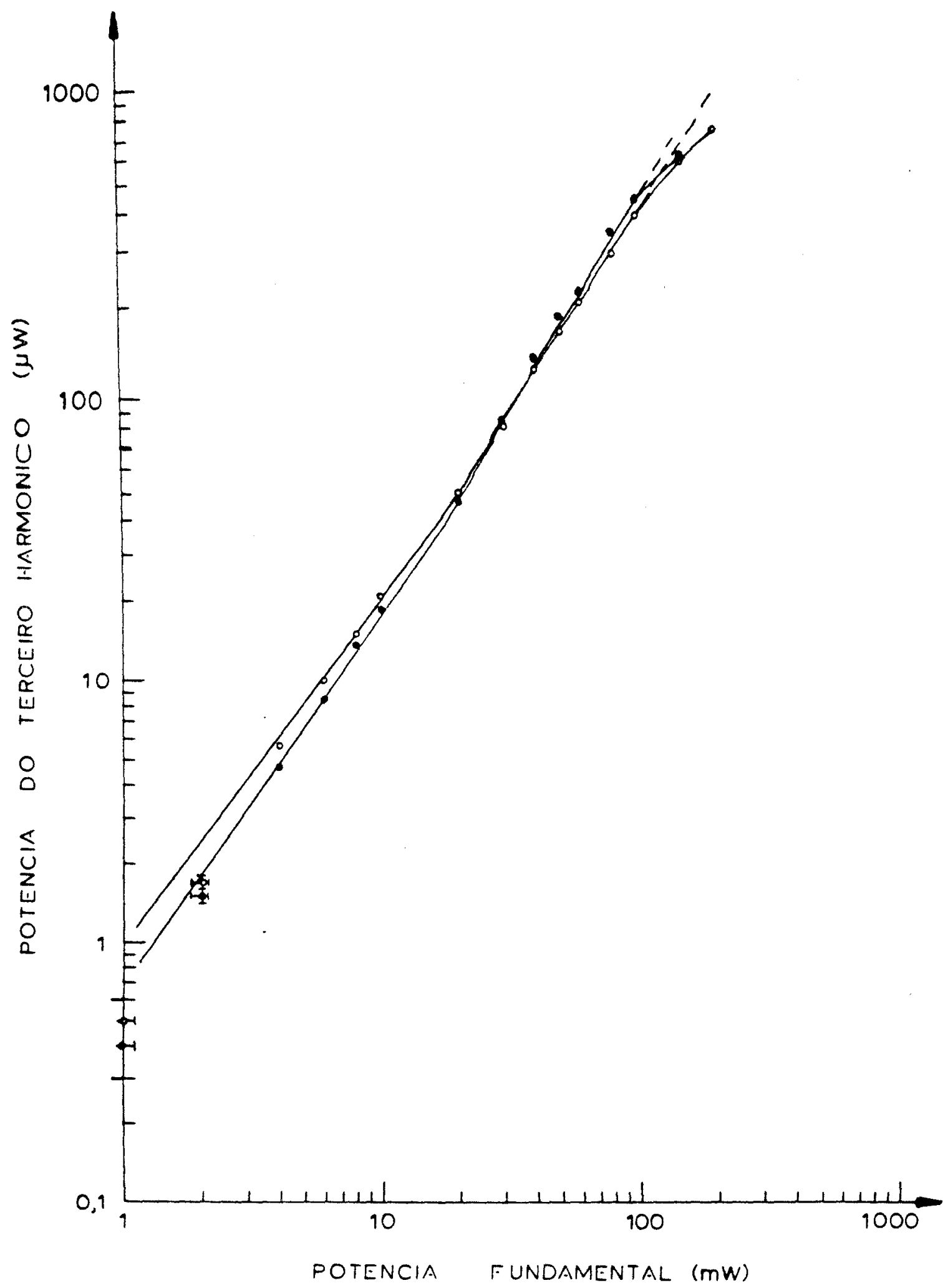

FIG. 4.1 - Potência do terceiro harmônico em função da potencia do sinal fundamental, tendo como parâmetro a frequência fundamental.

(0) $-8,8 \mathrm{GHz}$ e (•) $-10 \mathrm{GHz}$. 


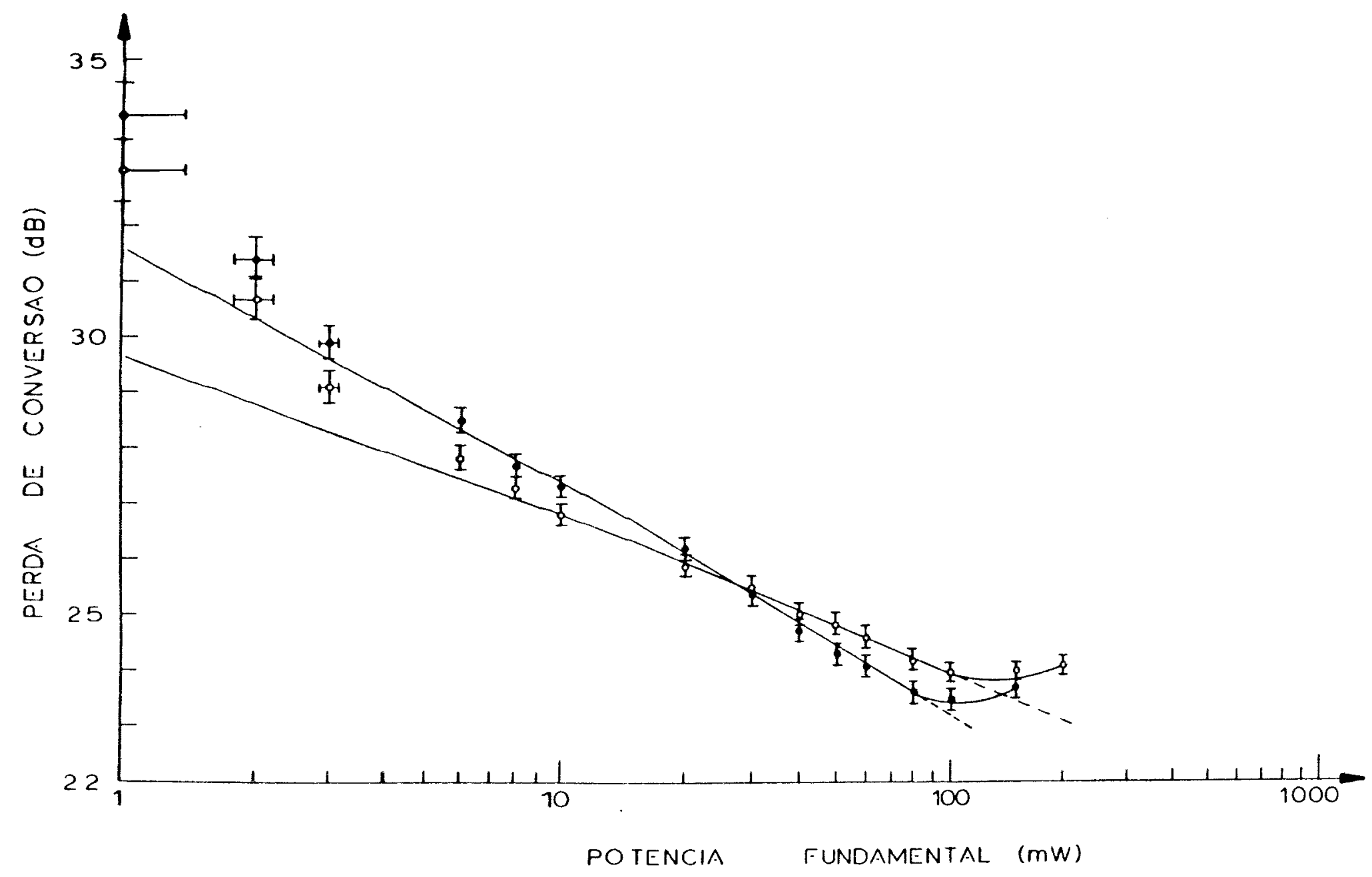

FIG. 4.2 - Pexda de conversáo do terceiro harmônico em funçáo da potência do sinal fundamental, tendo como parâmetro a frequência fundamental. (0) $-8,8 \mathrm{GHz}$ e (•) $-10 \mathrm{GHz}$. 
cia da fundamental em $\mathrm{mW}$.

Na figura 4.2, a equação da curva cuja frequência é 8,8 GHz é: $L=29,6-2,8 \log P_{f} ;$ para a curva de frequência $10 \mathrm{GHz}$ a equação é: $L=31,6-4,2 \log P_{f}$. Onde $I$ é a perda de conversão em $d B$ e $P_{f}$ a potência da fundamental em $\mathrm{mW}$.

os valores da potência e da perda de conversão do quarto harmônico em função da potência da fundamental e tendo como parâmetro a frequência do sinal fundamental, são mostrados nas figuras 4.3 e 4.4

Na figura 4.3 , a equação: $\mathrm{P}_{4}=7,6 \cdot 10^{-4} \mathrm{P}_{\mathrm{f}}^{2,66}$ corresponde a curva cuja frequencia é $8,5 \mathrm{GHz}$, enquanto a curva de frequên cia $8,7 \mathrm{GHz}$ tem equação: $\mathrm{P}_{4}=7,6 \cdot 10^{-4} \mathrm{P}_{\mathrm{f}}{ }^{2,54}$. Onde $\mathrm{P}_{4}$ é a potência do quarto harmônico em $\mu \mathrm{W}$ e $\mathrm{P}_{f}$ a potência do sinal fundamental em mW. A tangente destas curvas estão situadas entre os resultados de Nethercot $\left(\mathrm{P}_{4} \propto \mathrm{P}_{\mathrm{f}}{ }^{4}\right)$ (4) e Richardson $\left(\mathrm{P}_{4} \propto \mathrm{P}_{\mathrm{f}}{ }^{1,5}\right)$ (7).

Na figura 4.4, a curva de frequência $8,5 \mathrm{GHz}$ tem equação: $L=62,3-17,4 \log P_{\bar{f}}$ e a equação: $L=60,4-15 \log P_{f}$ corresponde a curva cuja frequência e $8,7 \mathrm{GHz}$. Nestas, L é a perda de conversão em $d B$ e $P_{f}$ a potência do sinal fundamental em $\mathrm{mW}$.

\subsection{Perda de conversão e isolação do misturador do quarto harmônico}

Nas figuras 4.5 e 4.6 mostramos os valores da perda de conversão em função da potência do oscilador-local, cuja frequência era $8,5 \mathrm{GHz}$, tendo como parâmetro a potência do sinal de rádio-frequência. A isolação entre os terminais do osciladorlocal e frequência-intermediária é mostrada em funcão da frequência do oscilador-local na figura 4.7. A equação desta reta é: $I=20,35+0,3 \mathrm{~F}$, onde $I$ é a isolação e $\mathrm{F}$ a frequência em GHz.

A linearidade entre os sinais de rádio-frequência e 


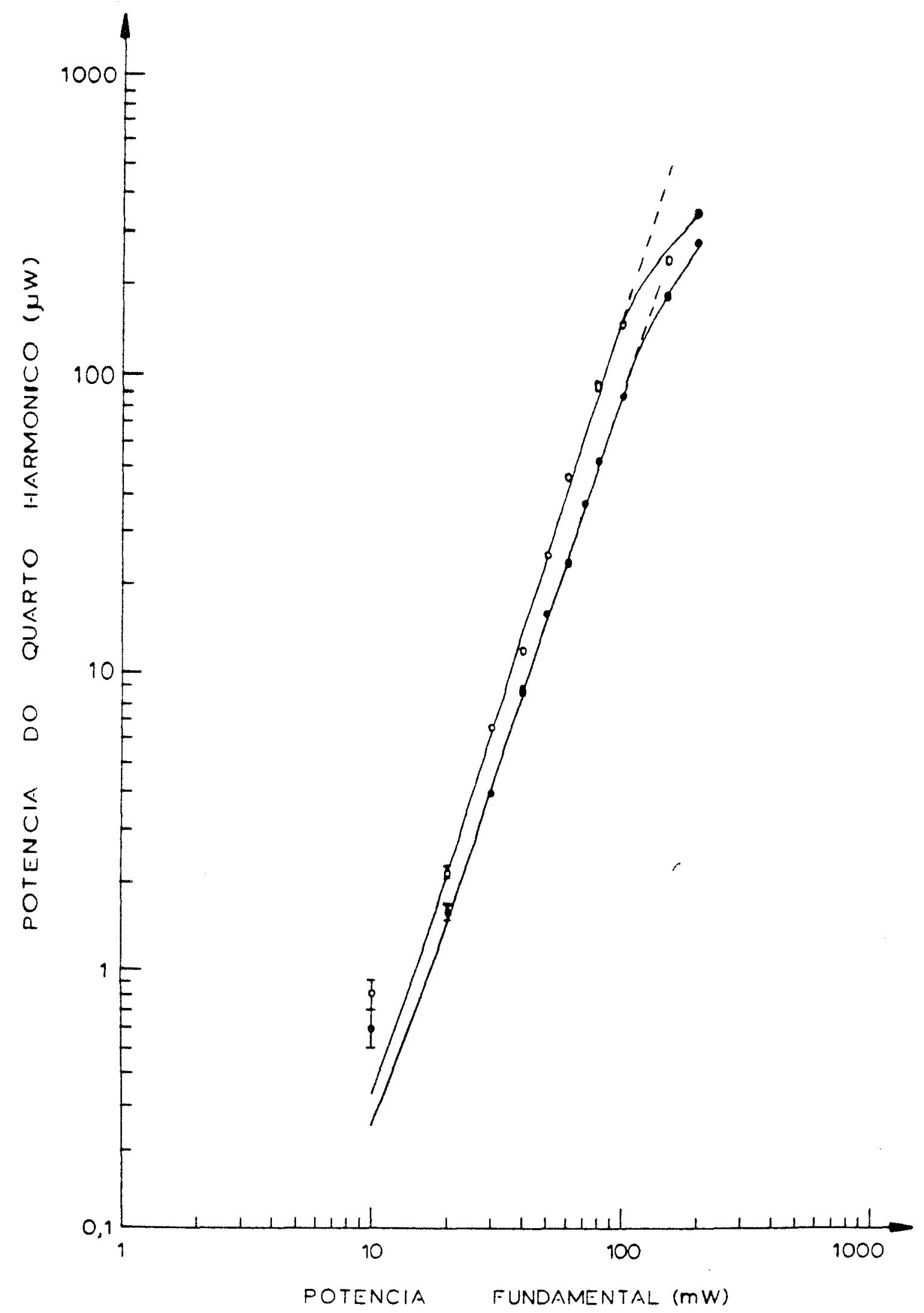

FIG. 4.3 - Potência do quarto harmônico em função da potência do sinal fundamental, tendo como parâmetro a frequência fundamental.

(0) $-8,5 \mathrm{GHz}$ e (•) $-8,7 \mathrm{GHz}$. 


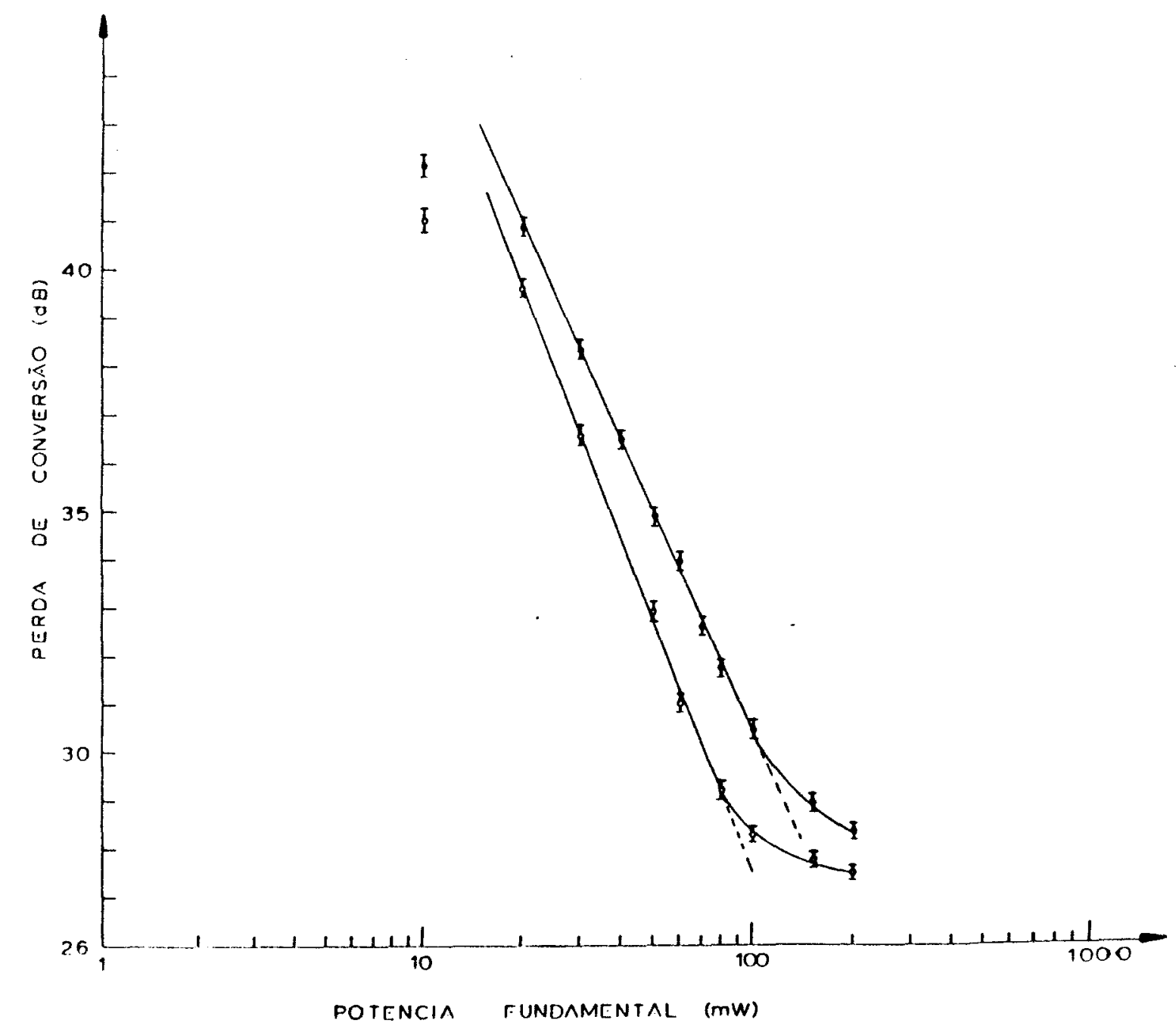

FIG. 4.4 - Perda de conversão do quarto harmônico em função da potência do sinal fundamental, tendo como parâmetro a frequência fundamental. (0) $-8,5 \mathrm{GHz}$ e (•) $-8,7 \mathrm{GHz}$. 


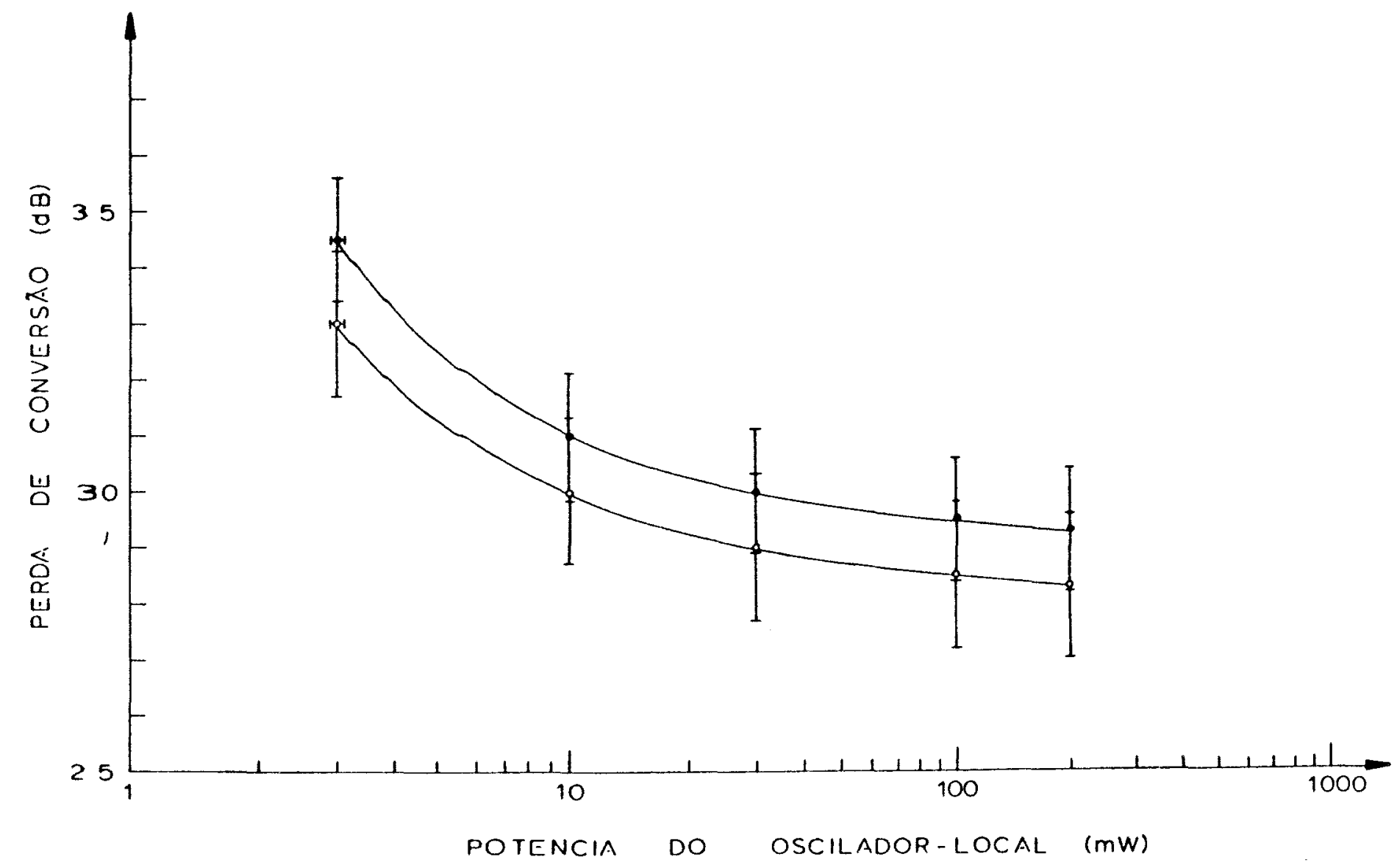

FIG. 4.5 - Perda de conversão do misturador do quarto harmônico em função da potência do oscilador-local, tendo como parâmetro a potência da RF. A frequência da FI é $30 \mathrm{MHz}$. (0) - $1 \mu \mathrm{W}$ e (•) - $20 \mu \mathrm{W}$. 


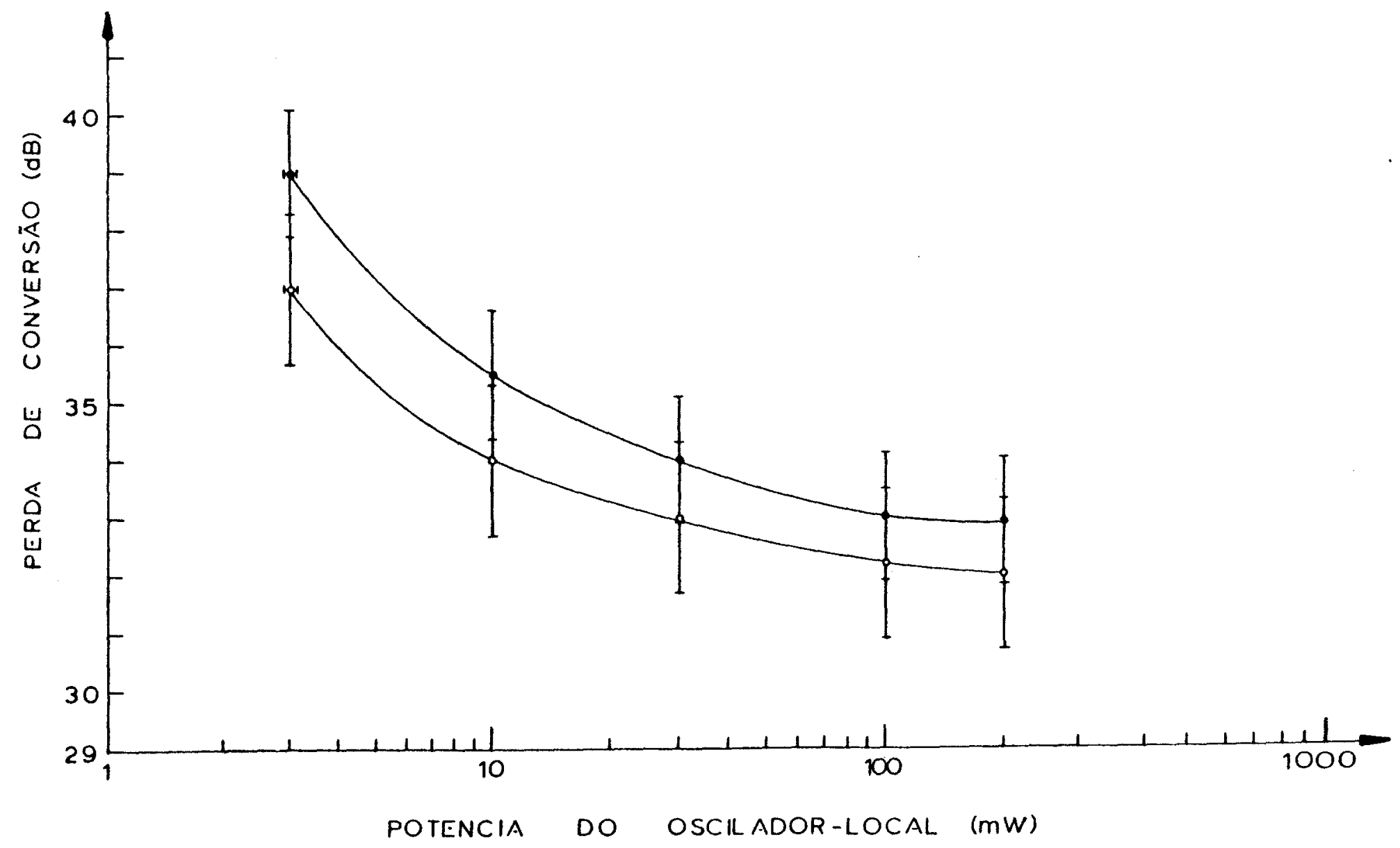

FIG. 4.6 - Perda de conversão do misturador do quarto harmônico em função da potência do oscilador-local, tendo como parâmetro a potência da RF. A frequência da FI é $60 \mathrm{MHz}$. (0) - l $\mu \mathrm{W}$ e (0) - $20 \mu \mathrm{W}$. 


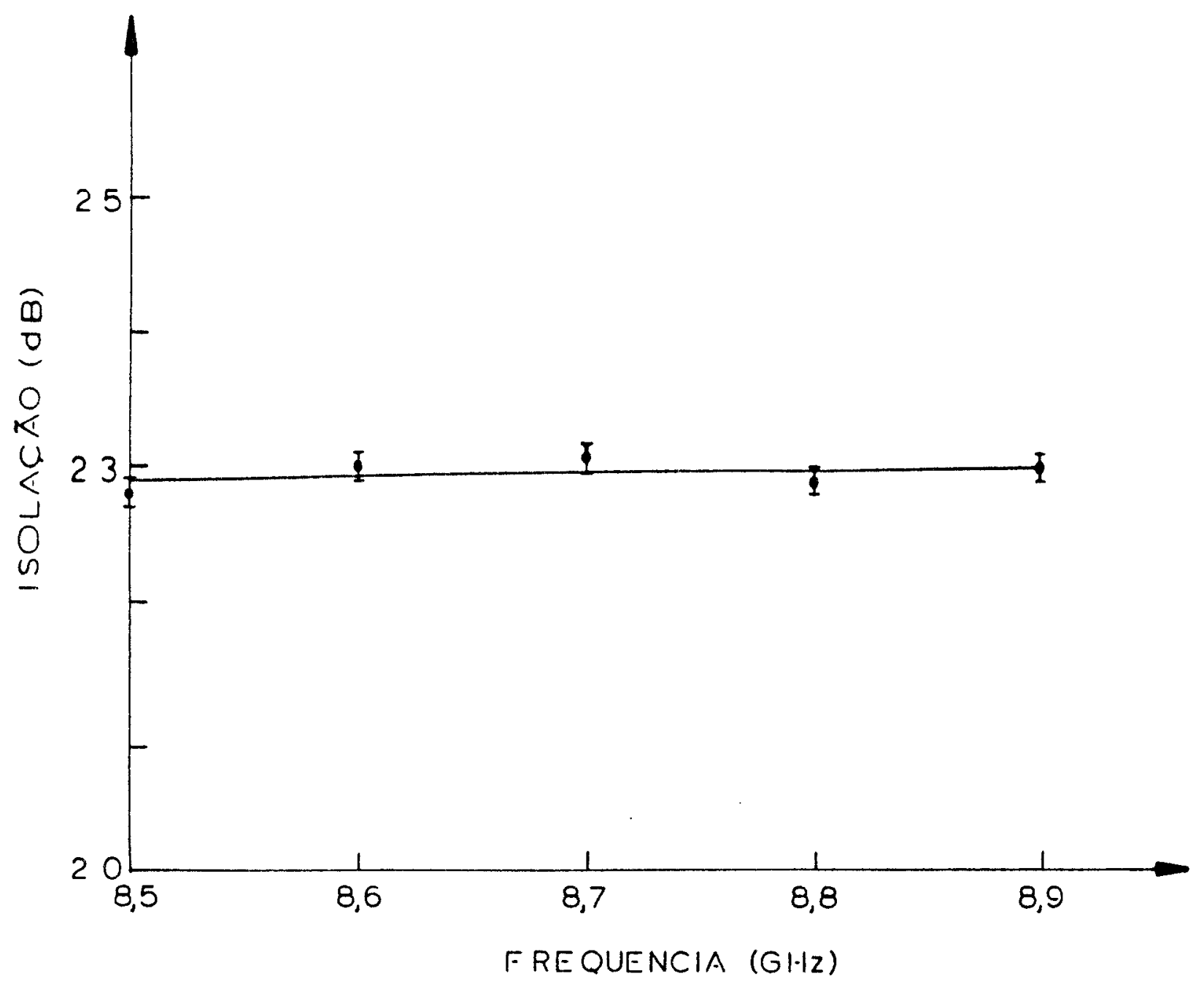

FIG. 4.7 - Isolação entre os terminais de osciladorlocal e frequência-intermediária em função da frequência do oscilador-local. 
frequencia-intermediária é mostrada nas figuras 4.8 e 4.9 , tendo como parâmentro a potência do oscilador-local, sendo sua frequência $8,5 \mathrm{GHz}$.

A pureza espectral da frequência-intermediária em 30 e 60 $\mathrm{MHz}$ é observada nas figuras 4.10 e 4.11 . Estas foram obtidas com potências dos sinais de $R F$ e OL de $1,0 \mu W$ e $100 \mathrm{~mW}$, a frequência do OL era $8,5 \mathrm{GHz}$.

O sinal da frequência-intermediária, 30 e $60 \mathrm{MHz}$ é mostra do nas figuras 4.12 e 4.13. Este sinal foi amplificado 28 dB e aplicado em uma carga de $50 \Omega$ do osciloscópio.

4.4. Calibração do frequencímetro de Banda-Q

A figura 4.14 mostra a curva de calibração obtida para 0 frequencímetro de Banda-Q.

Na figura 4.15 mostramos os modos do klystron de Banda-X (traco superior) e do quarto harmônico desta banda (traco inferior). Nesta podemos observar as absorções provocadas pelos frequencímentros de Banda-X e Q. A absoṛão do frequencímetro de Banda-X na frequência de $8,7 \mathrm{GHz}$ é visto em ambos os traços na mesma posição e a absorção do frequencímetro de Banda-Q, para meIhor visualização foi deslocado para o centro do modo do quarto harmônico.

O arranjo experimental usado é mostrado na figura 3.1 , no qual um frequencímetro de Banda-X foi introduzido entre o primeiro acoplador direcional e o atenuador, além disto o termistor $\mathrm{T}_{2}$ foi substituido por um diodo detetor. A voltagem do refletor do klystron de Banda-X foi modulada por um sinal dente de serra e assim todo o modo pode ser observado. 


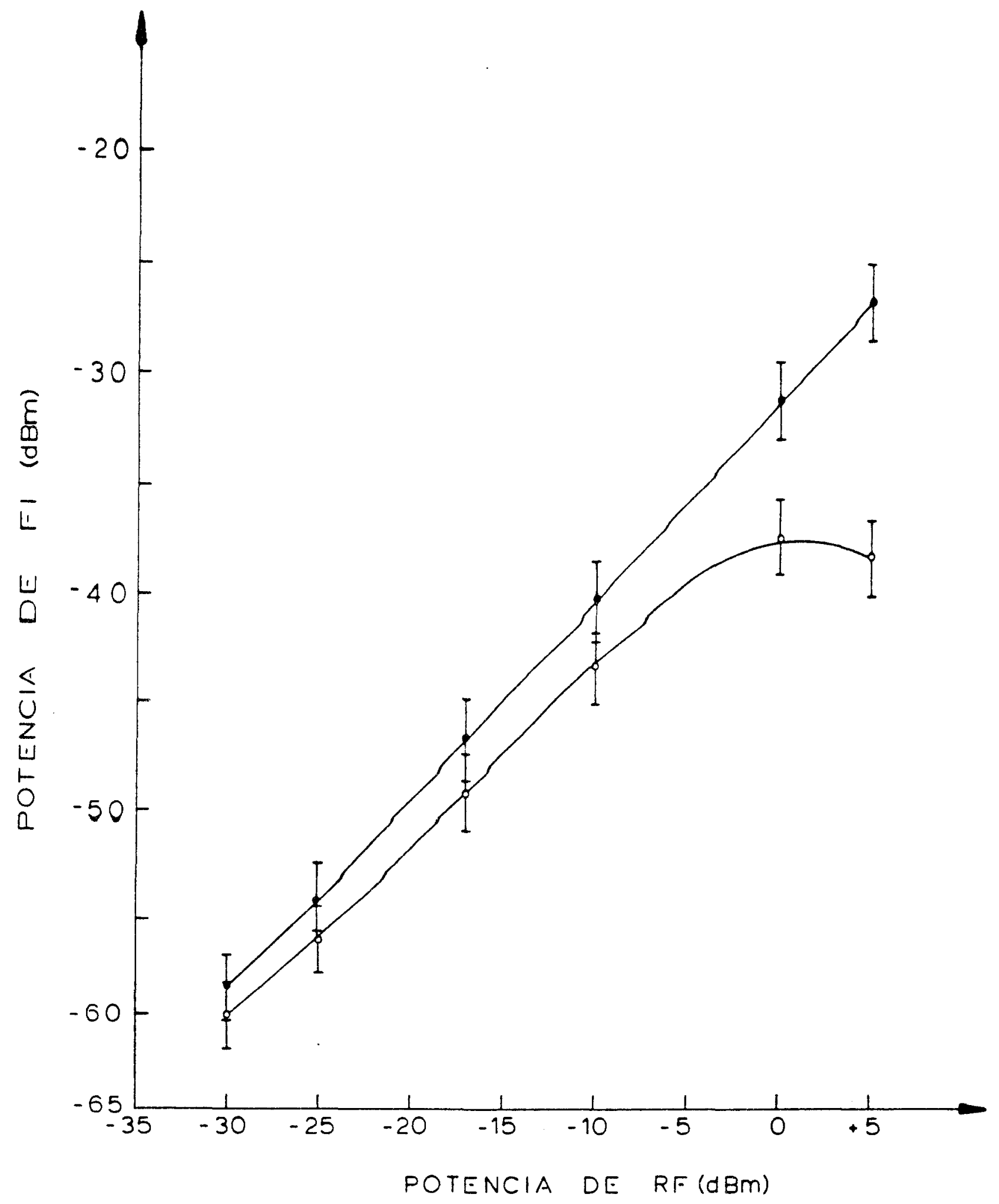

FIG. 4.8 - Linearidade entre os sinais de RF e FI. A potência da FI em função da potência de RF, tendo como parâmetro a potência do osciladorlocal. A frequência da FI é $30 \mathrm{MHz}$.

(•) $-20 \mathrm{dBm}$ e (0) $-10 \mathrm{dBm}$. 


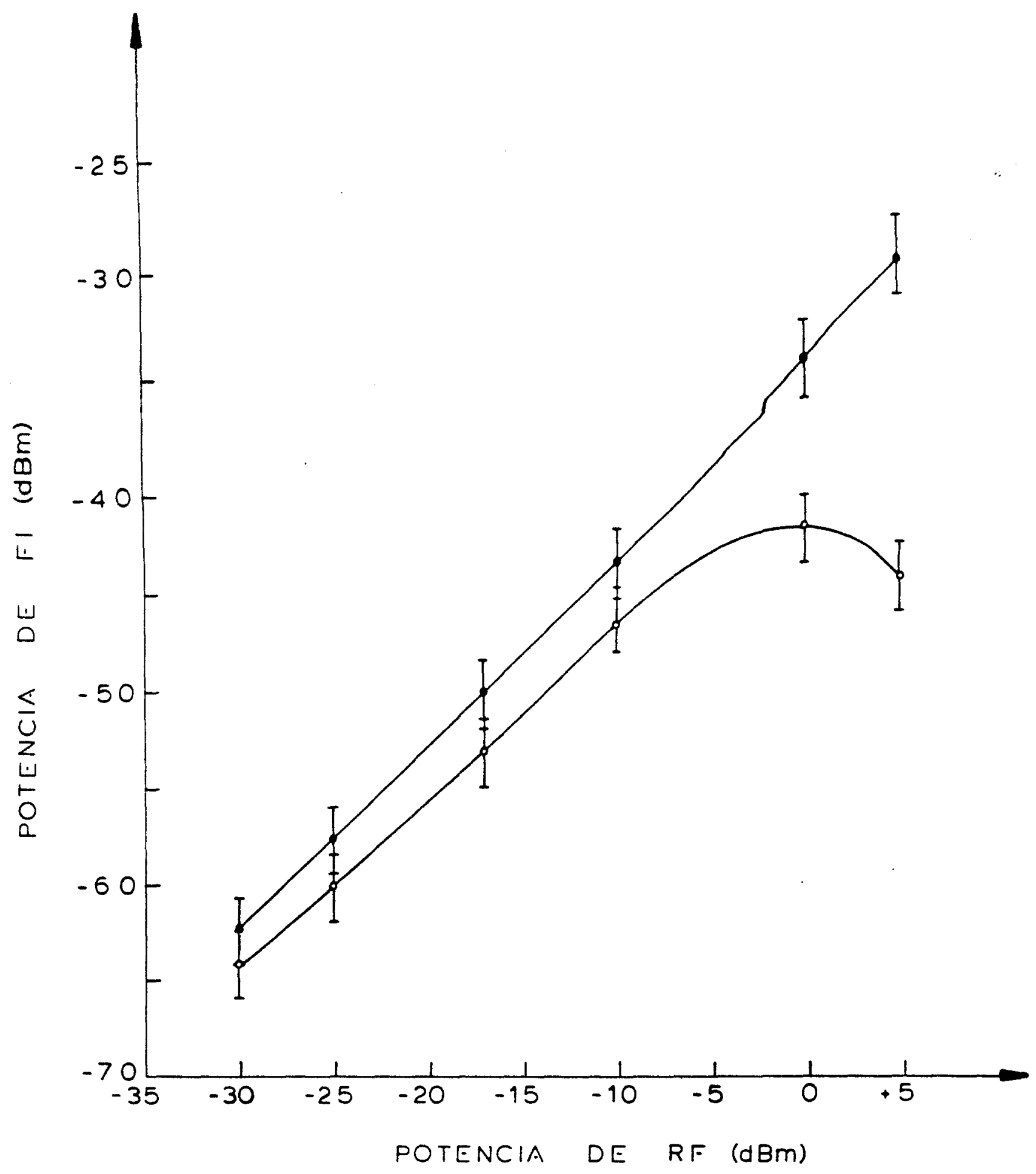

FIG. 4.9 - Linearidade entre os sinais de RF e FI. A potência da $F I$ em função da potência da RF, tendo como parâmetro a potência do osciladorlocal. A frequência da FI é $60 \mathrm{MHz}$.

(•) $-20 \mathrm{dBm}$ e $(0)-10 \mathrm{dBm}$. 


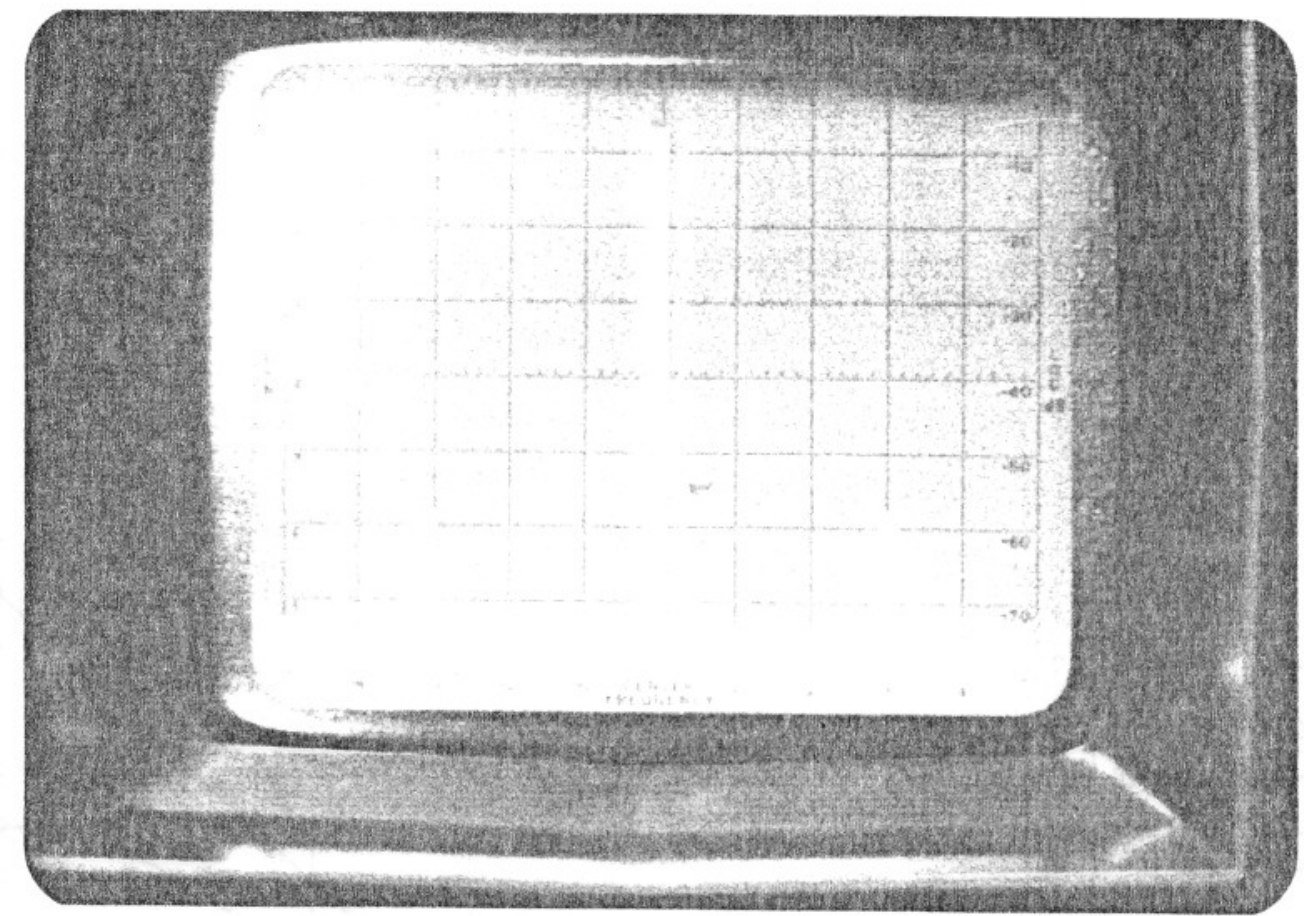

FIG. 4.10 - Espectro da frequencia-intermediaria de $30 \mathrm{MHz}$. cada divisao horizontal e igual a $10 \mathrm{MHz}$ e cada divisáo vertical e igual a - $10 \mathrm{dBm}$.

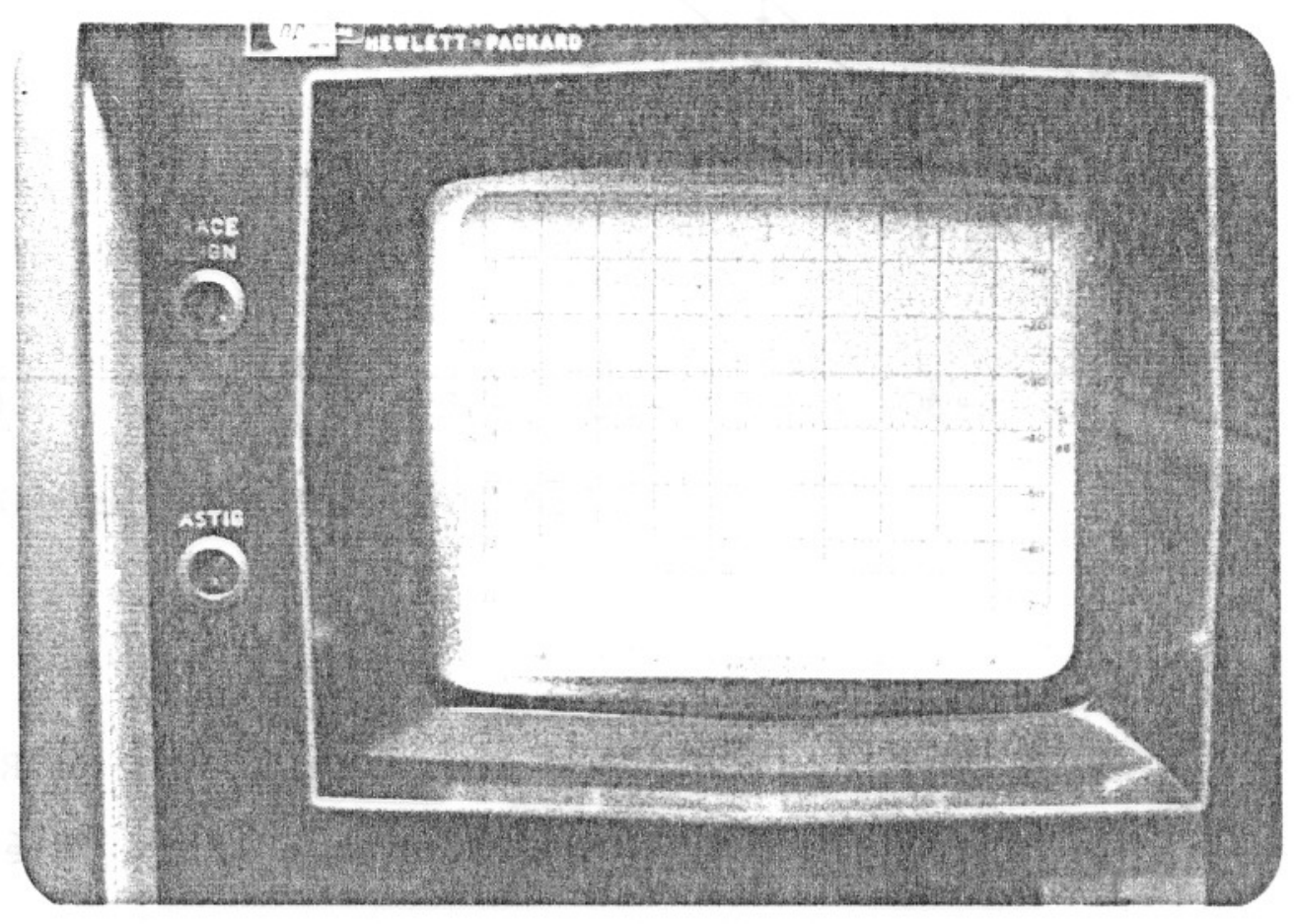

FIG. 4.11 - Espectro da frequência-intermediária de $60 \mathrm{MHz}$. Cada divisão horizontal e igual a $20 \mathrm{MHz}$ e cada divisão vertical e igual a - $10 \mathrm{dBm}$. 


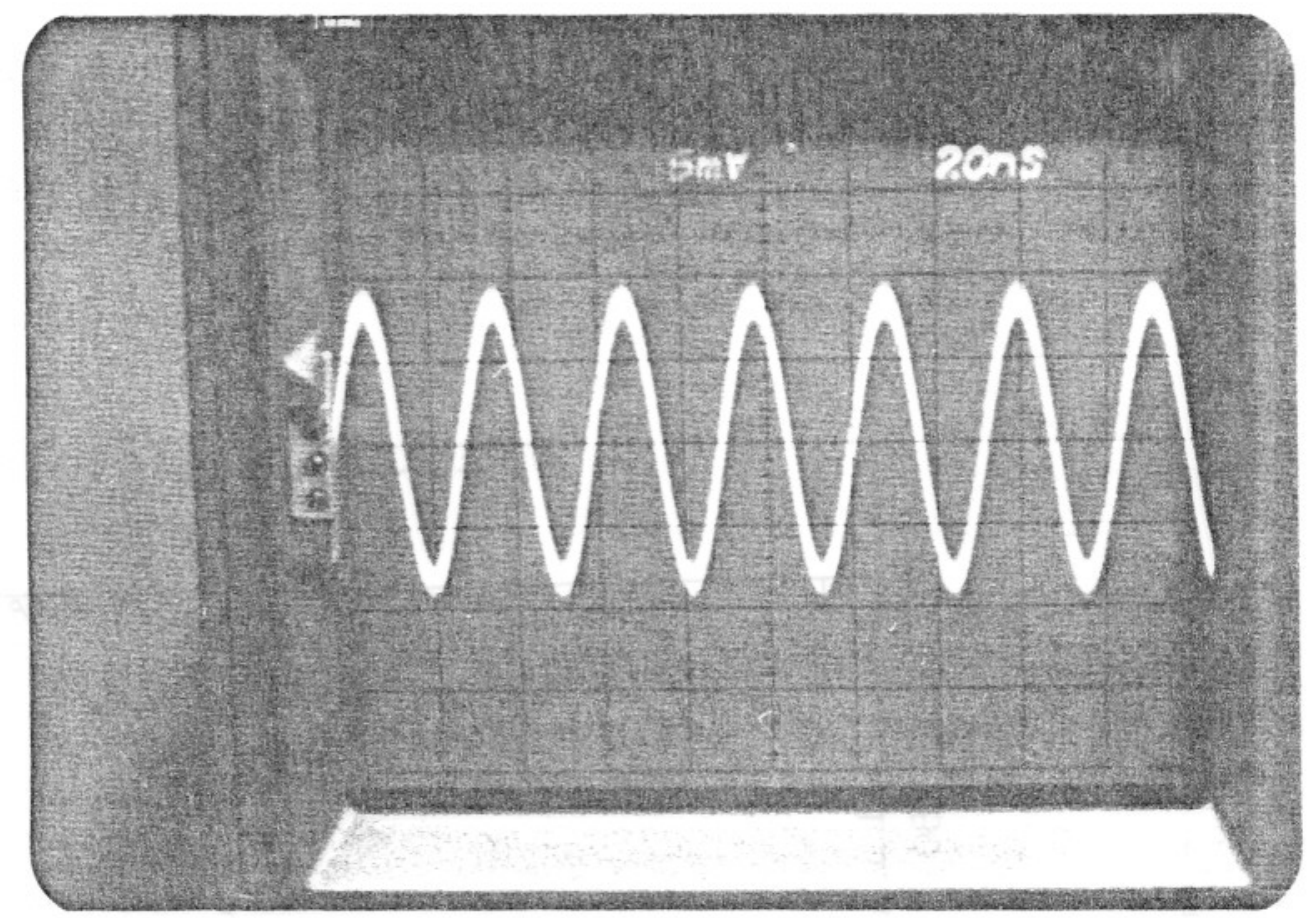

FIG. 4.12 - Sinal da frequência-intermediária de $30 \mathrm{MHz}$.

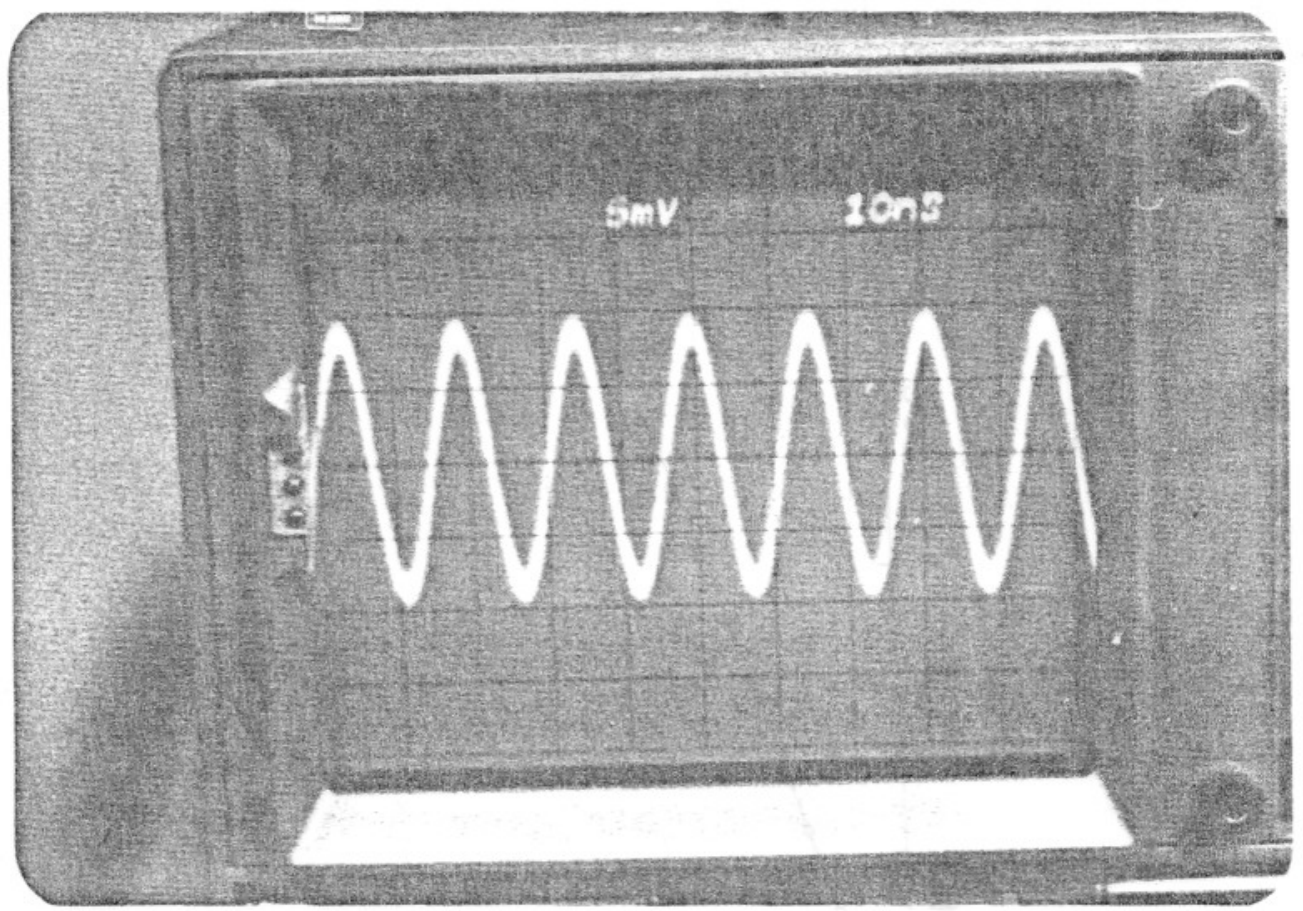

FIG. 4.13 - Sinal da frequência-intermediária de $60 \mathrm{MHz}$. 


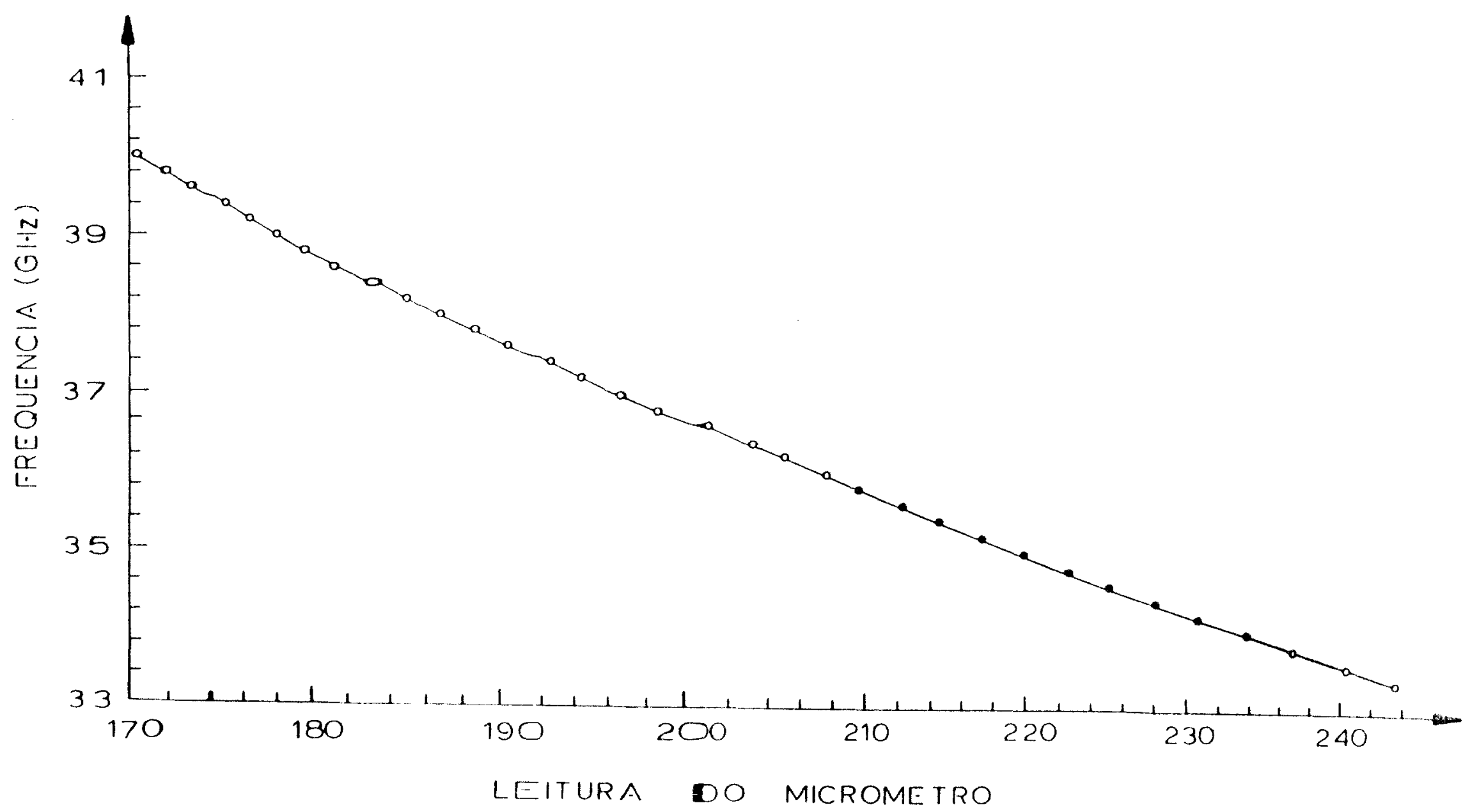

FIG - 4.14 - Curva de calibraçäo do frequencímetro - DBC-715-2 de Banda-Q. (•) ind icam os pontos obtidos com os dois métodos de calib ração citados na seçáo 3.4. 


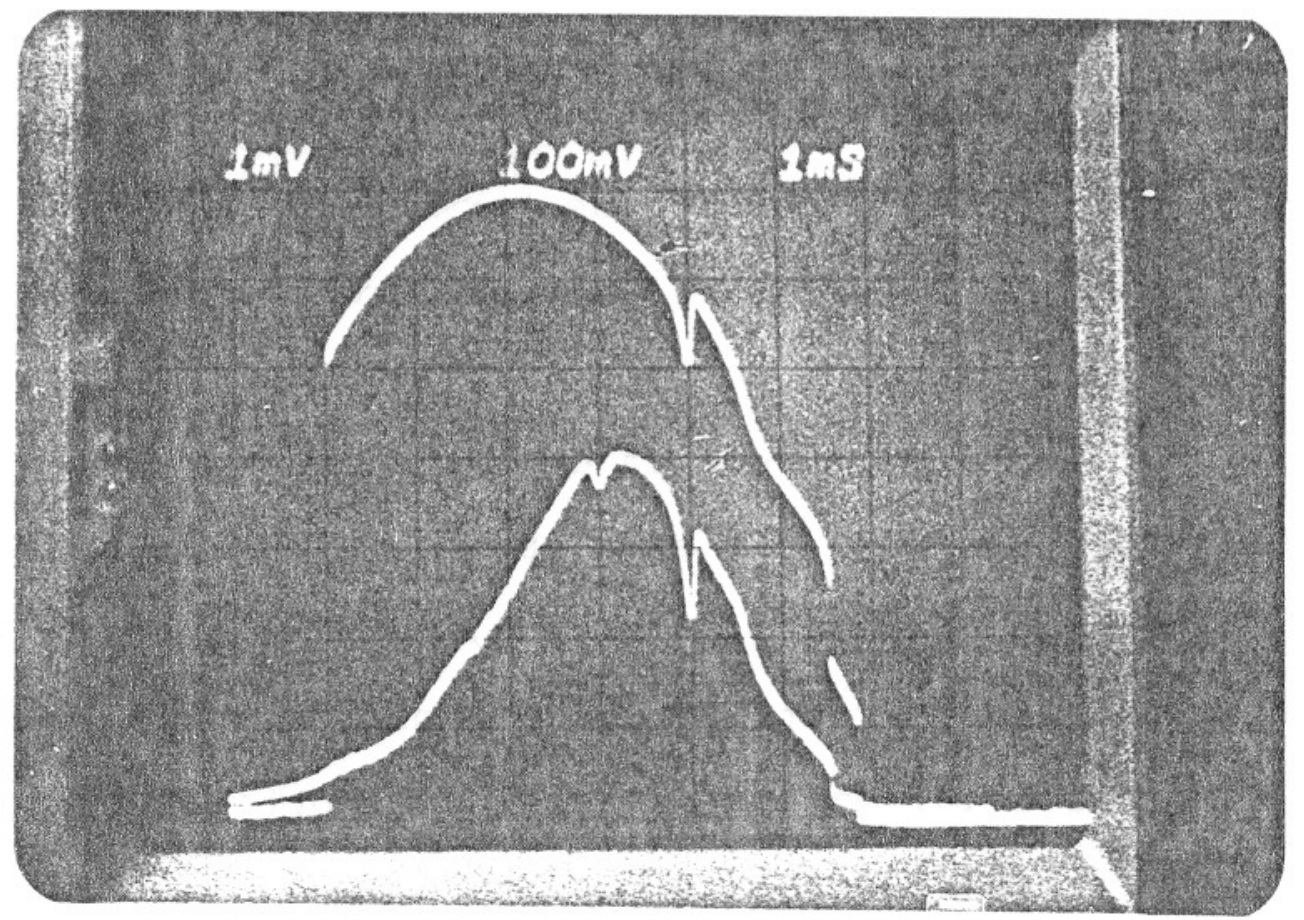

FIG. 4.15 - Modo do klystron de Banda-X (traco superior) e o modo do quarto harmônico (traço inferior). Observe as absorços provocadas pelos frequencímetros de Banda-x (visto a direita em ambos os modos) e de Banda-Q (visto no centro do traco inferior). 
4.5. Comparação entre o dispositivo construido e aqueles citados na Iiteratura

o gerador do terceiro e quarto harmônicos construido é comparado na figura 4.16, que consiste em um gráfico da perda de conversão em função do número do harmônico, com o modelo teórico discutido na secão 1.3 .3 e com similares descritos na literatura e em catálogos comerciais.

A curva (I) representa o resultado do modelo proposto por Page (20) para um gerador de harmônicos cujo elemento nãolinear $\dot{e}$ um diodo a cristal, que neste modelo consiste de uma resistência não-linear.

A curva (2) repreaenta os resultados de Grifone (5), 0 dispositivo conatruido por este autor e um gerador de harmônicos cujo circuito e altamente otimizado, cabe salientar que tal dispositivo não pode ser utilizado como misturador de harmônicos.

A curva (3) modtra os resultados obtidos neste trabalho.

A curva (4) exibe os resultados de um gerador de terceiro e quarto harmônicos da indústria Demornay-Bonardi (42). Este dispositivo pode ser utilizado como misturador de harmônicos, mas não há dados sobre seu desempenho.

os resultados de Richardson (43) são mostrados na curva (5): neste trabalho não há dados sobre o projeto do gerador de harmônicos, sendo apenas citadas as potências da fundamental, segundo e terceiro harmônicos.

Com os dados mostrados na figura 4.16. podemos dizer que - gerador de harmônicos construido é comparável àqueles.

o misturador do quarto harmónico de Banda-x é comparado a um misturador do terceiro harmônico da mesma banda, que é produzido pela indústria Hughes Aircraft Co. (44), cujo gráfico Perda de Conversão X Potência do oscilador-Local é visto na figura 4.17. 


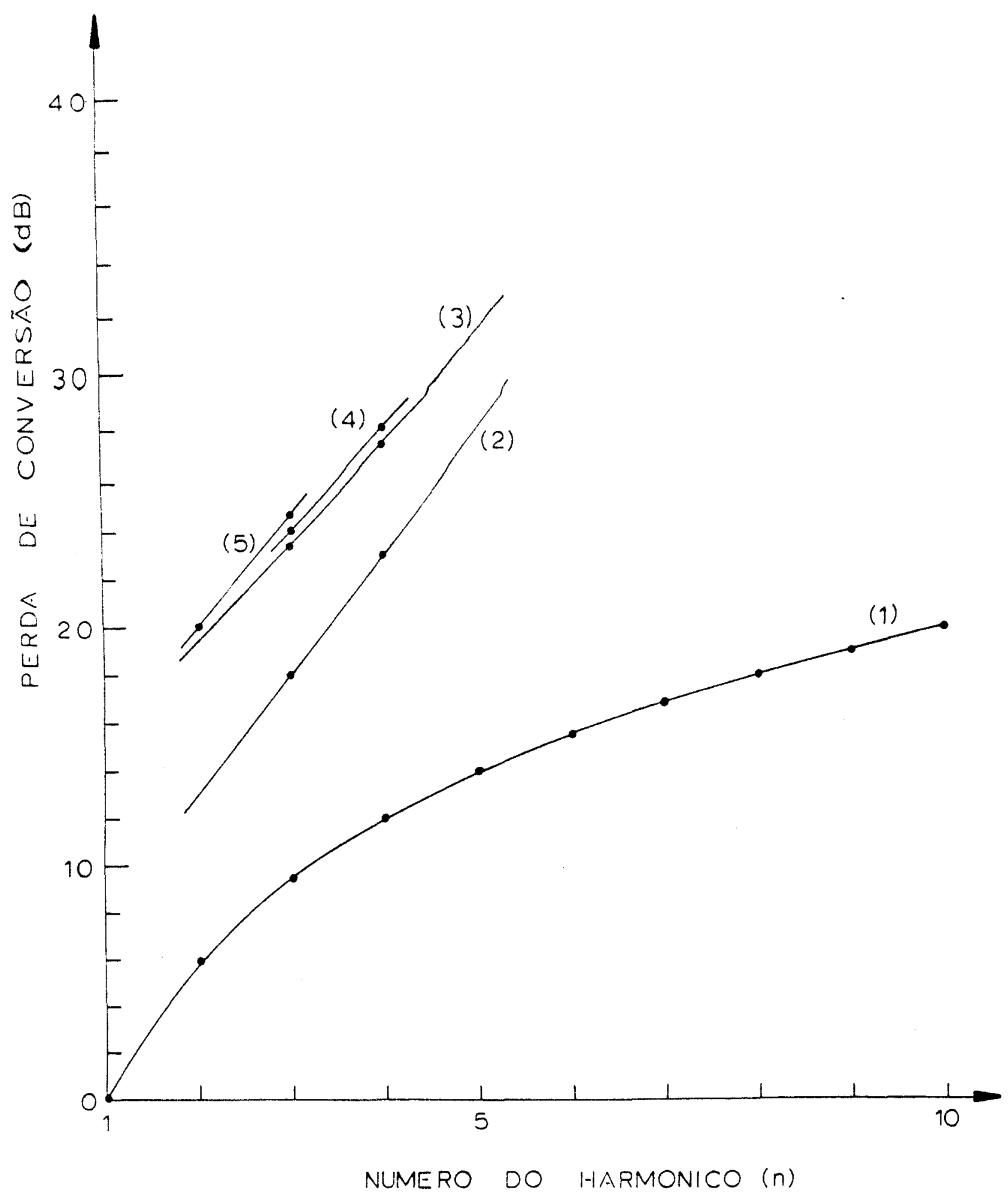

FIG. 4.16 - Comparação entre o gerador do terceiro e quarto harmônicos construido, curva (3); - modelo teórico proposto por Page (20), curva (1); os resultados de Grifone (5), curva (2); da indústria Demornay-Bonardi (42), curva (4) e Richardson (43), curva (5) . 
10. Conversion Luss: Conversion loss (dB) versus L.O. power (dim), with IF rrequency as a parameter.

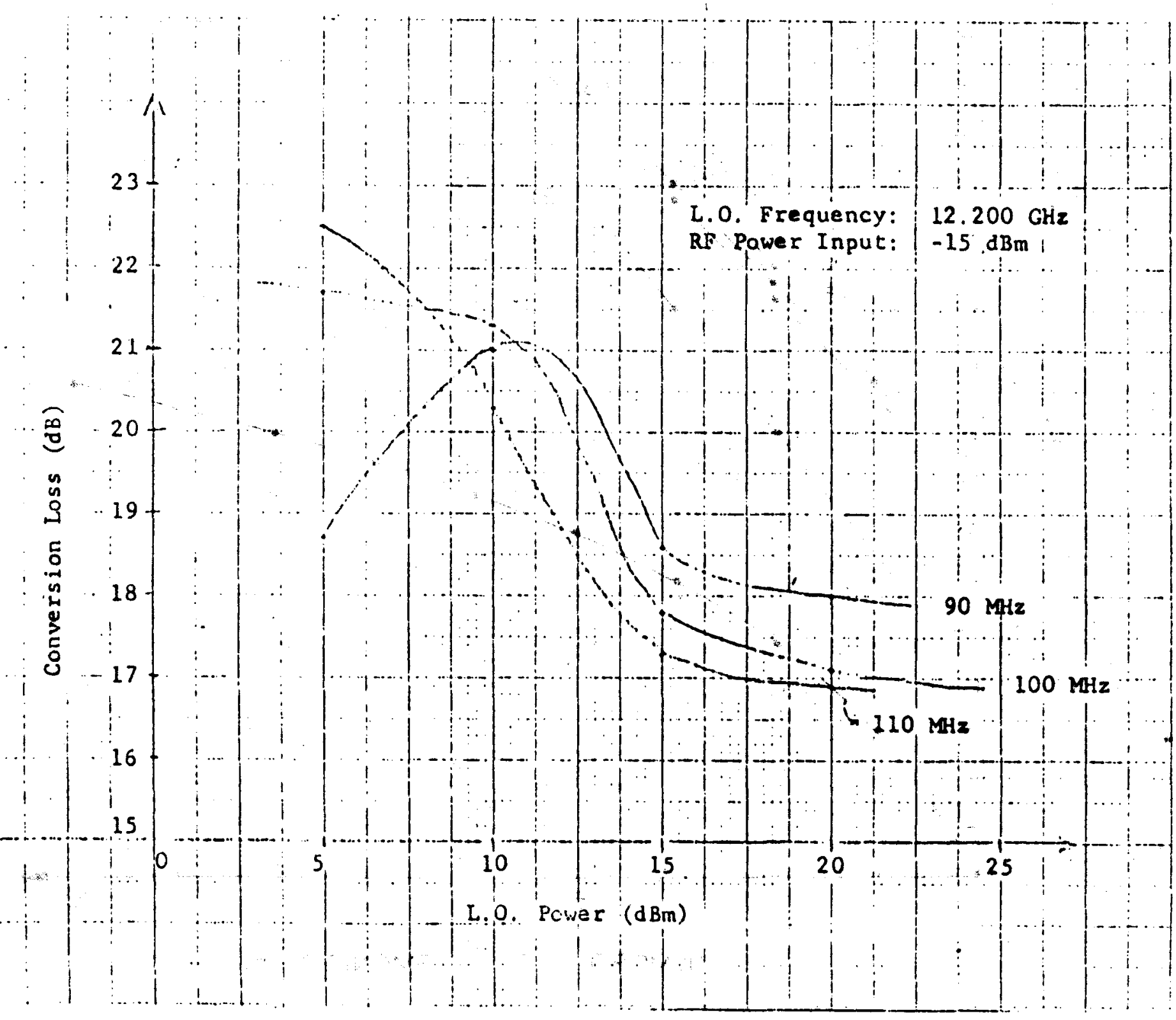

FIG. 4.17 - Perda de conversáo do misturador do terceiro harmônico de Banda-x produzido pela indústria Hughes Aircraft Co. 
Tal dispositivo é construido com técnica de microstripline e o elemento não-linear e um diodo schottky com isto consegue-se uma perda de conversão mais baixa.

Comparando as figuras 4.5 e 4.17 encontramos para $100 \mathrm{~mW}$ $(20 \mathrm{dBm})$ de potência do oscilador-local, as perdas de conversão de $28.5 \mathrm{~dB}$ e $17,1 \mathrm{~dB}$, respectivamente. Podemos dizer que o misturador do quarto harmônico de Banda-X contruido por nós é apenas dez vezes pior que o misturador do terceiro harmônico de Banda- $X$ produzido pela Hughes.

Cabe salientar que utilizamos apenas um diodo neste traba Iho sendo que os resultados aqui mostrados e comparados com aqueles da literatura, podem ser melhores ou piores quando um outro diodo for usado.

4.6. Conclusões

o dispositivo projetado e construido opera conforme as previsões e que em resumo tem as seguintes especificacões:

1. Gerador do quarto harmônico

- Erequência máxima - 49,6 GHz

- Erequência mínima - $32,8 \mathrm{GHz}$

- potência do harmônico - $\simeq 0,3 \mathrm{~mW}$

2. Gerador do terceiro harmônico

- Erequência máxima - 37,2 GHz

- frequência minima - 24,6 GHz

- potência do harmônico - $\simeq 0,8 \mathrm{~mW}$ 
3. Misturador do quarto harmônico

- Erequência de RF máxima - 49,6 GHz

- frequência de RF mínima - 32,8 GHz

- Erequência-intermediária - $30 \mathrm{MHz}$

- isolação dos terminais OL-FI - $23 \mathrm{~dB}$

- perda de conversão - 28,3 dB

4. Misturador do terceiro harmônico

- frequência de RF máxima - 37,2 GHz

- fręquência de RF mínima - 24,6 GHz

Outros dados nằ foram medidos

Com a comparacão realizada na seção anterior podemos concluir que o dispositivo construido é comparável quando não superior aos descritos na literatura.

\subsection{Sugestões para trabalhos futuros}

Em primeiro lugar deve-se caracterizar melhor o dispositi vo como gerador de harmônicos, isto pode ser conseguido utilizando-se como fonte fundamental um klystron $x-13$ da Varian que opera em toda a Banda-X e sua potência é $100 \mathrm{~mW}$. Com estes cados pode-se verificar se a potência do harmônico e consequentémente a perda de conversão é ou não função da frequência fundamental.

Com relação ao misturador de harmônicos, deve-se caracterizar o dispositivo como misturador do terceiro harmônico, isto pode ser conseguido utilizando-se um klystron que opere na Banda-Ka. Além disto, deve-se caracterizar o misturador do quarto harmônico em toda a banda de trabalho.

Em termos de aplicaçōes, deve-se testar o misturador do quarto harmónico como estabilizador de frequência de um klystron 
cie Banda-Q e o mesmo pode ser utilizado como frequencimetro de um espectrômetro de Ressonância Parmagnética Eletrônica (RPE)que ope rará na Banda-Q e será montado no Laboratório de Ressonância Magnética deste Departamento.

O dispositivo pode ser aplicado como gerador de microondas em experiências de RPE em amostras que tenham fortes absorçóes. Nestas, ele pode também ser utilizado como misturador na de teçào superheterodina do sinal de RPE. 


\section{REFERENCIAS BIBLIOGRAFICAS}

1. Montgomery, C. G., Technique of microwave measurements, MIT Radiation Laboratory Series. McGraw-Hill Book Co., Inc., New York, 1947.

2. Torrey, H. C. \& Whitmer, C. A., Crystal rectifiers, MIT Radiation Laboratory Series. McGraw-Hill Book Co., Inc., New York, 1948.

3. Gordy, W., Millimeter and submillimeter waves in physics, Proceedings of the Symposium on Millimeter Waves. Politechnic Press of the Politechnic Institute of Brooklin, New York, 1959.

4. Nethercot Jr., A. H., IRE Trans. MTT-2, 17-20 (1954).

5. Grifone, L., La ric. scient. 24, 1870-79 (1954).

6. Johnson, C. M. \& outros., Rev. of sci. inst. 25, 213-17 (1954).

7. Richardson, J. M. \& outros., IRE Trans. MTT-5, 131-35 (1957).

8. Coleman, P. D. \& outros., IRE Trans. MTT-7, 42-61 (1959).

9. Chang, K. K. N., R.CA rev. 19, 455-64 (1958)

10. Ohl, R. S. \& outros., Rev. of sci. inst. 30, 765-74 (1959).

11. Bauer, R. J. \& outros., Proc. IEEE. 54, 595-605 (1966).

12. Schneider, M. V. \& outros., Proc. IEEE. 58, 1402-04 (1970).

13. Schneider, M. V. \& outros., Int, jour, of infrared and millimeter waves. $2,15-22$ (1981).

14. Goy, P., Int. jour. of infrared and millimeter waves. $\underline{3}^{\text {, }}$ $221-34 \quad(1982)$.

15. Miller, S. E., Millimeter waves in communication, Proceedings of the Symposium on Millimeter waves. Politechnic Press of the Politechnic Institute of Brooklyn, New York, 1959.

16. Howes, M. J. \&outros., Variable impedance devices. John Wiley \& Sons, New York, 1978. 
17. Kittel, C., Introducao à física do estado sólido. Guanabara Dois, Rio de Janeiro, 1979.

18. Yepifanov, G., Physical principles of microelectronics. Mir Publishers, Moscow, 1974 .

19. Stokman, H., Jour. of appl. phys. 17, 110-20 (1946).

20. Page, C. H., Jour. res of the NBS. 56, 179-82 (1956)

21. Page, C. H. , Proc. IRE. 46, 1738-40 (1958).

22. Manley, J. M. \& Rowe, H. E., Proc. IRE . 44, 904-13 (1956).

23. Leeson, D. B. \& Weinreb, S., Proc. IRE. 47, 2076-84 (1959).

24. Utsunomiya, T. \& Yuan, S., Proc. IRE. 50, 57-65 (1962).

25. Leeson, D. B. \& Uhlir Jr, A., Proc. IRE. 47, 1724-29 (1959).

26. Pollack, H. W. \& Engelson, M., Microwave jour. 72-78 (12/1962).

27. Engelson, M., Circuit concepts. Tektronix Inc., Beaverton, 1969.

28. Moreno, T., Micorwave transmission design data. Sperry Gyroscope Co., Boston, 1944 .

29. Reich, H. J. \& outros., Microwave theory and techniques. Van Nostrand, New York, 1953.

30. Poole Jr., C. P. Electron spin resonance. John Wiley \& Sons, New York, 1967.

31. Ishii, T. K. Microwave engineering. The Ronald Press Co., New York, 1966.

32. Very High-Frequency Techniques, Radio res. lab. Harvard University, McGraw-Hill Book Co., Inc., New York, 1947.

33. Tellegen, B. D. H., Philips res. rep. $\underline{3}, 81-101$ (1948).

34. Hogan, C. I., B.S.T.J. 31, 1-31 (1952).

35. Davies, J. B., Philips res. rep. 15, 401-32 (1960)

36. Montgomery, C. G. \& outros., Principles of microwave circuits, MIT Radiation Laboratory Series. MCGraw-Hill Book Co., Inc., New York, 1948. 
37. Huggins, W. H., Proc. IRE. 35, 906, 1085, 1324 (1947). 38. Przedpelski, A. B., Electronic design. 5, 54 (1978). 39. Antena, 74, 33 (1975).

40. Catalogo Philips, 1979.

41. Manual do medidor de potencia HP modelo $432 \mathrm{~A}$.

42. Catalogo Demornay-Bonardi, 1975.

43. Richardson, J. M. \& Faris, J. J., IRE Trans. MTT-5, 208-12 (1957)

44. Manual do harmonic mixer model 44909H-001, Hughes Aircraft Co., 1980. 